ICOMB: ESTUdo E REPROJETO PARTICIPATIVO

PARA REDEFINIÇÃO DE UM SISTEMA PARA ENSINO-APRENDIZAGEM DE COMBINATÓRIA

Márcia Roberta dos Santos Pires da Silva

DissERTAÇÃO APRESENTADA
AO
INSTITUTO DE MATEMÁTICA E EstATÍSTICA
DA
UNIVERSIDADE DE SÃo PAUlo
PARA
OBTENÇÃO DO TÍTULO
DE
MESTRE EM CiÊnCIAS

Programa: Mestrado em Ciência da Computação Orientador: Prof. Dr. Leônidas de Oliveira Brandão 


\title{
ICOMB: ESTUDO E REPROJETO PARTICIPATIVO PARA REDEFINIÇÃO DE UM SISTEMA PARA ENSINO-APRENDIZAGEM DE COMBINATÓRIA
}

\author{
Esta versão da dissertação contém as correções e alterações sugeridas \\ pela Comissão Julgadora durante a defesa da versão original do trabalho, \\ realizada em 13/11/2015. Uma cópia da versão original está disponível no \\ Instituto de Matemática e Estatística da Universidade de São Paulo.
}

Banca Examinadora:

- Prof. Dr. Leônidas de O. Brandão (Presidente) - IME-USP

- Prof. Dr. Flávio Soares Corrêa da Silva - IME-USP

- Prof. Dr. Thiago Schumacher Barcelos - IFSP 
"Para aprender a sabedoria e o ensino; para entender as palavras de inteligência; para obter o ensino do bom proceder, a justiça, o juízo e a equidade; para dar aos simples prudência e aos jovens, conhecimento e bom siso.

Ouça o sábio e cresça em prudência; e o instruído adquira habilidade para entender provérbios e parábolas, as palavras e enigmas dos sábios. O temor do Senhor é o princípio do saber, mas os loucos desprezam a sabedoria e o ensino." Provérbios 1.2-7 


\section{Agradecimentos}

Primeiramente agradeço a Deus por sua grandiosa graça sobre minha vida.

Agradeço ao meu marido Pérsio pela presença e apoio incomensuráveis. Aos meus filhos Marcus e Matheus pela paciência.

À minha amiga fiel, Almira, que teve fé e acreditou em mim em todo tempo.

À amiga maravilhosa Maria José e ao meu "amigo arranjado", Diego.

Ao professor Thiago que me ajudou muito com sugestões extra-oficiais para o trabalho.

Aos alunos que se tornaram amigos e que trabalharam diretamente comigo para reprojetar o $i C o m b$ : Ewerton, Gisele, Sandra, Vanderlei e Victor.

Aos colegas e professores do grupo de pesquisa do Laboratório de Informática na Educação (LInE): Carla, Daniel, Danilo, Leiliana, Matheus, Maurício, Patrícia, Prof. Leônidas, Prof ${ }^{a}$ Anarosa, Reginaldo, Roberto, Romenig e Túlio. Principalmente àqueles que estudaram as mesmas disciplinas, programaram junto comigo, conduziram Cursos de Verão e participaram da minha pesquisa.

$\mathrm{E}$ a todos que estiveram envolvidos direta e indiretamente na execução deste trabalho e na minha vida nesse período. Muito obrigada! 


\section{Resumo}

SILVA, M. R. S. P. iComb: estudo e reprojeto participativo para redefinição de um sistema para ensino-aprendizagem de combinatória. 2015. 69 f. Dissertação (Mestrado) - Instituto de Matemática e Estatística, Universidade de São Paulo, São Paulo, 2015.

Os atuais avanços na área das Tecnologias da Informação e da Comunicação (TIC) estão mudando a Educação, com a disponibilização de sistemas educativos para apoiar as atividades no processo de ensino e de aprendizagem. Embora o tópico de combinatória seja relevante para o ensino médio e para os cursos de Ciências Exatas, este tópico tem sido desconsiderado nos avanços da Informática na Educação, principalmente ao se considerar o uso de ambientes de aprendizagem via Web. Atualmente, o $i C o m b$ é, no melhor de nosso conhecimento, o único sistema Web integrável a tais ambientes. Ele é um Módulo de Aprendizagem Interativa ( $i M A)$ integrável ao Sistema Gerenciador de Cursos (SGC) Moodle, por meio do plugin iTarefa. O iComb oferece atividades de autoria de exercícios, bem como, sua avaliação automática. No entanto, considerando sua usabilidade, foram detectados alguns problemas na interface. $\mathrm{O}$ foco deste trabalho está relacionado ao reprojeto do sistema $i C o m b$ e seu impacto na aprendizagem de combinatória. Para a reconstrução do $i C o m b$ adotou-se o método de design de interação, buscando-se a participação efetiva de usuários finais do sistema, em todas as atividades desse processo, com (i) sessões de teste de usabilidade utilizando a versão Java do iComb para identificar problemas e guiar o redesenho do sistema, e (ii) prototipagem e avaliação da interface do sistema redesenhado. Esse processo permitiu implementar uma nova versão do iComb utilizando tecnologias associadas ao HTML5, que será brevemente disponibilizado como software livre.

Palavras-chave: Análise Combinatória, Sistemas Web, Design de Interação, usabilidade, ensino de combinatória, Ensino a Distância, HTML5, Módulo de Aprendizagem Interativa, iMA, iTarefa, Moodle. 


\section{Abstract}

SILVA, M. R. S. P. iComb: study and participative design to redefine a system to teach and learn counting techniques. 2015. 69 f. Dissertação (Mestrado) - Instituto de Matemática e Estatística, Universidade de São Paulo, São Paulo, 2015.

Current advances in Information and Communication Technologies (ICT) are changing Education with delivering software to support learning/teaching activities. Although being relevant for Science, Technology, Engineering, and Mathematics (STEM) courses, Combinatorial Analysis is almost disregarded in these advances, mostly if we consider their integration with Learning Management Systems. Currently, iComb is, at the best of our knowledge, the only system with such a possibility. It is an interactive Learning Module (iLM) that can be integrated to Moodle, through the iAssign plugin. iComb provides authoring activities as well as their automatic assessment. Nevertheless, considering the system usability, several interaction problems were detected during sessions with teachers and students. In this work it is described the process of redesigning the iComb system by adopting Interactive Design, to conduct controlled sessions of system use for (i) identifying usability issues for guiding the system redesign; and (ii) prototyping and evaluate the redesigned system interface, with end-users. This process allowed to implement new version of iComb using HTML5 related technologies that will be sooner available as free software, in order to reach a larger audience. Preliminary results on the interface evaluation indicate that both students and teachers felt more comfortable using the new interface of iComb and found it easier to execute common tasks.

Keywords: Counting techniques, Web systems, Interaction Design, usability, combinatorics learning, Distance Learning, HTML5, Interactive Learning Modules, iLM, iAssign, Moodle. 


\section{Sumário}

Glossário viii

$\begin{array}{ll}\text { Lista de Abreviaturas } & \text { ix }\end{array}$

$\begin{array}{ll}\text { Lista de Figuras } & \text { x }\end{array}$

Lista de Tabelas $\quad$ xi

1 Introdução $\quad 1$

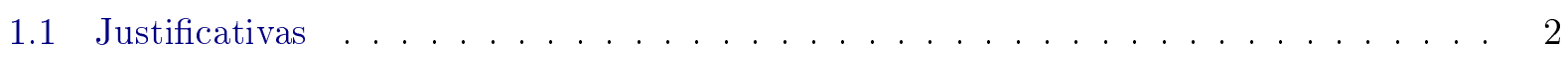

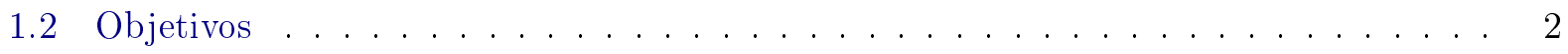

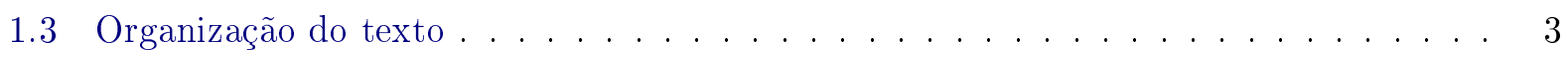

2 Fundamentação $\quad \mathbf{4}$

2.1 Avaliação automática, sistemas educativos $W e b$ e tutores inteligentes . . . . . . . . 4

2.2 Análise Combinatória e Combien? . . . . . . . . . . . . . . . 5

2.2.1 Descrição do modelo de resolução de problemas . . . . . . . . . . . . . . 6

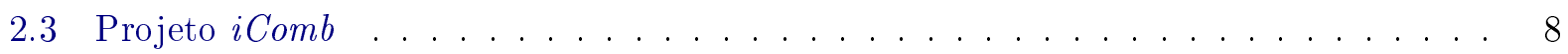

2.3.1 Exemplos de resolução de problemas . . . . . . . . . . . . . . 9

2.3 .2 Recursos de Ajuda . . . . . . . . . . . . . . . . . . 12

2.3.3 Ferramenta para autoria de novos exercícios . . . . . . . . . . . . . . 12

2.3 .4 Módulos de Aprendizagem Interativa (iMA) . . . . . . . . . . . . . 13

3 Métodos $\quad 16$

3.1 Análise de Conteúdo . . . . . . . . . . . . . . . . . . . . . . 16

3.2 Processo de Design de Interação . . . . . . . . . . . . . . . . . . . 17

3.2.1 Teste de usabilidade de sistemas interativos . . . . . . . . . . . . . . . . 19

3.2.2 Prototipagem de Storyboard Interativo Cooperativo . . . . . . . . . . . . . 20

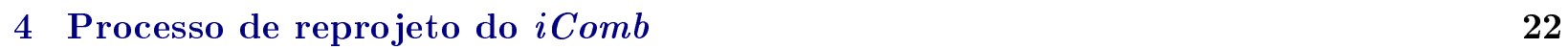

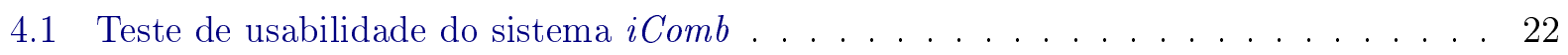

4.1 .1 Descrição das sessões de teste . . . . . . . . . . . . . . . . . 23

4.1.2 Análise dos resultados do teste do $i C o m b \quad \ldots \ldots \ldots \ldots \ldots$

4.2 Reprojeto e Prototipagem Participativa do $i C o m b \ldots \ldots$. . . . . . . . . . . 30

4.2 .1 Designs da interface do $i C o m b \quad \ldots \ldots \ldots \ldots \ldots \ldots \ldots$

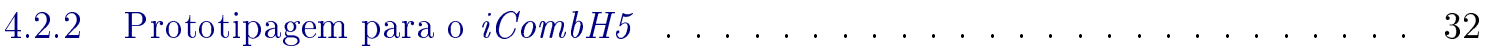


4.2 .3 Novos Conjuntos Universo . . . . . . . . . . . . . . . . . . . . . 33

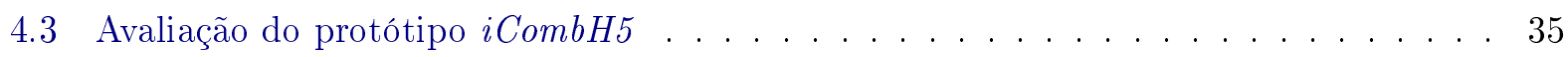

4.3.1 Resultados do teste do protótipo $i \mathrm{CombH5} \ldots \ldots \ldots \ldots$

5 Conclusões $\quad 39$

5.1 Contribuições . . . . . . . . . . . . . . . . . . . . . 40

$5.1 .1 \quad$ Produção Científica . . . . . . . . . . . . . . . . . . . . 40

5.2 Trabalhos Futuros . . . . . . . . . . . . . . . . . 40

A Exemplar da carta de consentimento $\quad 42$

B Documentação dos testes de usabilidade do $i C o m b \quad 43$

C Roteiro visual para o design da interface do $i$ Comb. 49

$\begin{array}{ll}\text { Referências Bibliográficas } & 64\end{array}$ 


\section{Glossário}

Applet É um mini-aplicativo Java (http://www.java. com/en/about/), 14

HTML5

HyperText Markup Language, versão 5 é uma linguagem para estruturação e apresentação de conteúdo para a World Wide Web, 2

Plugin

Na informática, um plugin ou módulo de extensão é um programa de computador usado para adicionar funções a outros programas maiores, provendo alguma funcionalidade especial ou muito específica. Geralmente pequeno e leve, é usado somente sob demanda. Fonte: Wikipédia (http://pt.wikipedia.org/ wiki/Plug-in), 33

Princípio Aditivo O Princípio Aditivo é um princípio básico de contagem e pode ser escrito em termos de conjuntos por: Se $A_{1}, A_{2}, \ldots, A_{m}$ são conjuntos finitos disjuntos, então o número de elementos na união desses conjuntos é a soma dos números de elementos nos conjuntos. (Rosen, 2007), 7

Princípio Multiplicativo O Princípio Multiplicativo é um princípio básico de contagem e é frequentemente usado com conjuntos desta forma: Se $A_{1}, A_{2}, \ldots, A_{m}$ são conjuntos finitos, então o número de elementos no produto cartesiano desses conjuntos é o produto do número de elementos em cada. (Rosen, 2007), 7

Protocolo Verbal Protocolo verbal é o método do "pensar alto" (think aloud): o usuário é convidado a dizer em voz alta o que está pensando enquanto realiza a tarefa, 31 
Storyboard

Teste Piloto
Storyboard são roteiros gráficos organizados em sequência com o propósito de prévisualizar um filme, animação ou gráfico animado, incluindo elementos interativos em websites, 20

Teste Piloto é um teste preliminar, de caráter experimental, aplicado a uma pequena amostra de participantes e que serve para avaliar aspectos de seu funcionamento e corrigir eventuais falhas antes de sua implantação definitiva, 19 


\title{
Lista de Abreviaturas
}

\author{
ADS Análise e Desenvolvimento de Sistemas \\ AVA Ambientes Virtuais de Aprendizagem \\ CEC Centro de Ensino de Computação \\ CISP Cooperative Interative Storyboard Prototyping \\ DP Design Participativo \\ DI Design de Interação \\ FIE Frontiers in Education Conference \\ IFSP Instituto Federal de Educação, Ciência e Tecnologia de São Paulo \\ iMA Módulo de Aprendizagem Interativa \\ HCI Human Computer Interaction \\ IHC Interação Humano-Computador \\ JVM Java Virtual Machine \\ LInE Laboratório de Informática na Educação \\ LIP6 Laboratoire d'Informatique de Paris 6 \\ LMS Learning Management System \\ MOCAH Modèles et Outils en Ingénierie des Connaissances pour l'Apprentissage Humain \\ MOODLE Modular Object-Oriented Dynamic Learning Environment \\ OA Objetos de Aprendizagem \\ SAW Sistema de Aprendizagem via Web \\ SBC Sociedade Brasileira de Computação \\ SBIE Simpósio Brasileiro de Informática na Educação \\ SGC Sistema Gerenciador de Cursos \\ STI Sistema Tutor Inteligente \\ TIC Tecnologias da Informação e da Comunicação \\ WIE Workshop de Informática na Escola
}




\section{Lista de Figuras}

2.1 As quatro interfaces do Combien? . . . . . . . . . . . . . . . 7

2.2 As interfaces do iComb e da Construction Ensemble do Combien? com a mesma

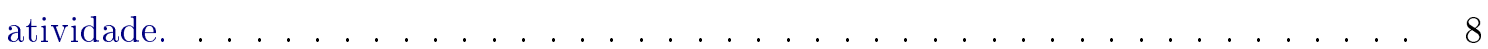

2.3 A resolução do primeiro problema proposto no iComb. . . . . . . . . . . . . . . 11

2.4 As imagens dos recursos de ajuda do $i C o m b . \ldots \ldots \ldots \ldots \ldots$. . . . . . . . . 12

2.5 Interface do $i C o m b$ durante a autoria de exercício, momento da escolha do conjunto universo. . . . . . . . . . . . . . . . . . . . . 13

2.6 As interfaces do $i G e o m, i G r a f, i$ VProg e iTangram. . . . . . . . . . . . . . 14

3.1 Modelo do ciclo do design de interação. Baseado em Preece et al. (2005). . . . . . . . 18

4.1 Exercício no iComb integrado no Moodle. . . . . . . . . . . . . . . . . . . . 24

4.2 Gráfico da questão nível de ensino que estudou Análise Combinatória . . . . . . . . . 26

4.3 Resposta de um dos participantes para a questão 1 do pré-teste. . . . . . . . . . . . 26

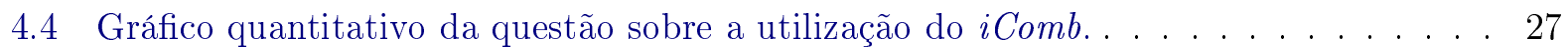

4.5 A média de tempo durante a utilização do $i C o m b . \ldots \ldots \ldots$. . . . . . . . 28

4.6 Gráfico sobre o entendimento dos participantes em cada fase do processo de resolução. 28

4.7 Gráfico sobre o recurso ajuda do iComb. . . . . . . . . . . . . . . . . . . 29

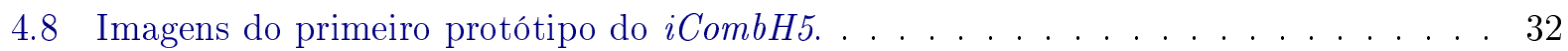

4.9 Interface do protótipo do $i$ CombH5 durante o processo de resolução de exercício. . . 33

4.10 Imagens dos universos para o iCombH5. . . . . . . . . . . . . . . . . 35

4.11 Gráfico sobre o entendimento dos participantes em cada fase do processo de resolução. 37

4.12 Gráfico sobre o feedback do iCombH5 para corrigir erros cometidos. . . . . . . . . . 37

A.1 Carta de consentimento assinada pelos participantes da equipe. . . . . . . . . . . . 42 


\section{Lista de Tabelas}

2.1 Características dos sistemas Combien? e iComb. . . . . . . . . . . . . . 9

4.1 Resumo dos comentários sobre os pontos fortes do $i$ Comb. . . . . . . . . . . . . . 27

4.2 Tabela das dificuldades enfrentadas pelos usuários durante a utilização do iComb. . . 27

4.3 Resumo dos comentários sobre os pontos fracos do iComb. . . . . . . . . . . . . 29

4.4 Tabela sobre a adequação dos elementos gráficos da interface do iComb. . . . . . . . 29

4.5 Tabela dos universos do $i$ CombH5. . . . . . . . . . . . . . . . . 34

4.6 Valores relativos ao aspecto visual da interface do $i$ CombH5 . . . . . . . . . . . 36 



\section{Capítulo 1}

\section{Introdução}

Os atuais avanços nas Tecnologias da Informação e Comunicação (TIC) estão mudando a forma como as pessoas aprendem, impactando a educação formal e informal. Em particular, os sistemas computacionais e novas tecnologias tem sido utilizadas para apoiar o processo de ensino e aprendizagem, alterando o cenário educacional nas últimas décadas.

A incorporação de tais sistemas no ambiente escolar pode motivar os alunos ${ }^{1}$ e permitir novas estratégias para o ensino-aprendizagem ${ }^{2}$, fornecendo um meio de comunicação que é familiar aos alunos (Buckingham, 2007; Leite et al., 2009).

Adicionalmente, um particular tipo de sistema computacional evoluiu bastante na última década, possibilitando o gerenciamento mais eficaz de cursos via Web, que será designado neste texto como Sistemas Gerenciadores de Cursos (SGC), mas vale apontar que na literatura esses sistemas podem receber variados nomes, como Sistema ou Ambiente Virtual de Aprendizagem ${ }^{3}$. Atualmente os SGC são software básicos para qualquer instituição de ensino (Llamas et al., 2011), sendo empregado, inclusive, em cursos presenciais como forma de ampliar os canais de comunicação entre professores e alunos.

Nota-se que esse tipo de sistema pode alavancar a demanda por sistemas educativos que forneçam um maior nível de interatividade (Dalmon et al., 2011b, 2012).

Villarreal e Borba (2010) afirmam que estão disponíveis inúmeros sistemas educativos para apoiar o processo de ensino e aprendizagem de uma grande variedade de conceitos matemáticos. No entanto, poucos sistemas têm sido especificamente desenvolvidos para auxiliar a aprendizagem de Análise Combinatória (Ribeiro, 2013). Além disso, de modo geral, não é possível integrar esses sistemas a um SGC. Pelo nosso conhecimento, o $i$ Comb é o único sistema que fornece tal integração (Eisenmann, 2009; Eisenmann e Brandão, 2009).

O sistema educativo $i C o m b$ : Combinatória Interativa na Internet foi implementado na linguagem Java, na forma de applet, sendo um Módulo de Aprendizagem Interativa (iMA) que pode ser integrado ao Moodle 4 por meio do iTarefa (Rodrigues et al., 2010). Ele possui ferramenta para autoria de novos exercícios, bem como, avaliação automática das atividades, proporcionando aos alunos

\footnotetext{
${ }^{1}$ O termo "aluno" será empregado para os "aprendizes" imersos em ambientes formais de aprendizagem, dentro de alguma escola.

${ }^{2}$ Neste texto o termo "ensino-aprendizagem" será empregado para designar algum aspecto do processo do ensino ou da aprendizagem, adotando-se o hífen conforme recomenda Lima (2012).

${ }^{3}$ Uma vez que esses sistemas propiciam um real ambiente para ensino-aprendizagem, optou-se pela primeira designição, SGC. Em Inglês é mais comum o uso do termo Learning Management System.

${ }^{4}$ Moodle é um SGC de código aberto, usado por um grande público em todo o mundo.
} 
retroação $0^{5}$ imediata para as respostas das atividades realizadas. O $i C o m b$ visa também desenvolver raciocínio crítico dos alunos sobre as técnicas de contagem, devido ao seu método de resolução de problemas que utiliza a estratégia de divisão e conquista, o qual possibilita o particionamento do problema em subproblemas menores e mais simples, para, posteriormente, compor a solução final.

No entanto, desde o lançamento da primeira versão do iComb, problemas de usabilidade foram identificados no sistema. Um único experimento foi realizado com o sistema que contou com a participação de professores de matemática. Nesse experimento constatou-se que o iComb é uma ferramenta útil no ensino-aprendizagem de combinatória, porém, a maioria dos participantes avaliaram como sendo de razoável dificuldade a utilização do sistema (Eisenmann, 2009). Além disso, atualmente a tecnologia Java empregada no $i C o m b$ tem acarretado dificuldades adicionais para o funcionamento de applets em navegadores Web.

Desse modo, tais questões foram identificadas como reais obstáculos para o uso efetivo do $i$ Comb e serviu de motivação para o reprojeto do sistema.

No processo de reprojeto, buscou-se a participação efetiva de usuários finais do sistema em todas as atividades, nos testes de usabilidade para detectar problemas na versão corrente do $i C o m b$, no desenvolvimento do redesenho da interface do sistema, na construção baseada em prototipagem participativa e na avaliação do protótipo iCombH5. Esse processo permitiu implementar uma nova versão do $i C o m b$, utilizando tecnologias associadas ao $H T M L 5^{6}$ para que possa ser empregado em ambiente escolar.

Nas próximas seções serão apresentadas as justificativas e os objetivos para o desenvolvimento deste trabalho.

\section{$1.1 \quad$ Justificativas}

Este trabalho se justifica principalmente pelos seguintes itens:

- A escassez de sistemas educacionais para apoiar o ensino-aprendizagem de combinatória que proporcionem interatividade via Web.

- A utilização do método "divisão e conquista" como estratégia para resolução de problemas de combinatória tem apresentado bons resultados. O iComb foi implementado utilizando-se dessa metodologia.

- Tem-se observado que os novos usuários do iComb sentem dificuldades para usar o sistema.

A partir desses tópicos observa-se que a interface do $i C o m b$ deveria ser avaliada e redesenhada para proporcionar melhores condições de uso do sistema, e assim oferecer seu potencial para a aprendizagem de combinatória.

\subsection{Objetivos}

O objetivo geral deste trabalho é evoluir o sistema $i$ Comb já existente, de modo a possibilitar que o mesmo seja uma opção fácil para ser utilizada em ambientes escolares.

\footnotetext{
${ }^{5}$ O termo retroação será empregado no sentido de alguma resposta a partir de uma ação, ou seja, como tradução do termo Inglês feedback.

${ }^{6}$ HTML5 é um símbolismo para a versão 5 do HyperText Markup Language, uma linguagem para estruturação e apresentação de conteúdo para a World Wide Web.
} 
Dessa forma, tem-se como objetivos específicos:

(i) verificar a existência de problemas de usabilidade, conforme indicado em trabalhos anteriores (Eisenmann, 2009; Eisenmann e Brandão, 2009);

(ii) desenvolver o reprojeto do iComb para a obtenção de uma nova versão que venha de encontro às necessidades dos usuários.

\subsection{Organização do texto}

No presente capítulo foram apresentados o contexto em que este trabalho está inserido, assim como as justificativas para o seu desenvolvimento e, por fim, uma síntese de seus principais objetivos.

No Capítulo 2 será apresentada a fundamentação necessária para compreensão deste trabalho, iniciando com uma breve explanação sobre avaliação, sistemas educativos e tutores inteligentes. Seguindo com a discussão do ensino de análise combinatória, a apresentação do sistema Combien? e o seu modelo para a resolução de exercícios, e findando com o detalhamento do projeto $i$ Comb.

O Capítulo 3 descreve os métodos e técnicas utilizadas no desenvolvimento do projeto, desde a metodologia de análise do conteúdo coletado durante o teste de usabilidade do iComb até as atividades e técnicas abordadas do processo de Design de Interação.

No Capítulo 4 são apresentadas todas as atividades do processo de reprojeto do $i C o m b$, desde as sessões de teste de usabilidade com a versão do iComb Java, bem como, os resultados e a análise dos dados coletados nas técnicas aplicadas nessas sessões. Seguindo das atividades do desenvolvimento de design da interface do sistema e a prototipagem participativa do $i C o m b$ e, findando com a avaliação do protótipo $i \mathrm{CombH} 5^{7}$.

No Capítulo 5 será apresentada a conclusão deste trabalho, bem como suas principais contribuições e trabalhos futuros.

\footnotetext{
${ }^{7}$ O termo "iCombH5" será empregado para o protótipo do iComb em HTML5 a fim de não gerar confusão com a versão atual do $i C o m b$.
} 


\section{Capítulo 2}

\section{Fundamentação}

Neste capítulo apresenta-se os principais conceitos envolvidos para compreensão deste trabalho.

Na Seção 2.1 tem-se uma breve explanação sobre avaliação, sistemas educativos e tutores inteligentes. Na Seção 2.2 discute-se o ensino de análise combinatória e apresenta o sistema do qual serviu de inspiração para o desenvolvimento da versão inicial do $i$ Comb, o sistema Combien? descrevendo o modelo para a resolução de problemas combinatórios implementado nesse sistema. E por fim, na Seção 2.3 detalha-se o projeto $i C o m b$, apresentando alguns exemplos de resolução de problemas, os recursos de ajuda disponíveis no sistema, a ferramenta para autoria de exercícios, bem como, as suas características específicas de um $i M A$.

\subsection{Avaliação automática, sistemas educativos Web e tutores inte- ligentes}

A avaliação é parte fundamental do processo educacional, sendo importante a mensuração de quanto o aluno aprendeu (Young, 2011). Vale destacar que esta mensuração também é necessária para o professor avaliar a sua prática, e.g., sempre buscando aprimorar seu conteúdo didático e, eventualmente, o adaptando para sua turma de alunos.

Existem vários tipos de avaliação, como a somativa, a diagnóstica e a formativa. A somativa é empregada ao final do processo, enquanto a diagnóstica é usada antes do início do processo educacional (curso) e a formativa é utilizada ao longo do curso para avaliar a aprendizagem e o próprio material instrucional.

Sempre que possível, é interessante que o professor empregue um processo de avaliação contínuo, geralmente como parte da avaliação formativa, visando conseguir acompanhar melhor o desempenho dos alunos. Esta retroação é importante para o aluno compreender melhor os conceitos trabalhados (Perrenoud, 1999; Santos, 2005).

Entretanto, considerando que um professor tem mais de uma classe por dia, com mais de 30 alunos por sala e sem auxílio, uma possibilidade de ajuda é o emprego de sistemas educativos com $a$ valiação automática.

Nesse sentido, mesmo em cursos presenciais, o uso da World Wide Web e algumas de suas muitas opções de ferramentas computacionais adquirem um papel preponderante, pois podem fornecer retroação imediata para os alunos.

Alguns estudos reforçam a importância da qualidade da retroação, indicando que em ambientes 
educacionais formais, a demora em fornecer ao aluno uma resposta a respeito de suas tarefas pode gerar frustações (Hara e Kling, 1999; Hentea et al., 2003).

Deste modo, uma contribuição é proporcionar sistemas que possam informar rapidamente o desempenho do aluno.

Vale destacar que a literatura de jogos educacionais também reconhece a importância da retroção, por exemplo, Perrotta et al. (2013), p.9, afirma que:

Feedback imediato e construtivo. Um dos mecanismos mais poderosos dos jogos de video game é a capacidade de fornecer feedback em tempo real, não apenas como avaliação, mas muitas vezes como orientação para facilitar o desempenho correto. Esta é em grande parte a ideia da avaliação formativa no ensino. ${ }^{1}$

Nesse sentido, também a qualidade da interação do aluno com o sistema educativo é importante para que efetivamente o sistema auxilie no aprendizado e não seja mais uma barreira.

A utilização de Sistemas Tutores Inteligentes (STI) auxiliam o aluno durante sua aprendizagem analisando o seu nível de conhecimento e habilidades, considerando as recomendações do professor, para interagir ativamente visando ampliar a sua aprendizagem durante a realização das atividades ou na sugestão de novas tarefas (Aleven et al., 2008; Dalmon et al., 2010).

Nesse contexto, um sistema educativo implementado com a funcionalidade de tutor automático inteligente pode guiar os alunos em seus estudos, aumentar a facilidade e a rapidez com que eles assimilam o conteúdo, além de proporcionar o benefício de ganho de tempo ao professor.

\subsection{Análise Combinatória e Combien?}

A análise combinatória é um ramo da matemática discreta que aborda problemas de enumeração e de contagem de subconjuntos de um conjunto finito que satisfazem a condições preestabelecidas (Batanero et al., 1997; Morgado et al., 1991). Seu ensino, geralmente, envolve fórmulas matemáticas que os estudantes precisam aplicar para resolver os problemas propostos. Por isso muitos alunos adotam a estratégia de memorizar as fórmulas e alguma regra para aplicá-las, o que agrava um problema recorrente observado no ensino de matemática, como ressaltado na tese de Buxton (1985), p. 84:

A matemática foi vista por quase todos os pesquisados como uma montanha de material, fórmulas, rotinas e fatos. Para todos eles, em algum momento de seu aprendizado, esta visão foi resultado de pararem de tentar entender e passarem a tentar memorizar. ${ }^{2}$

Uma consequência imediata dessa prática é que os assuntos vão cumulativamente deixando de ser compreensíveis. Eventualmente o estudante consegue acertar o exercício, mas quando erra não entende a razão de seu erro (Giroire et al., 2006).

Desse modo, sistemas educacionais que proporcionem um método alternativo para a resolução dos problemas combinatórios podem trazer benefícios em relação a essa dificuldade.

\footnotetext{
${ }^{1}$ Immediate and constructive feedback. One of the most powerful mechanisms of video games is the ability to provide feedback in real time, not only as evaluation, but more often as guidance to facilitate and correct performance. This is largely in line with the idea of formative assessment in education.

${ }^{2}$ Mathematics was seen by nearly all of my subjects as a movntain of material, formulae, routines and facts. This view resulted from them all having moved from trying to understand to trying to remember at some atage (sic) in their learning.
} 
Neste contexto, o grupo Modèles et Outils en Ingénierie des Connaissances pour l'Apprentissage Humain (MOCAH) da Université Pierre et Marie Curie - Laboratoire d'Informatique de Paris 6 $(L I P 6)^{3}$, construiu um sistema que visa ajudar estudantes do sistema educacional francês a aprender combinatória utilizando linguagem matemática, denominado Combien? (Le Calvez et al., 2008).

O Combien? é implementado na forma de um modelo sistemático de resolução que particiona o problema, oferecendo uma interface com uma linguagem próxima àquela que os estudantes utilizam na resolução dos problemas e ao mesmo tempo, permite uma rigorosa argumentação matemática.

Os especialistas do grupo MOCAH foram capazes de estabelecer classes de problemas combinatórios, de maneira que em cada uma dessas classes o Combien? possui uma interface específica (Calvez et al., 2003). Cada uma dessas interfaces do Combien? foi projetada para resolver uma certa classe de problemas, contendo exercícios que são resolvidos com um método similar. Quatro interfaces foram definidas, conforme mostra a Figura 2.1, a saber:

(a) Construction Ensemble - Conta o número de conjuntos que satisfazem algumas restrições;

(b) Construction Liste - Conta o número de listas que verificam algumas restrições;

(c) Construction Ensemble par Case - Conta o número de conjuntos que satisfazem algumas restrições, porém faz separação em casos diferentes;

(d) Liste par Case - Conta o número de listas que verificam algumas restrições, porém faz separação em casos diferentes.

O sistema francês dispõe de recursos para avaliação automática, conseguindo, inclusive, avisar o aluno sobre caminhos errados ainda na fase de particionamento do problema. Por esta característica o Combien? pode ser classificado como um sistema tutor inteligente.

Na Subseção 2.2.1 está detalhada a metodologia de "divisão e conquista" para resolução de problemas de contagem utilizado na interface Construction Ensemble do sistema Combien?

\subsubsection{Descrição do modelo de resolução de problemas}

O modelo de resolução de problemas relativos à contagem, implementado na interface Construction Ensemble, deve ter como base o conjunto universo composto por todos os objetos considerados. Por exemplo, considerando um baralho usual, com 52 cartas, o conjunto universo é formado por todas elas.

Deste modo, os problemas combinatórios considerados são do tipo "descobrir qual a cardinalidade (número de objetos) do conjunto com determinada propriedade".

Um exemplo simples envolvendo decomposição por subconjuntos seria: "Quantas são as possibilidades de retirar 5 cartas, sem reposição, e obter exatamente 4 azes e uma dama de paus?" Como o baralho de 52 cartas tem apenas 4 azes e uma só dama de paus, o conjunto resultante tem cardinalidade 1.

A proposta do Combien? para resolver um problema de contagem é encontrar uma decomposição dele em subproblemas, de modo que o conjunto resposta seja equivalente à união ou ao produto dos subproblemas. Mais especificamente, sendo $U$ o conjunto universo e $X \subseteq U$ o subconjunto resposta para determinado problema sobre $U$. Então, a resposta esperada pelo Combien? é a cardinalidade de

\footnotetext{
${ }^{3}$ http://lip6.fr
} 

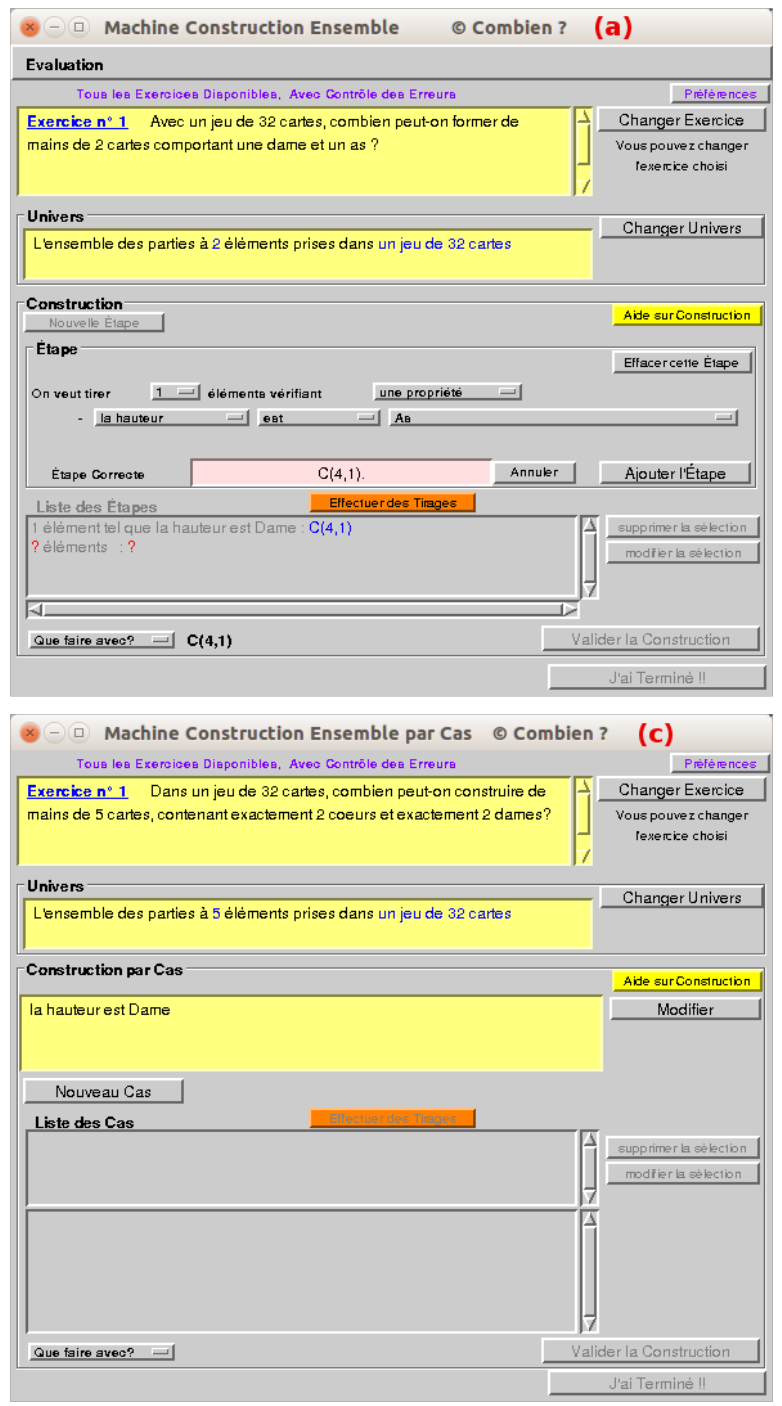
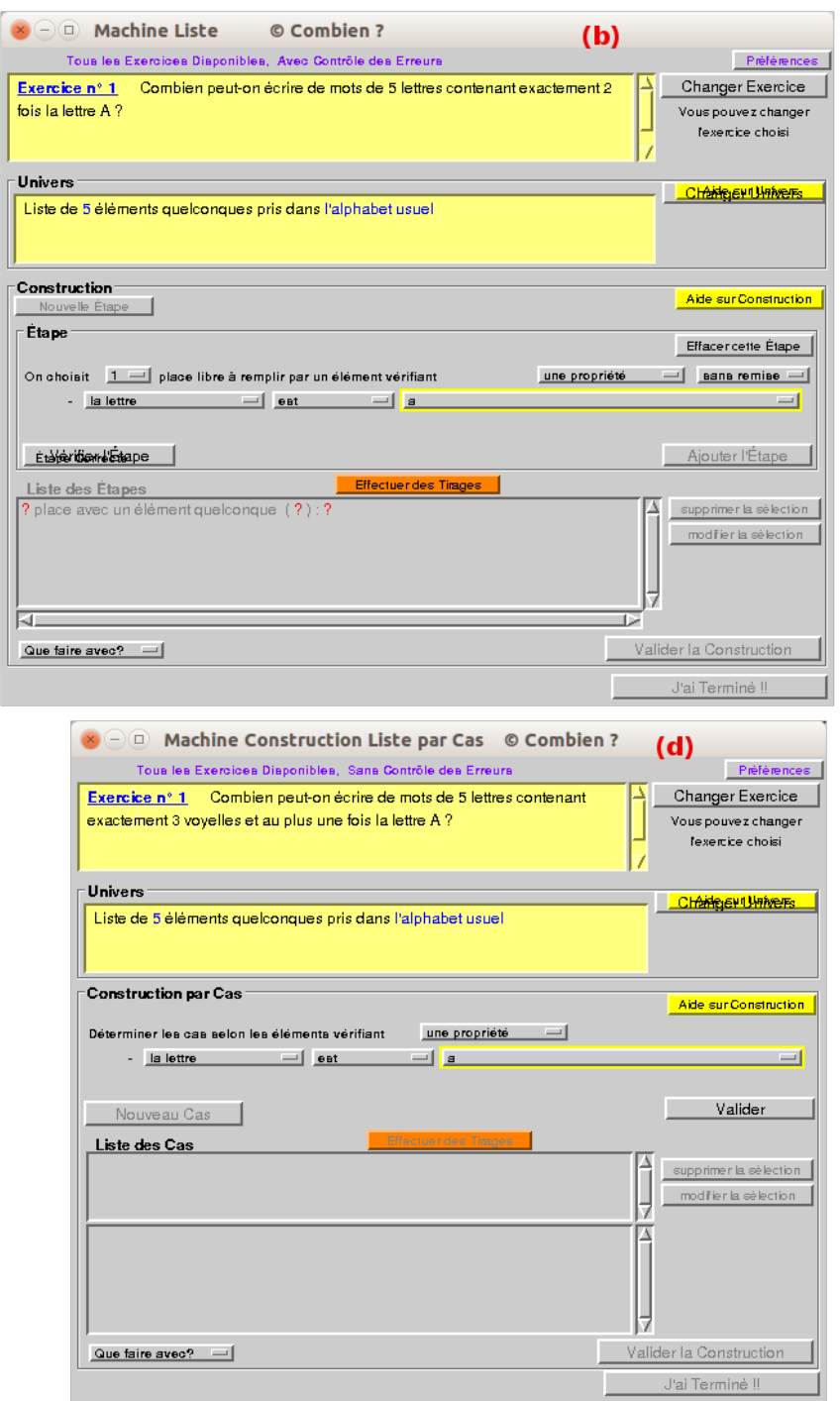

Figura 2.1: As quatro interfaces do Combien?.

$X$, ou seja \# $X$, mas o aluno não pode simplesmente digitar o valor $\# X$, deve decompor o problema em subconjuntos viáveis $Y_{i=1, \ldots, k}$ apresentando estes subconjuntos e, para cada um deles, determinar sua cardinalidade. Ao final, ainda precisa apresentar como deveria ser obtida a recomposição do conjunto $X$, indicando se $\# X=\sum_{i=1}^{k} \# Y_{i}$, ou se $\# X=\prod_{i=1}^{k} \# Y_{i}$.

A construção dos subconjuntos (ou subproblemas) é o estágio. Note que a recomposição dos conjuntos correspondem no exemplo acima, respectivamente, aos princípios aditivo ou multiplicativo. No princípio aditivo a soma das partes corresponde à soma do todo,

$$
\text { sendo } Y_{i} \subseteq U(i=1,2, \ldots, k) \rightarrow \bigcap_{i=1,2, \ldots, k} Y_{i}=\emptyset \mathrm{e} \bigcup_{i=1,2, \ldots, k} Y_{i}=X
$$

Enquanto que no princípio multiplicativo, o produto das partes resulta no todo,

$$
\text { sendo } Y_{i} \subseteq U(i=1,2, \ldots, k) \rightarrow \prod_{i=1,2, \ldots, k} Y_{i}=Y_{1} \times Y_{2} \times \ldots Y_{k}=X
$$

No Combien? a cada passo de construção do estágio verifica se este pode resultar numa decomposição válida. Um exemplo trivial, para entender os estágios válidos, mas considerando um 
universo diferente é o seguinte: considerando dois dados usuais (com seis faces), qual é o total de possibilidades de, ao lançar simultaneamente ambos os dados, obtermos, nos dois, valores pares?

Neste exemplo, pode-se admitir cada dado como um estágio e assim contar o número de possibilidades para cada um deles. A solução final seria obtida pelo produto de ambas as contagens. A validade do particionamento nestes dois estágios é assegurada pelo princípio multiplicativo.

O sistema Combien? foi utilizado em vários experimentos realizados pelo grupo MOCAH, sendo relatado alguns benefícios didáticos para professores e alunos (Le Calvez et al., 2008). Entretanto, o Combien? não pode ser utilizado em cursos Web, pois ele é aplicativo local, apesar de ser implementado em uma variante de $L I S P^{4}$.

Esta restrição foi o principal motivador para o surgimento do projeto $i C o m b$, que será apresentado a seguir, Seção 2.3.

\subsection{Projeto $i C o m b$}

O projeto $i C o m b$ : Combinatória Interativa na Internet foi baseado na experiência com a interface Construction Ensemble do Combien? que possui bons recursos para auxílio à resolução de exercícios de contagem (Eisenmann e Brandão, 2009). A Figura 2.2 mostra as interfaces para resolução de exercícios do iComb e do Combien? durante a definição de um estágio para resolver um problema envolvendo conjunto universo baralho.
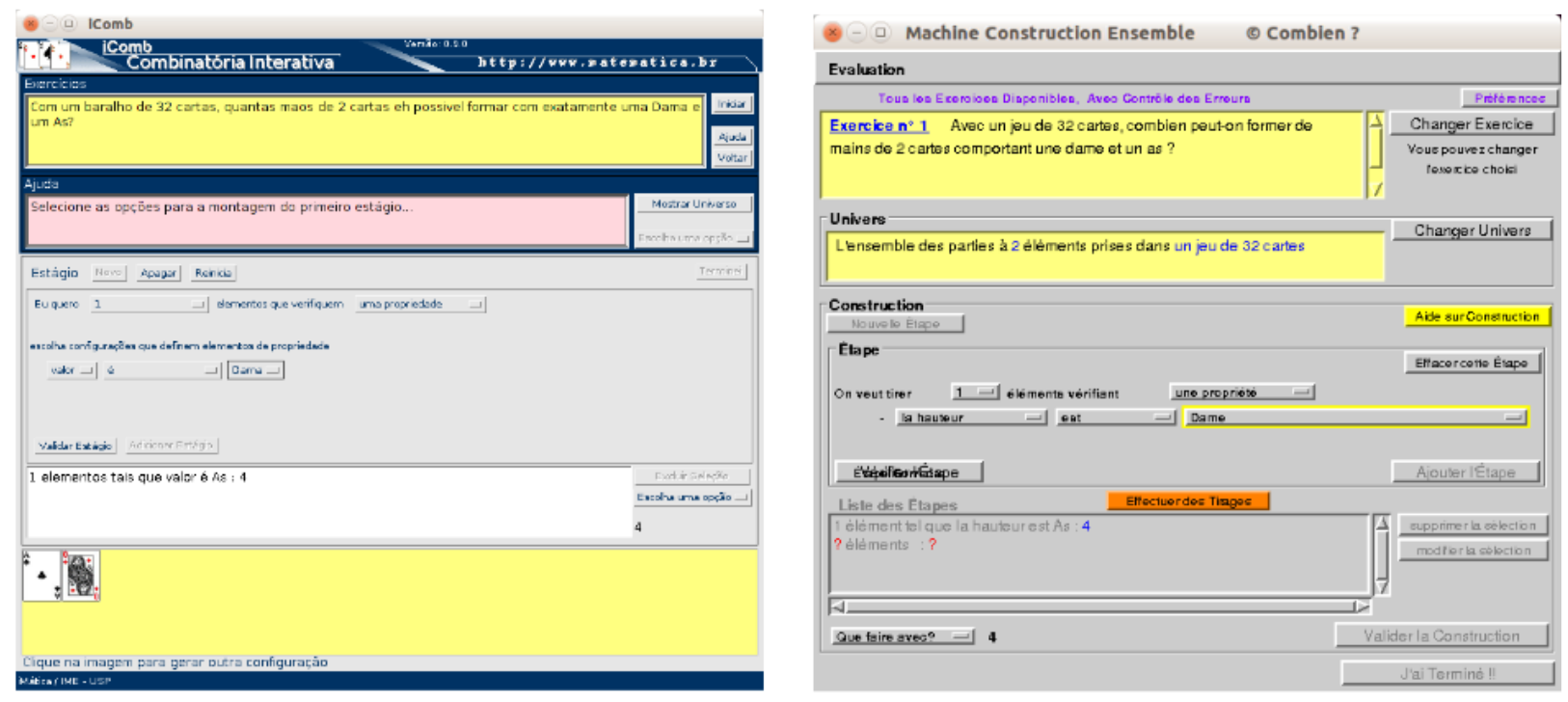

Figura 2.2: As interfaces do iComb e da Construction Ensemble do Combien? com a mesma atividade.

O iComb preservou características importantes do Combien?, tais como a detecção de erros durante a resolução de exercícios e a avaliação automática dos mesmos. Ele ainda não dispõe de todos os tipos de exercícios aceitos no Combien?, entretanto, com o iComb é possível criar novos exercícios, além da possibilidade de ser utilizado em ambientes Web. O iComb possui um recurso de ajuda que apresenta as imagens dos universos existentes, o que facilita a visualização por parte dos alunos para suas soluções.

A tabela 2.1 mostra as características existentes nos sistemas Combien? e iComb.

\footnotetext{
${ }^{4}$ LISP é uma família de linguagens de programação baseadas no paradigma funcional, vindo daí seu nome, LISt Processing.
} 
Tabela 2.1: Características dos sistemas Combien? e iComb.

\begin{tabular}{|l|c|c|}
\hline Características existentes & \multicolumn{2}{|c|}{ Sistemas } \\
& Combien $\boldsymbol{\text { ? }}$ & $\boldsymbol{i} \boldsymbol{C o m b}$ \\
\hline \hline Disponível para descarregamento e utilização & $\mathrm{X}$ & $\mathrm{X}$ \\
\hline Método "divisão e conquista" para resolução de exercícios & $\mathrm{X}$ & $\mathrm{X}$ \\
\hline Detecção de erros durante a resolução de exercícios & $\mathrm{X}$ & $\mathrm{X}$ \\
\hline Avaliação automática dos exercícios & $\mathrm{X}$ & $\mathrm{X}$ \\
\hline Internacionalização & $\mathrm{X}$ & $\mathrm{X}$ \\
\hline Apresentação de Conjuntos Universo (imagens dos elementos) & & $\mathrm{X}$ \\
\hline Criação de novos exercícios & & $\mathrm{X}$ \\
\hline Executável em navegadores Web & & $\mathrm{X}$ \\
\hline Integração à Ambientes Virtuais de Aprendizagem & & $\mathrm{X}$ \\
\hline
\end{tabular}

Nas Subseções seguintes apresentam-se exemplos de resolução de problemas para um melhor entendimento do funcionamento do sistema; recursos de ajuda disponíveis no $i C o m b$; ferramenta para autoria de novos exercícios; e por fim, as características que ele possui sendo um $i M A$.

\subsubsection{Exemplos de resolução de problemas}

Com a finalidade de esclarecer o modelo de resolução de problemas do $i$ Comb serão apresentados dois exemplos, ambos com a sequência de ações que o aluno deve fazer para resolvê-los no sistema.

De modo geral, qualquer problema considerado no $i$ Comb deve apresentar a seguinte estrutura:

"Com $\mathbf{j}$ elementos do universo, quantos subconjuntos de $\mathbf{k}$ elementos é possível formar respeitando restrição $\mathbf{1}$, restrição $\mathbf{2}, \ldots$, restrição i?".

Sendo o universo o conjunto de objetos considerados (e.g. um baralho usual, que totalizam 52 cartas) e as restrições são propriedades impostas sobre o universo, a partir das quais deverá ser possível contar o total de opções existentes (e.g., como o "número de retiradas de cartas satisfazendo as restrições").

A fim de ilustrar, considere o primeiro problema a seguir:

"Com um baralho de 32 cartas, quantas são as possibilidades de retirar 2 cartas, sem reposição, e obter exatamente uma Dama e um Ás?"

Deste modo, para este problema acima exposto o sentido da estrutura geral de um problema no $i C o m b$, é:

- Os $\mathbf{j}$ elementos do universo são as 32 cartas do baralho.

O baralho de 32 cartas é formado a partir de um baralho comum (52 cartas), onde foram retiradas as cartas com valor inferior a sete, de forma que cada naipe $(\boldsymbol{\phi}, \nabla, \diamond$ e $\mathbf{p})$ contenha as cartas 7, 8, 9, 10, Valete, Dama, Rei e Ás.

- Os subconjuntos de $\mathbf{k}$ elementos são as possibilidades de retirar 2 cartas.

- No problema tem-se duas restrições: restrição 1 a carta ser exatamente uma Dama, e restrição 2 a carta ser exatamente um Ás. 
No iComb cada restrição é um estágio (subproblema), e para iniciar a resolução deve-se definir as propriedades de cada estágio e calculá-los utilizando as estruturas combinatórias clássicas como combinação, arranjo, fatorial e exponenciação. Para o exemplo, poderiam ser criados 2 estágios:

Estágio 1: uma carta com a propriedade de ter o valor Dama

$$
C_{4,1}=4 \text { possibilidades }
$$

Estágio 2: uma carta com a propriedade de ter o valor Ás

$$
C_{4,1}=4 \text { possibilidades }
$$

Para finalizar, o aluno deverá informar o que fazer com os estágios construídos, escolhendo uma entre as duas opções possíveis do sistema: somar ou multiplicar.

Neste caso, o número total de possibilidades será obtido multiplicando-se o número de possibilidades do Estágio 1 pelo número de possibilidades do Estágio 2:

portanto, $4 \times 4=16$ possibilidades totais,

pois tem-se dois eventos (estágios) independentes que ocorrem simultaneamente, como explicado anteriormente, neste caso aplica-se o Princípio Multiplicativo.

Para terminar o exercício no $i C o m b$ o aluno deve solicitar a validação final e, em caso de uma construção bem sucedida, o sistema irá apresentar uma tela final com a construção passo a passo da solução do problema. A Figura 2.3 mostra, na imagem em último plano, a composição da construção de cada um dos dois estágios possíveis para o problema em questão, em segundo plano, mostra a tela do sistema após a construção final e em primeiro plano, o resultado da avaliação final pelo $i C o m b$.

Agora, considere o segundo problema:

"Com um baralho de 32 cartas, quantas são as possibilidades de retirar uma carta e ela ser uma Dama ou um Ás?"

Para este problema o sentido da estrutura geral de um problema no $i C o m b$, é:

- Os j elementos do universo são as 32 cartas do baralho. O universo em questão é o mesmo detalhado no problema anterior.

- Os subconjuntos de $\mathbf{k}$ elementos são as possibilidades de retirar uma carta.

- Tem-se também, duas restrições: restrição 1 a carta ser uma Dama, ou restrição 2 a carta ser um Ás.

Já se sabe que cada restrição no $i C o m b$ é um estágio. Então, inicia-se a resolução definindo as propriedades de cada estágio e os calcula utilizando as estruturas combinatórias clássicas como combinação, arranjo, fatorial e exponenciação. Para esse problema, também é preciso criar 2 estágios:

Estágio 1: uma carta com a propriedade de ter o valor Dama 


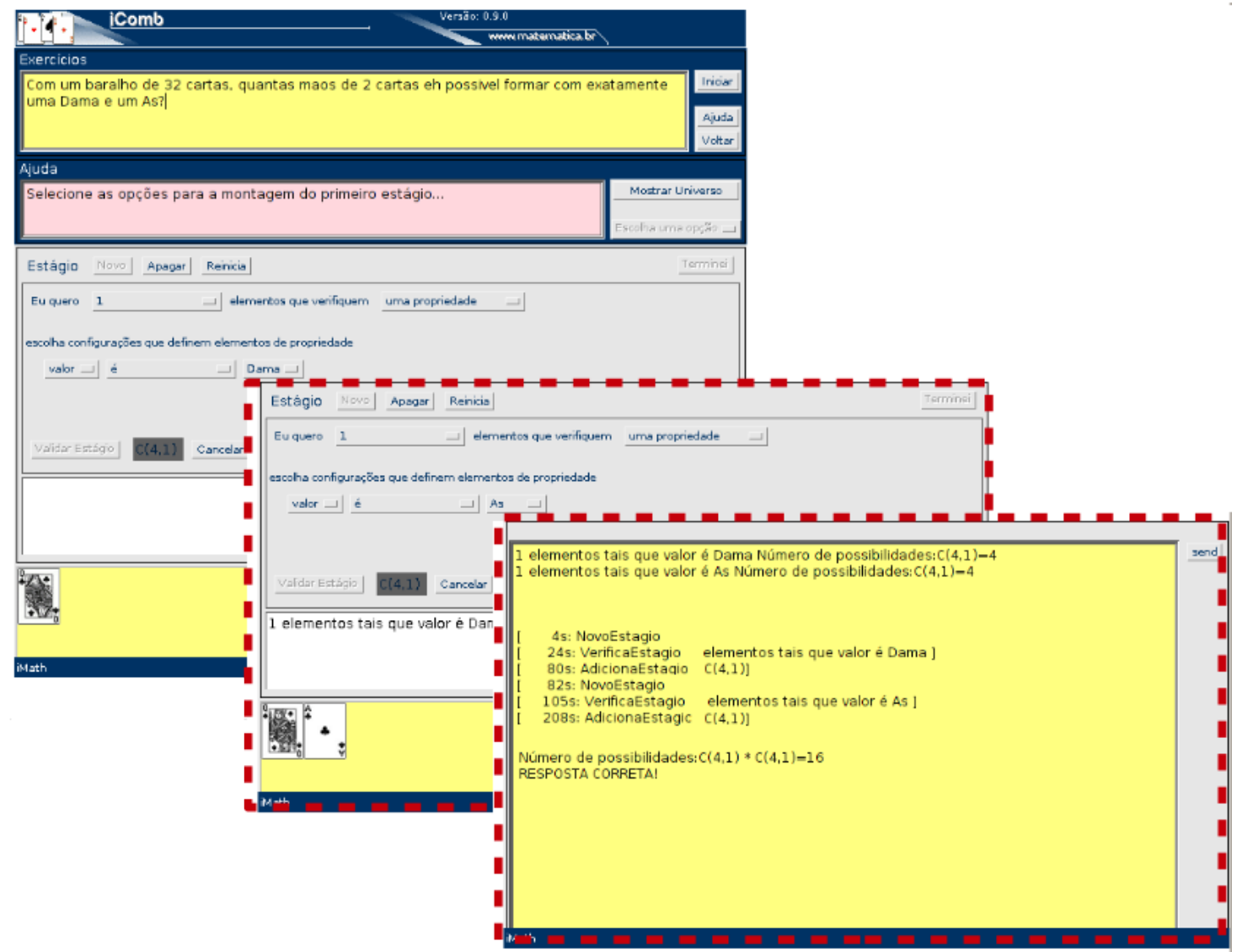

Figura 2.3: A resolução do primeiro problema proposto no iComb.

$C_{4,1}=4$ possibilidades

Estágio 2: uma carta com a propriedade de ter o valor Âs

$C_{4,1}=4$ possibilidades

Novamente, para finalizar, o aluno deverá informar o que fazer com os estágios construídos, escolhendo uma entre as duas opções possíveis no sistema.

E neste problema o número total de possibilidades será obtido adicionando-se o número de possibilidades do Estágio 1 ao número de possibilidades do Estágio 2:

portanto, $4+4=8$ possibilidades totais.

pois agora, tem-se dois eventos (estágios) disjuntos, esse é o Princípio Aditivo.

Para terminar o exercício no $i C o m b$ o aluno deve solicitar a validação final e, em caso de uma construção bem sucedida, o sistema irá apresentar uma tela final com a construção passo a passo da solução do problema, como mencionado anteriormente.

O método de particionamento das restrições do problema, permite que o aluno construa seu raciocínio a partir das opções disponíveis no sistema, descrevendo um algoritmo de enumeração referente a solução final do problema (Calvez et al., 2003; Giroire et al., 2006; Tisseau et al., 2000). 


\subsubsection{Recursos de Ajuda}

O iComb possui três recursos de ajuda, exemplificado na Figura 2.4, cada um com uma característica peculiar, porém todas com o mesmo objetivo, auxiliar os usuários na utilização do sistema durante a resolução do exercício.

(a) Ajuda tradicional, acionada pelo botão "Ajuda", apresenta os conceitos do iComb de forma generalizada.

(b) Ajuda contextual, apresenta-se no quadro fixo, denominado "Ajuda", da interface, as mensagens contidas neste quadro são atualizadas em função da ação que o usuário vai realizar.

(c) Ajuda por figuras, que mostra as imagens e os atributos dos elementos do conjunto universo em questão, acionada pelo botão "Mostrar Universo".

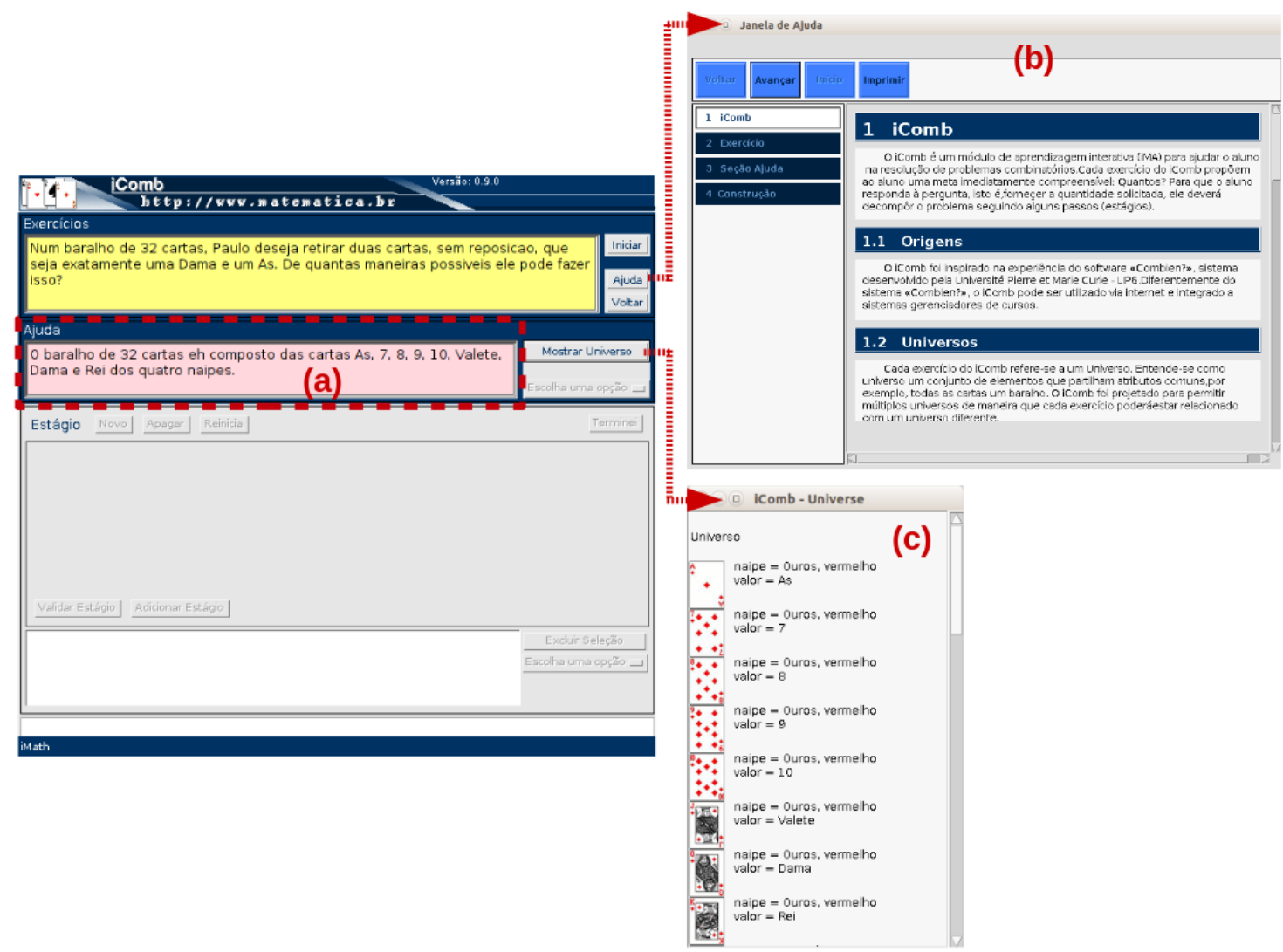

Figura 2.4: As imagens dos recursos de ajuda do iComb.

O recurso ajuda por figuras, a ferramenta para criar novos exercícios e também, o recurso de integração do sistema à SGC são características específicas do iComb.

\subsubsection{Ferramenta para autoria de novos exercícios}

Uma característica interessante do iComb é que ele foi desenhado de forma a possibilitar a autoria de novos exercícios de contagem de modo relativamente simples. Isso quer dizer que um professor de Matemática, com pouco treinamento, é capaz de criar novas atividades com o sistema, seja com o iComb local ou na Web. 
Assim, supondo a utilização do iComb integrado a um sistema gerenciador de cursos (SGC), é possível que um professor inclua novos exercícios à base de dados de um repositório de Conteúdos Digitais, como o iRepositório ${ }^{5}$ (Nascimento, 2014).

A ferramenta de criação de um exercício no iComb utiliza-se de uma sequência de ações na interface específica para autoria. Tais ações servem para montar um arquivo de texto composto de enunciado, dica, subdivisões do problema e gabarito do exercício; sendo gravado com a extensão *.cmb, esta extensão é específica do $i C o m b$.

Se for utilizada a versão $i C o m b$ local a atividade será gravada em um diretório da máquina. Se estiver na $W e b$ a atividade será gravada e adicionada ao repositório digital.

A Figura 2.5 apresenta a interface do $i C o m b$ para criação de exercício no editor online do repositório do Tarefas Interativas para Internet (iTarefa).

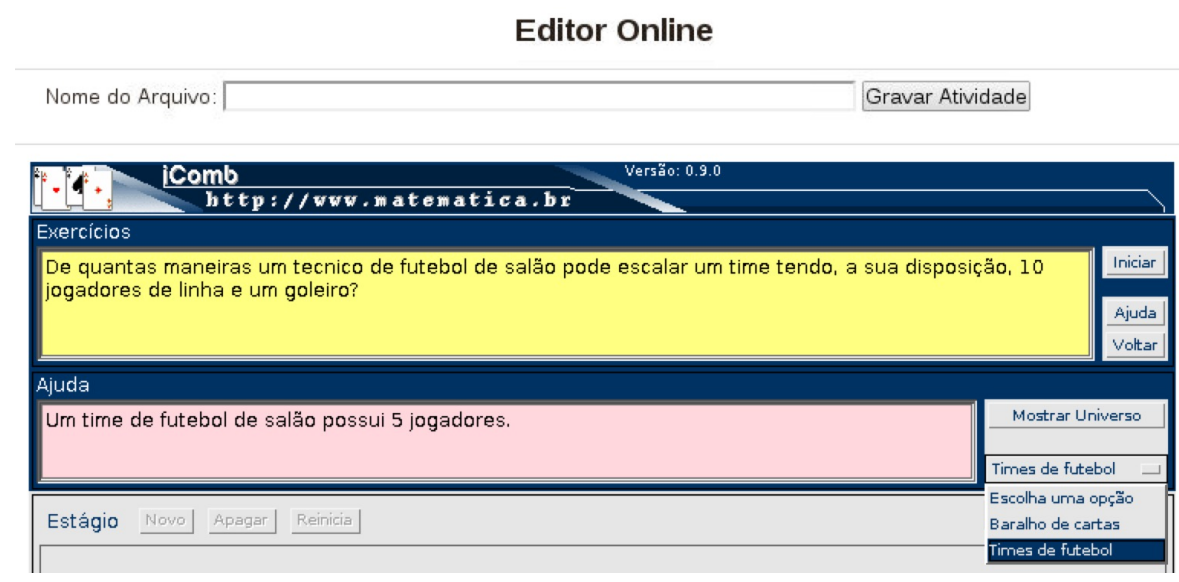

Figura 2.5: Interface do iComb durante a autoria de exercicio, momento da escolha do conjunto universo.

Por possuir essas características específicas o iComb é um Módulo de Aprendizagem Interativa (iMA). A seguir, na Subseção 2.3.4, detalha-se as especificações de um iMA e mostram os iMA existentes.

\subsubsection{Módulos de Aprendizagem Interativa (iMA)}

Os Módulos de Aprendizagem Interativa ( $i M A$ ) são sistemas educacionais com características similares que visam facilitar e melhorar o trabalho do professor e simultaneamente fornecer ao aluno um ambiente motivador de atividades interativas (Dalmon et al., 2011a).

Os $i M A$ possuem ferramentas de autoria de exercícios que promovem interatividade de retroação imediata (feedback) e oferecem avaliação automática destes exercícios (Brandão et al., 2004; Isotani e Brandão, 2008). Porém, a característica principal dos $i M A$ é possibilitar integração com navegadores $W e b$ e dispor de recursos de comunicação baseados no protocolo $H \mathrm{TTP}^{6}$.

Além do $i C o m b$ implementar o protocolo para $i M A$ tem-se também, outros quatro sistemas educacionais que compartilham desta mesma especificação são eles: (i) iGeom - Geometria Interativa na Internet (Isotani e Brandão, 2003), (ii) iGraf - Gráficos Interativos na Internet (Prado, 2008), (iii) iVProg - Programação Visual e Interativa na Internet (Kamiya e Brandão, 2009) e (iv)

\footnotetext{
${ }^{5}$ iRepositório - Repositório de Conteúdos Digitais Interativos é um projeto para disponibilizar um novo componente para o Moodle para armazenamento, classificação e busca de objetos de aprendizagem (OA). Além disso ele é integrado ao iTarefa.

${ }^{6}$ O Hypertext Transfer Protocol (HTTP) é o protocolo base da Web.
} 
iTangram, que é uma implementação digital do quebra-cabeça com peças geométricas do Tangram (Souza et al., 2008). Na Figura 2.6 apresentam-se as interfaces desses quatro iMA.
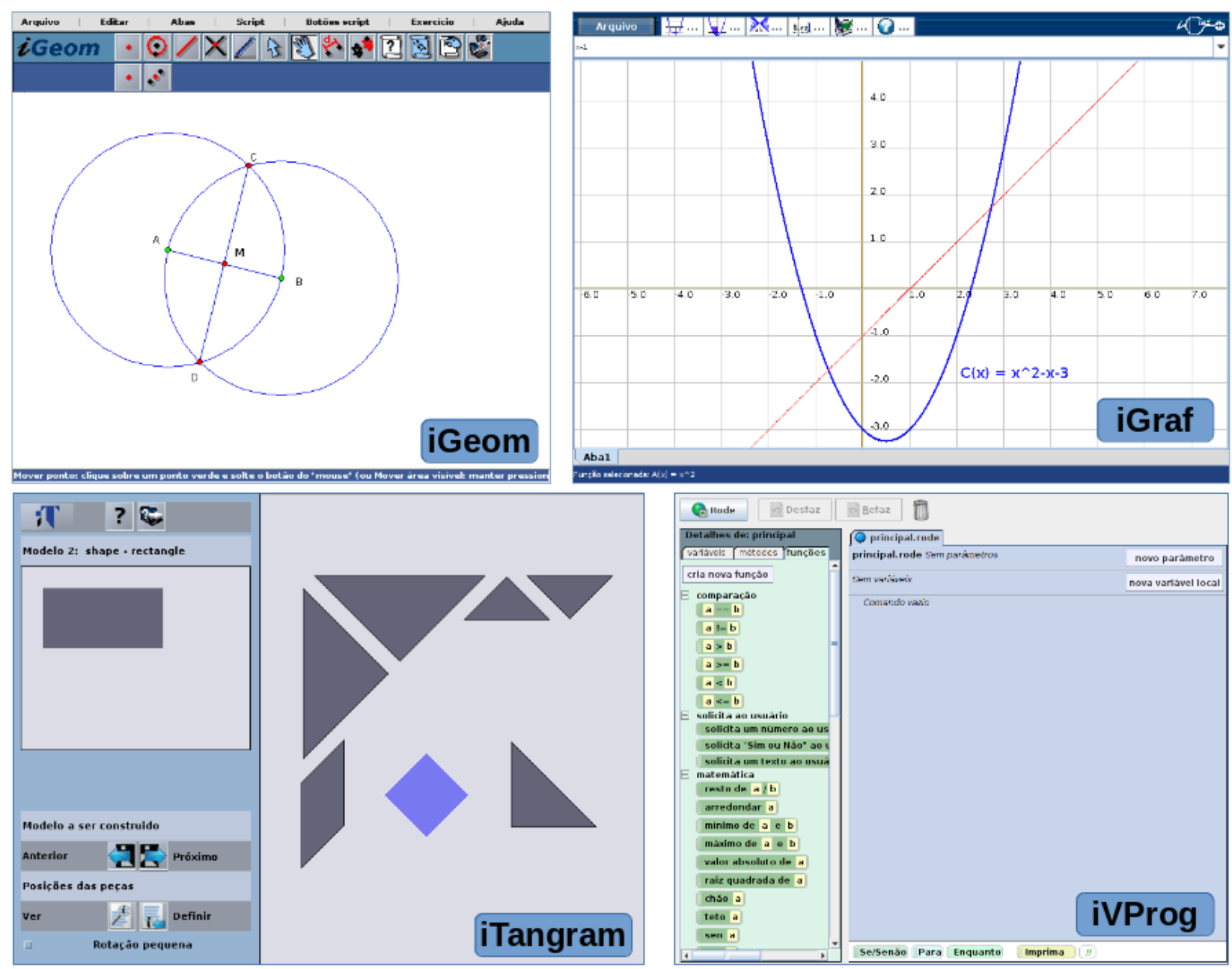

Figura 2.6: As interfaces do iGeom, iGraf, iVProg e iTangram.

A maioria dos $i M A$ ainda são implementados na forma de applets . Entretanto atualmente já tem-se disponível o iVProg implementado em HTML5 (https://github.com/LInE-IME-USP/ ivprog-html).

A proposta dos $i M A$ surgiu no início dos anos 2000, com os sistemas iGeom e o Sistema de Aprendizagem via Web(SAW) (Moura e Brandão, 2005), este último um Sistema Gerenciador de Cursos (SGC) implementado no grupo de pesquisa em que este projeto de mestrado está inserido. A primeira versão do SAW foi utilizada em cursos no IME-USP em 2004.

No início do projeto $i C o m b$ o único SGC que possibilitava sua integração como $i M A$ era o SAW (Moura et al., 2007), porém, o desenvolvimento do SAW estava restrito ao grupo de pesquisa deste projeto, o que dificultava sua evolução, que acontecia de forma rápida em de outros sistemas gerenciadores, como era o caso do sistema Modular Object-Oriented Dynamic Learning Environment (Moodle). Que associado às grandes vantagens do Moodle: sistema livre, estrutura interna modular e sua grande popularidade fez com que o SAW perdesse espaço e passou-se a adotar o Moodle como plataforma.

No final de 2008 foi testado o primeiro protótipo do pacote $i$ Tarefa que possibilitou a integração de iMA ao Moodle (Rodrigues e Brandão, 2009). Além da inserção de tarefas que podem ser 
compartilhadas por grupos de professores, outro recurso bastante útil do iTarefa é o seu editor que permite a integração de atividades interativas em qualquer área de texto do Moodle, como em uma mensagem de fórum.

Existem versões disponíveis do iTarefa para Moodle 1.9 e para as versões 2.4 até 2.7, esta última sendo a mais recente do Moodle(Julho de 2014). O iTarefa para Moodle pode ser descarregado a partir da URL: https://moodle.org/plugins/view.php?plugin=mod_iassign.

Assim, o $i C o m b$ pode ser facilmente integrado ao Moodle, ou qualquer outro SGC que implemente o padrão de comunicação dos iMA (Dalmon et al., 2011a). 


\section{Capítulo 3}

\section{Métodos}

O objetivo deste capítulo é descrever as técnicas e metodologias que foram empregadas no desenvolvimento deste projeto de mestrado.

As seções que se seguem descrevem todo o aparato de técnicas e métodos que foram utilizadas no processo de reprojeto do iComb. Na Seção 3.1 tem-se a descrição da metodologia utilizada para descrever e interpretar os dados coletados na avaliação do iComb e, na Seção 3.2 são abordadas as atividades e técnicas do processo de design de interação.

\subsection{Análise de Conteúdo}

A Análise de Conteúdo proporciona uma forma aperfeiçoada de se analisar dados coletados em várias técnicas sendo elas, entrevistas, observação, vídeos, entre outras. Para estudo desse tema, dois autores foram consultados Bardin (1986) e Franco (2012). A seguir descreve-se brevemente o método.

Análise de Conteúdo é um método de pesquisa usado para descrever e interpretar o conteúdo de toda classe de documentos e textos. Essa análise é conduzida por um conjunto de técnicas sistemáticas qualitativas ou quantitativas, que ajuda a reinterpretar as mensagens e atingir uma compreensão de seus significados num nível que vai além de uma leitura comum.

A análise de conteúdo exige do pesquisador, disciplina, dedicação, paciência e tempo.

A análise dos dados é guiada por cinco etapas, a saber:

(i) Pré análise ou preparação das informações. Essa etapa constitui-se de uma leitura geral em todos os materiais coletados para que seja feita a eleição dos materiais pertinentes ao objetivo da pesquisa e após seja feita a codificação dos materiais, onde se estabelece um código que possibilite identificar rapidamente cada elemento nos documentos a serem analisados.

(ii) Unitarização do conteúdo em unidades. Na unitarização considera-se recortes de todo o material eleito em unidades de registro. As unidades de registro podem ser palavras, frases, parágrafos ou mesmo documentos em formato integral, de maneira que seja possível comparar com o mesmo conteúdo semântico, para que possam ser agrupadas tematicamente em categorias.

(iii) Categorização das unidades de registro. A categorização é o agrupamento das unidades de registro considerando a parte comum existente entre elas. Classifica-se por semelhança 
ou analogia, segundo critérios que podem ser semânticos, originando categorias temáticas. Para a constituição das categorias deve-se atender alguns critérios como: validade, pertinência ou adequação; exaustividade ou exclusividade; inclusividade; homogêneidade; e objetividade, consistência ou fidedignidade.

(iv) Tratamento dos resultados. Para essa etapa é feita a descrição de cada uma das categorias, sendo assim produzido um texto síntese em que se expresse os significados presentes nas unidades de análise incluídas em cada categoria.

(v) Inferência e interpretação. Uma boa análise de conteúdo deve atingir uma compreensão mais aprofundada do conteúdo das mensagens através da inferência e interpretação. Essa etapa consiste em compreender e captar os conteúdos manifestos e latentes contidos no material coletado.

A utilização da metodologia da análise de conteúdo nesta pesquisa é justificada pela necessidade de descrever e interpretar adequadamente os resultados coletados nas técnicas aplicadas para avaliação da implementação do sistema $i C o m b$ em Java. A análise desses resultados são apresentadas na Subseção 4.1.2.

\subsection{Processo de Design de Interação}

O processo de design de interação é uma atividade prática, criativa e de tomada de decisão. Seu objetivo é projetar produtos interativos que forneçam suporte às atividades dos usuários (Preece et al., 2005).

O conceito de design de interação também envolve a forma, mas seu foco está no comportamento $^{1}$. O design de interação está fortemente preocupado com as necessidades e desejos da maioria que usarão o produto (Cooper et al., 2007).

Outro conceito importante ao design de interação é o envolvimento de usuário no desenvolvimento do projeto, que por isso é referido como design centrado no usuário.

Segundo Preece et al. (2005) o design de interação envolve quatro atividades básicas, são elas:

(i) Identificação de necessidades e estabelecimento de requisitos. Esta atividade envolve trabalho de campo, a fim de identificar o contexto no qual o sistema irá ser utilizado e as características de seus usuários. A coleta de dados pode ser feita através de técnicas tais como observação direta, entrevistas, testes de desempenho na realização de tarefas, questionário, entre outras formas de testes. Com a coleta de dados se obtem valiosas informações de como o sistema, a ser desenvolvido, será utilizado pelos usuários e por meio de suposições poder estabelecer os seus requisitos.

(ii) Desenvolvimento de designs alternativos. O desenvolvimento de soluções alternativas, ou designs alternativos, devem abranger os requisitos que foram pré-estabelecidos. Esta atividade envolve os projetos da aparência da interface e o comportamento do sistema. O desenvolvimento de designs alternativos é, muitas vezes, necessário para explorar e superar limitações e constrangimentos e também, para obter feedback relevante de usuários.

\footnotetext{
1 "Like many other design fields interaction design also has an interest in form but its main focus is on behavior" Cooper et al. (2007).
} 
(iii) Construção de protótipos dos designs alternativos. Essa é a atividade que caracteriza o design de interação, uma vez que nela consta a projeção do sistema de forma interativa, a prototipação. Protótipos atuam como uma representação material dos modelos produzidos e, nesse sentido, pode ser utilizados para discutir e avaliar os designs alternativos com os usuários. Os protótipos podem ser produzidos com alta fidelidade (baseada em software) ou de baixa fidelidade (baseada em papel e lápis, de plástico, adesivos e assim por diante), dependendo do atual estágio de desenvolvimento. Os usuários podem ativamente se envolver em atividades de prototipagem, particularmente com protótipos de baixa fidelidade; quando este é o caso, esta atividade é denominada de prototipagem participativa (Wixon e Ramey, 1996).

(iv) Avaliação. Avaliar o que está sendo construído durante o processo determina a usabilidade e aceitabilidade do sistema computacional. Problemas que surgem durante a atividade de avaliação induz a um novo ciclo de atividades.

Estas atividades devem ser complementares e iteradas constantemente. A Figura 3.1 apresenta um modelo simples do ciclo de atividades do design de interação.

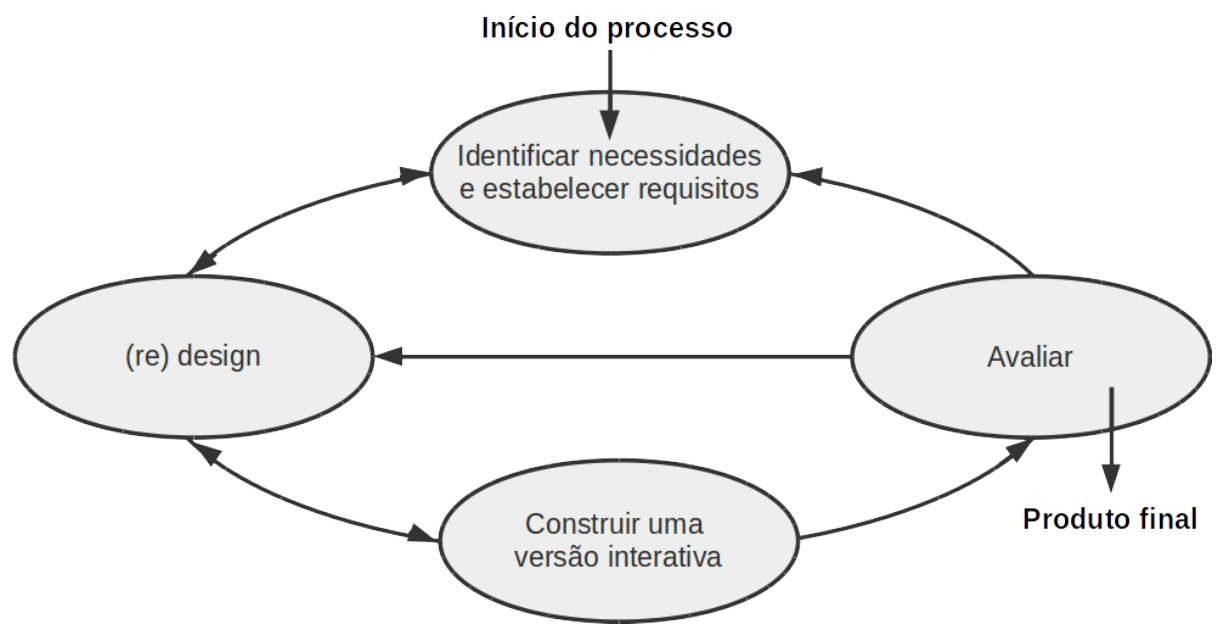

Figura 3.1: Modelo do ciclo do design de interação. Baseado em Preece et al. (2005).

Segundo Gould e Lewis (1985) a iteração é um processo inevitável e gera refinamento do design com base em feedbacks, que são obtidos a partir do envolvimento de usuários e desenvolvedores do projeto que passam a discutir requisitos, necessidades, desejos e aspirações a respeito do que é realmente necessário e viável.

No que diz respeito à concepção de sistema (software) educativo, este processo foi aplicado com sucesso no desenvolvimento de aplicações destinadas a aprendizagem móvel (Cadaval e Hartmann, 2014), interação social online (Medeiros et al., 2013) e apoio a crianças com necessidades especiais (Muñoz et al., 2012), entre outros exemplos. O rico feedback dos usuários envolvidos no processo de ensino e aprendizagem (Muñoz et al., 2012) e um ritmo rápido no desenvolvimento (Medeiros et al., 2013) são algumas vantagens associadas ao uso do processo de design centrado no usuário.

Vale ressaltar que o processo de reprojeto do iComb envolveu as seguintes atividades do design de interação: 
- Avaliação da implementação existente do sistema $i$ Comb. Para avaliar a versão do iComb Java foi aplicado a metodologia de teste de usabilidade combinado com outras técnicas para coleta de dados. A descrição e os resultados dessa atividade se encontram na Seção 4.1.

- Desenvolvimento de designs da interface do $\boldsymbol{i C o m b}$. O desenvolvimento dos designs da interface do sistema foi guiado pela técnica de storyboarding. Essa atividade é apresentada na Subseção 4.2.1.

- Construção de protótipos do iComb. Para construir o primeiro protótipo do iCombH5, em papel, utilizou-se do storyboard desenvolvido na atividade anterior. Já o protótipo digital foi avaliado utilizando, também, a técnica storyboarding. A prototipagem participativa do iCombH5 está detalhada e ilustrada na Subseção 4.2.2.

- Avaliação do protótipo do $\mathbf{i C o m b H 5}$. Para avaliar a usabilidade do $i$ CombH5 foi realizado um teste piloto com os usuários que fizeram parte da equipe do projeto. O detalhamento desta sessão está apresentado na Seção 4.3.

A seguir, são brevemente descritos o teste de usabilidade, Subseção 3.2.1, e a técnica para a prototipagem de storyboard interativo cooperativo (Cooperative Interative Storyboard Prototyping), técnica abordada no Design Participativo, Subseção 3.2.2.

\subsubsection{Teste de usabilidade de sistemas interativos}

Usabilidade é um atributo da qualidade que está relacionada à forma como os usuários são capazes de operar um sistema interativo em um contexto específico de utilização. Ela também pode ser definida sendo uma combinação de atributos como, facilidade de aprendizagem (learnability), facilidade de uso, eficiência, minimização de erros, eficácia, segurança no uso, flexibilidade e robusteza (ISO9241, 1998).

A deficiência em um desses critérios de usabilidade pode causar grandes barreiras para o uso de uma determinada aplicação.

Os testes de usabilidade são métodos fundamentais para identificar a deficiência do sistema em algum desses atributos, sendo centrados no usuário. Além disso, um usuário deve ser capaz de aprender facilmente os procedimentos para simplesmente interagir com o sistema.

Assim, pode-se inferir que o processo de interagir com o sistema tem alguma semelhança com um processo de aprendizagem. Esta semelhança foi discutida anteriormente por Zaharias e Poylymenakou (2009), Squires e Preece (1999) e Ardito et al. (2006) que consideram a importância da usabilidade em sistemas educacionais.

Segundo Rocha e Baranauskas (2003) o teste de usabilidade é aplicado quando se tem uma implementação real do sistema em algum formato que pode ser desde uma simulação da capacidade interativa do sistema, sem nenhuma funcionalidade; ou um protótipo básico implementando um cenário, como o protótipo do $i$ CombH5; ou até a implementação completa, como é o caso do sistema $i C o m b$.

Os testes são realizados em situações controladas de laboratório, onde os usuários são observados diretamente pelos avaliadores (Mayhew, 1999). As tarefas aplicadas durante o teste devem ser representativas e devem dar cobertura às partes mais significativas da interface do sistema. Para 
se coletar dados durante um teste deve-se combinar várias técnicas, sejam elas, experimentais, observacionais ou de questionamento.

Os testes de usabilidade do $i C o m b$ e teste piloto do $i C o m b H 5$ estão detalhados e serão apresentados, respectivamente na Seção 4.1 e na Seção 4.3.

\subsubsection{Prototipagem de Storyboard Interativo Cooperativo}

Antes de apresentar a técnica de storyboarding, Prototipagem de Storyboard Interativo Cooperativo (Cooperative Interative Storyboard Prototyping - CISP), é necessário a familiarização com o tema design participativo (Participatory Design).

O design participativo é uma metodologia que caracteriza-se pelo envolvimento dos usuários finais de um sistema computacional durante o processo de desenvolvimento do design. Trata-se de um conjunto de teorias, práticas e estudos que apoiam a participação ativa do usuário em diferentes atividades do ciclo do design em questão. Segundo Rocha e Baranauskas (2003) o design participativo define-se por ser orientado ao contexto de trabalho, envolver colaboração em vários níveis e apresentar uma abordagem iterativa ao design.

Muitas são as motivações para o uso das abordagens participativas, entre elas o fato de ter um ambiente de trabalho democrático que tende a melhorar, tanto o desenvolvimento do sistema quanto o trabalho dos usuários; e por ser considerada uma abordagem potencialmente positiva em ambientes inclusivos de design.

Conforme Rocha e Baranauskas (2003) são muitas as técnicas que promovem o design participativo, as quais se caracterizam pela simplicidade e o pouco comprometimento com recursos. Entre tantas técnicas tem-se as mais utilizadas que são brainstorming, storyboarding e workshops.

Cada projeto tem sua particularidade e especificidade, cabe aos desenvolvedores estudar a necessidade, ou não, de utilizar técnicas do design participativo. Para o redesign da interface do iComb optou-se por utilizar a técnica Prototipagem de Storyboard Interativo Cooperativo ou Cooperative Interative Storyboard Prototyping (CISP). Trata-se de uma técnica que gera e modifica cooperativamente designs de interfaces, ou ainda, avalia interfaces existentes comparando com interfaces alternativas.

Associa-se à técnica um programa (software) ou outro ambiente que geralmente é usado como material para criação dos storyboard.

O processo do storyboarding envolve iterações de três etapas principais, exploração, avaliação e modificação de storyboard.

A primeira etapa, exploração do storyboard, serve para realização de tarefas pelo usuário final. Durante esta etapa são registradas as interações do usuário. Na segunda, avalia o storyboard por meio de análise e discussão do registro da interação. E na terceira é realizada a modificação do storyboard conforme o que foi analisado e discutido.

Ao final das iterações desse processo, como resultado, tem-se o storyboard ou o protótipo melhorado e o registro das interações dos usuários.

Esta técnica é frequentemente usada na fase de design de um sistema computacional. Porém, a prática participativa estende-se a todo o ciclo de vida de um programa (software), desde a fase de identificação do problema, passando pelas fases de levantamento e análise de requisitos, desenvolvimento de design da interface, avaliação e redesign do sistema.

Na Educação Matemática, e.g., utilizou-se de storyboarding para evoluir no design de uma 
tarefa de aprendizagem matemática (Jones, 2008). Já Medeiros et al. (2007) também fizeram uso da técnica para melhorar a qualidade das atividades de documentação e validação de requisitos de um sistema computacional. 


\section{Capítulo 4}

\section{Processo de reprojeto do $i C o m b$}

A primeira versão do $i C o m b$ foi apresentada em 2008 a partir da dissertação de mestrado de Eisenmann (2009).

O sistema $i C o m b$ foi implementado em Java, na forma de applet, entretanto os applets Java tem enfrentado problemas, por exemplo, os navegadores como o Firefox tem introduzido diretivas de segurança que impõem vários passos para permitir sua execução. Isso tem acarretado dificuldades adicionais aos projetos que empregam applets, como relatado em Ribeiro et al. (2014).

De outra parte, o padrão HTML5 tem incorporado recursos que permitem a construção de sistemas Web, adicionalmente a interpretação de códigos em HTML5 tem sido largamente implementada em variados dispositivos, não apenas navegadores $W e b$ para computadores.

Segundo Fontanette et al. (2002) um sistema computacional é um artefato que tem que estar em evolução e requer constantes modificações, sejam elas para corrigir erros, melhorar desempenho ou adicionar novos requisitos ao sistema.

Dessa forma, optou-se por desenvolver uma nova versão do iComb em HTML5, sendo o primeiro passo para o atual projeto examinar a interação do usuário com o sistema. Isso se fez necessário porque encontra-se no texto da dissertação o registro de um único experimento realizado com o sistema $i C o m b$, onde a maioria dos participantes do tal experimento avaliaram ser de razoável dificuldade a usabilidade do sistema, e também, desde a finalização do mestrado em 2009 o iComb nunca foi aplicado ao contexto de sala de aula.

Para o processo de reprojeto do sistema $i$ Comb adotou-se uma abordagem adaptada do Design de Interação segundo a proposta de Preece et al. (2005).

Neste capítulo, serão apresentadas todas as atividades do processo de reprojeto do $i$ Comb. Na Seção 4.1 são descritas as sessões de teste de usabilidade com a versão do $i$ Comb Java, bem como, os resultados e a análise dos dados coletados por meio das técnicas aplicadas nessas sessões. Na Seção 4.2 apresenta-se as atividades do desenvolvimento de designs da interface do sistema e a prototipagem participativa do iComb. E por fim, a Seção 4.3 o protótipo do $i$ CombH5 avaliado pelos usuários, onde está a descrição do teste piloto, bem como, os resultados dos dados coletados.

\subsection{Teste de usabilidade do sistema $i C o m b$}

A primeira atividade do processo de reprojeto do $i$ Comb foi avaliar da implementação existente do sistema. Para isso, organizou-se duas sessões com usuários do sistema onde foram utilizadas a metodologia de teste de usabilidade combinada com outras técnicas para coleta de dados. 
A Subseção 4.1.1 descreve detalhadamente as sessões de teste.

\subsubsection{Descrição das sessões de teste}

Como público-alvo para participar do teste de usabilidade foram escolhidos professores de matemática dos ensinos fundamental e médio e alunos de graduação.

A razão da escolha deve-se a dois fatores principais, primeiro por ser necessário que o professor conheça a tecnologia antes de tentar empregá-la em atividades didáticas. O segundo fator é que os sistemas Combien? e iComb foram desenhados visando o ensino-aprendizagem de combinatória para os níveis de ensino médio e superior.

Vale destacar que os professores de matemática também foram o público-alvo no experimento do trabalho inicial de Eisenmann (2009).

Foram realizadas duas sessões separadas por tipo de usuário, primeiro com professores depois com alunos. Entretanto, ambos realizaram atividades no "papel aluno", ou seja, resolvendo exercícios.

Os dois grupos de usuários participaram do teste de forma voluntária. No convite à participação foi explanado o objetivo dos testes e explicado que nomes ou imagens dos participantes não seriam divulgados. Apesar disso, os participantes assinaram uma Carta de Consentimento para uso dos dados coletados nas atividades no processo de reprojeto do $i$ Comb. O exemplar dessa carta encontrase no Apêndice A.

As sessões foram realizadas em lugares diferentes, mas ambas em laboratórios de informática com acesso a Internet.

A primeira sessão contou com a participação de um grupo de cinco (5) professores de Matemática das redes pública e privada de São Paulo e foi realizada num dos laboratórios do Centro de Ensino de Computação do Instituto de Matemática e Estatística (CEC-IME-USP). Todos os professores tinham conhecimento básico de informática, sendo que nenhum deles tinha treinamento específico sobre ferramentas computacionais.

Sobre a experiência de uso didático do computador, dos cinco (5) professores somente um (1) afirmou sempre empregar o computador para apoiar a aprendizagem, enquanto dois (2) nunca empregaram.

A outra sessão teve a participação de um grupo de quatro (4) alunos do segundo semestre de graduação do curso Superior de Tecnologia em Análise e Desenvolvimento de Sistemas (ADS) do Instituto Federal de Educação, Ciência e Tecnologia de São Paulo, Campus Cubatão (IFSP Cubatão). O curso ADS tem duração de seis semestres e consta em sua grade currícular a disciplina de Matemática Aplicada, disciplina que aborda o conteúdo de Análise Combinatória. Essa sessão ocorreu num dos laboratórios do IFSP Cubatão.

Todos os alunos tinham experiência em programação e ainda não haviam tido nenhuma disciplina de IHC em seu curso.

Destaca-se que número pequeno de participantes pode ser justificado por ter sido de participação voluntária, sem qualquer compensação, seja ela financeira ou, no caso dos alunos, sem contar qualquer crédito em seu curso. Entretanto, esse número está compatível com as recomendações de Nielsen (2003) que indicou que testes com 5 usuários podem detectar cerca de $80 \%$ dos problemas de usabilidade.

Sabe-se que existem críticas sobre esse "número mágico" de Nielsen, no entanto, tal como observado por Lindgaard e Chattratichart (2007), mais importante do que o número de usuários são as 
características dos participantes, os objetivos do teste e, principalmente, o potencial de realimentar os resultados do teste no processo iterativo de design quando não se trata de um teste puramente avaliativo.

Os testes de usabilidade concentram-se nas necessidades dos usuários de um sistema interativo, tendo sua característica principal o fato de ser controlado firmemente pelo avaliador (Mayhew, 1999). Diante disso, as sessões de teste tiveram um limite total de tempo de 2 horas e 30 minutos, sendo este dividido em intervalos para execução de quatro tarefas propostas aos participantes:

- Pré-teste (45 minutos). O pré-teste foi realizado com lápis e papel, sem qualquer consulta a colegas ou à Web. Ele foi composto por três exercícios de combinatória, semelhantes aos que seriam resolvidos no $i C o m b$, sendo o grau de dificuldade crescente em relacão à ordem de apresentação dos exercícios. O objetivo dessa tarefa foi observar a estratégia que os participantes usariam para resolver os exercícios propostos, e posteriormente, comparar com o método de resolução de exercícios utilizando o $i C o m b$.

- Teste do sistema $i$ Comb (45 minutos). Os participantes resolveram alguns exercícios no sistema $i C o m b$ integrado ao Moodle ${ }^{1}$ por meio do $i$ Tarefa $^{2}$. A Figura 4.1 apresenta um dos exercícios propostos aos participantes. Vale salientar que durante o desenvolvimento dessa tarefa, a tela do computador de cada participante foi gravada para possibilitar uma análise detalhada da interação dos participantes com o sistema (Souza et al., 1999). E também, os participantes foram diretamente observados pelo pesquisador, pois isso possibilita o registro de algum fato inesperado durante a sessão de trabalho no computador (Olson e Moran, 1996).

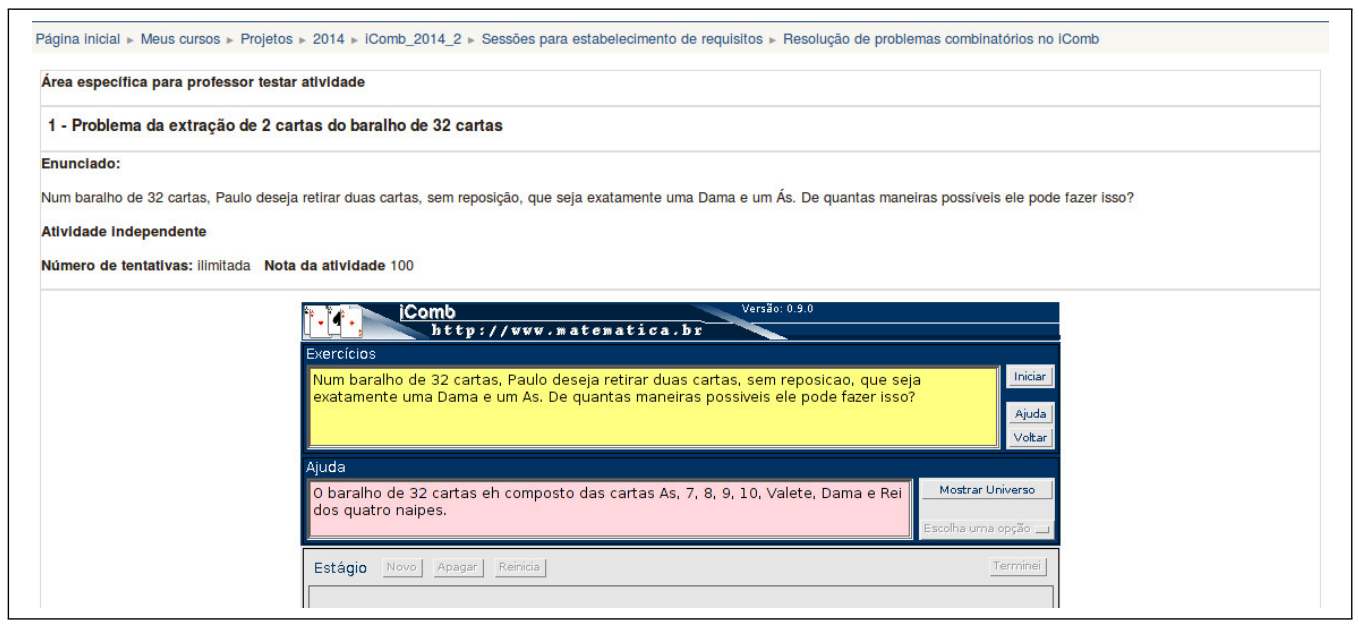

Figura 4.1: Exercício no iComb integrado no Moodle.

- Questionário eletrônico (30 minutos). Após concluir a resolução dos exercícios no iComb os participantes responderam um questionário.

- Pós-teste (30 minutos finais). O pós-teste teve o objetivo de detectar se a metodologia para resolução de exercícios implementada no iComb influenciou na estratégia dos participantes após o contato com o programa. Ele foi composto por um exercício de combinatória de igual dificuldade dos exercícios aplicados no pré-teste, e uma questão sobre a contribuição do programa na resolução do mesmo.

\footnotetext{
${ }^{1}$ https: //moodle.org/

${ }^{2}$ https: //moodle.org/plugins /view.php?plugin $=$ mod_iassign
} 
Os documentos referentes as tarefas descritas acima encontram-se no Apêndice B para eventuais consultas.

Cada tarefa tinha um período de tempo máximo pré determinado para sua execução. Se acaso, o participante terminasse a tarefa antes do tempo previsto passaria para a próxima, caso contrário, só iria para a próxima tarefa após esgotado o tempo.

O apoio computacional durante as sessões foi restrito à indicar ao usuário que deveria buscar informações no próprio sistema. Os laboratórios foram devidamente preparados para a execução do teste de usabilidade. Foi necessário instalar nos computadores:

- Navegador Web. Tanto o questionário eletrônico, quanto as atividades interativas foram colocados no Moodle de modo que os participantes não precisaram instalar o iComb ou se preocupar em gravar o arquivo do exercício, bastando clicar em um botão para que a resposta do exercício fosse enviada ao servidor.

- Programa (software) que cria vídeos capturando a tela do computador. No laboratório utilizado no CEC no IME-USP é disponível uma rede local sob sistema operacional GNU/Linux (distribuição Debian). Assim, foi instalado o programa RecordMyDesktop ${ }^{3}$. Já no laboratório do IFSP Cubatão, que utiliza sistema operacional Windows, foi instalado o programa Camtasia Studio ${ }^{4}$.

Antes de iniciar as sessões de teste foi explicado a todos os usuários que os resultados do teste não seriam colocados publicamente e o anonimato de cada participante estaria garantido, principalmente no uso das gravações de vídeo e audio que foram feitas.

Na Subseção 4.1.2 serão apresentados e discutidos os resultados das tarefas aplicadas nessas sessões.

\subsubsection{Análise dos resultados do teste do $i C o m b$}

A combinação das técnicas empregadas durante as sessões de teste do sistema, observação direta dos participantes e gravação em vídeo da tela do computador, possibilitaram a coleta de informações valiosas sobre a usabilidade do $i C o m b$. Adicionalmente, as respostas dos participantes às questões do questionário eletrônico, de certa forma, confirmaram tais informações, as quais são apresentadas nesta seção.

Com o intuito de descrever e interpretar adequadamente as questões dissertativas apresentadas no questionário e nos conteúdos dos documentos do projeto foi adotada a metodologia da análise de conteúdo sugerida por Bardin (1986).

Antes mesmo de se apresentar os resultados do teste sobre a usabilidade do $i C o m b$, um aspecto interessante chamou a atenção sobre o assunto combinatória. Na questão "Em que nível de ensino você estudou Análise Combinatória?", proposta no questionário eletrônico, apenas um (1) professor e dois (2) alunos participantes afirmaram ter examinado o assunto em seu curso durante o Ensino Médio, conforme mostra a Figura 4.2. Diante dessas afirmações, pode ser que o conteúdo de Análise Combinatória esteja sendo relegado no currículo escolar.

\footnotetext{
${ }^{3}$ RecordMyDesktop é um software livre que possibilita registrar em vídeo o que ocorre em determinada região da tela do computador, disponível para sistemas GNU/Linux.

${ }^{4}$ O Camtasia Studio é um software de criação de vídeo, desenvolvido pela TechSmith que permite fazer vídeo a partir da captura da tela do computador.
} 


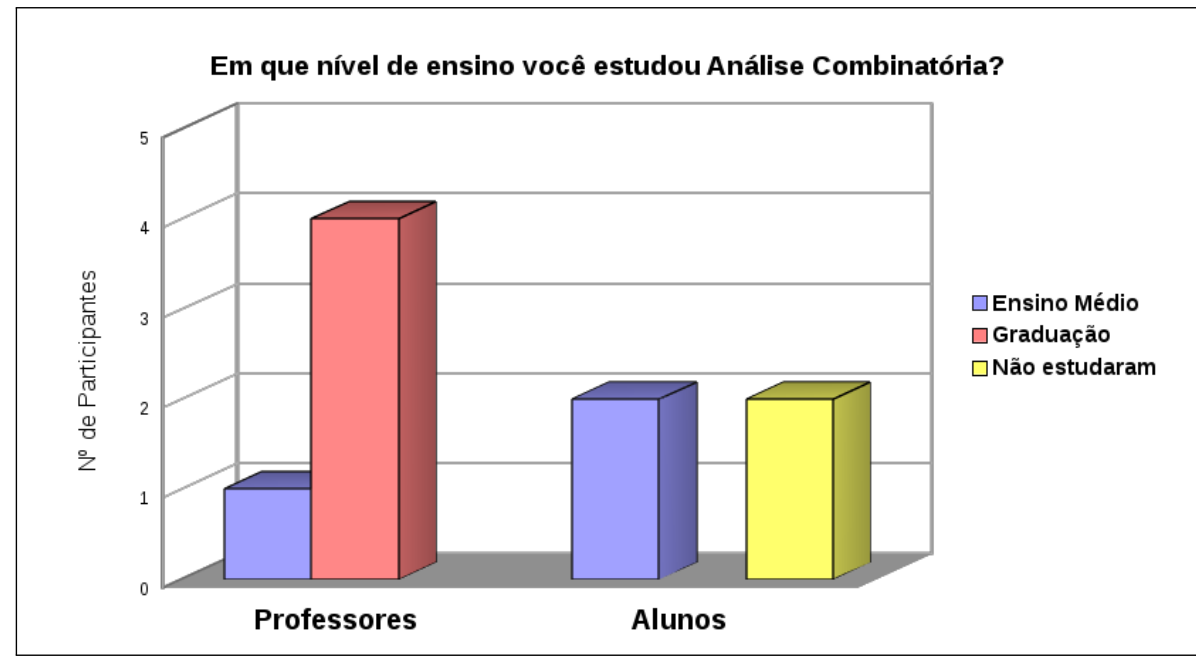

Figura 4.2: Gráfico da questão nível de ensino que estudou Análise Combinatória

$\mathrm{Na}$ análise dos documentos do pré-teste foi verificado que três (3) professores e dois (2) alunos adotaram a estratégia de divisão e conquista para resolver os exercícios. Vale notar que, mesmo os participantes nunca terem tido contato com o iComb (ou com o Combien?), a estratégia por eles empregada é semelhante aquela presente em ambos os sistemas.

A Figura 4.3 mostra a resposta de um participante para a primeira questão proposta no pré-teste.

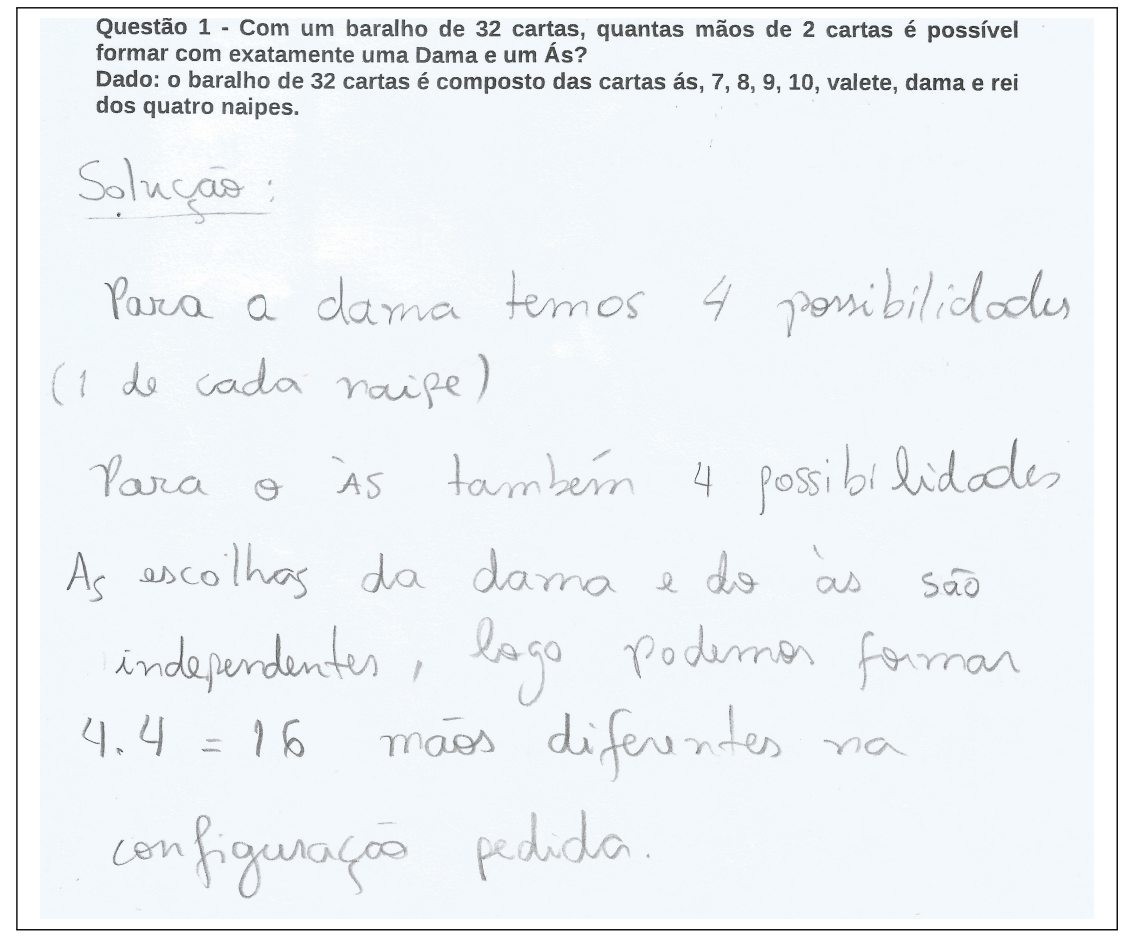

Figura 4.3: Resposta de um dos participantes para a questão 1 do pré-teste.

Nos documentos do pós-teste, a maioria dos usuários comentou como válida a estratégia de resolução presente no sistema, mas lamentou quanto a sua limitação em resolver somente uma classe de exercícios combinatórios.

Na tabela 4.1 estão listados os "pontos fortes do iComb" e a quantidade de participantes que comentaram sobre o assunto. O método implementado para a resolução de problemas teve destaque nos registros dos comentários. 
Tabela 4.1: Resumo dos comentários sobre os pontos fortes do iComb.

\begin{tabular}{|l|c|}
\hline Pontos fortes do $\boldsymbol{i}$ Comb & número de ocorrências \\
\hline \hline Método de resolução de problemas & 9 \\
\hline Avaliação automática & 1 \\
\hline Imagens dos elementos do conjunto universo & 1 \\
\hline
\end{tabular}

Diante de todas essas evidências pode-se confirmar a eficácia do iComb. A eficácia é um critério de usabilidade que se refere a quanto um sistema é bom em fazer o que se espera dele (Preece et al., 2005). Logo, o iComb é eficaz, mesmo sendo somente para uma classe específica de problemas combinatórios.

Por outro lado, quanto a facilidade de uso do sistema, tem-se que a maioria dos usuários relataram que utilizar o sistema foi "Difícil" ou "Muito difícil". As respostas quantitativas estão apresentadas na Figura 4.4 e as justificativas das dificuldades enfrentadas pelos usuários estão listadas na Tabela 4.2.

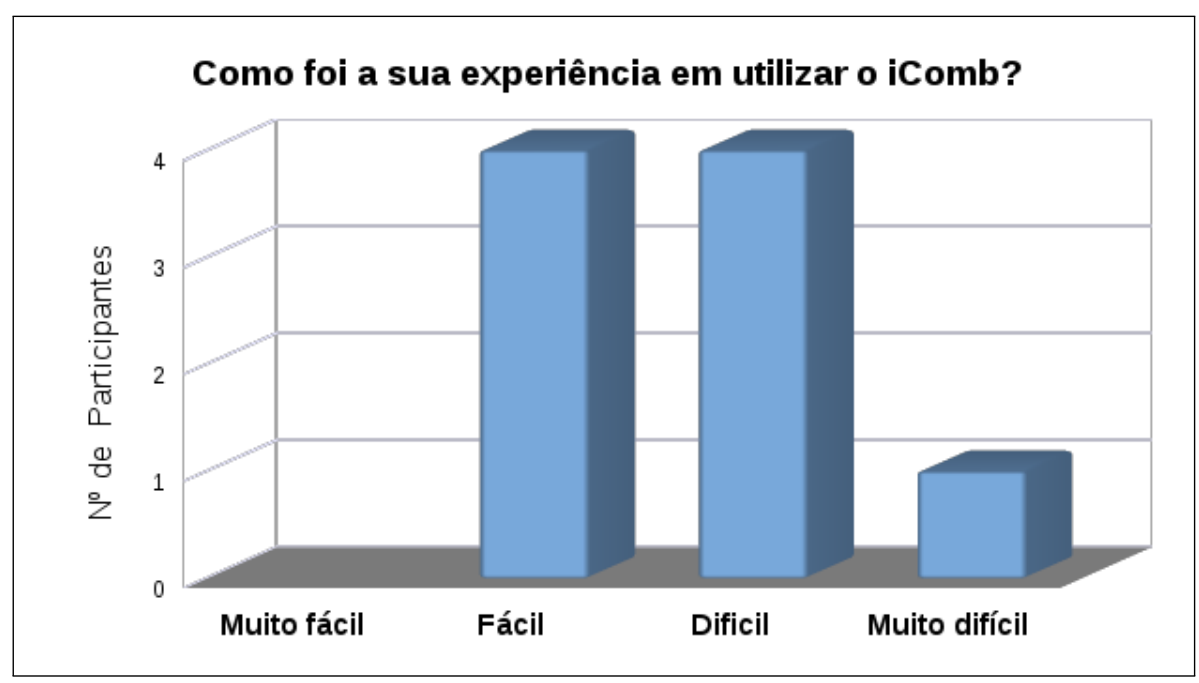

Figura 4.4: Gráfico quantitativo da questão sobre a utilização do iComb.

Tabela 4.2: Tabela das dificuldades enfrentadas pelos usuários durante a utilização do iComb.

\begin{tabular}{|l|c|}
\hline Dificuldades enfrentadas durante a utilização do $\mathbf{i C o m b}$ & Número de ocorrências \\
\hline \hline Entender como iniciar o processo para resolver o exercício & 5 \\
\hline Compreender os termos empregados no sistema & 2 \\
\hline Divisão necessária para resolução do exercício & 1 \\
\hline Lentidão do sistema & 1 \\
\hline
\end{tabular}

Também foi constatado, nas anotações do observador, que cinco (5) dentre os nove (9) participantes apresentaram dificuldades durante as fases do processo de resolução de exercício no $i C o m b$.

Observou-se nos vídeos, que a média de tempo que os participantes demoraram para resolver os exercícios no sistema foi de 7 minutos e 37 segundos. Sendo que, somente no início da resolução os usuários demoraram em média quase 5 minutos para terminar o primeiro estágio. A Figura 4.5 mostra o gráfico com as médias do tempo que cada grupo de usuários demorou em cada etapa durante a utilização do $i C o m b$. 


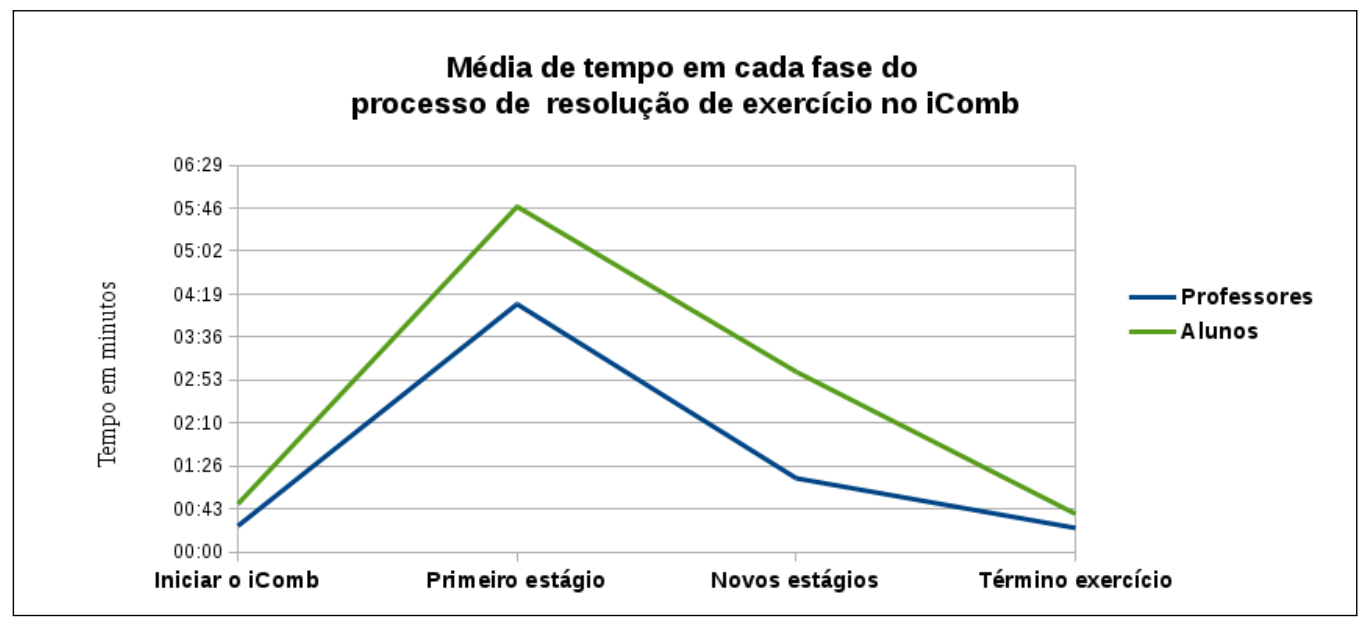

Figura 4.5: A média de tempo durante a utilização do iComb.

Outros dados trazem evidências de problemas quanto à facilidade de aprendizagem (learnability) para a utilização do $i C o m b$. Na Figura 4.6 apresenta-se sobre o entendimento do que fazer em cada fase do processo de resolução do exercício. Na fase inicial (primeiro estágio), seis (6) participantes disseram que foi "dificilmente" ou "muito dificilmente" entender que ação fazer. Já na fase seguinte (adicionar estágio) o número de participantes diminuiu um pouco, apenas quatro (4), vindo este a aumentar durante a fase de finalização da resolução.

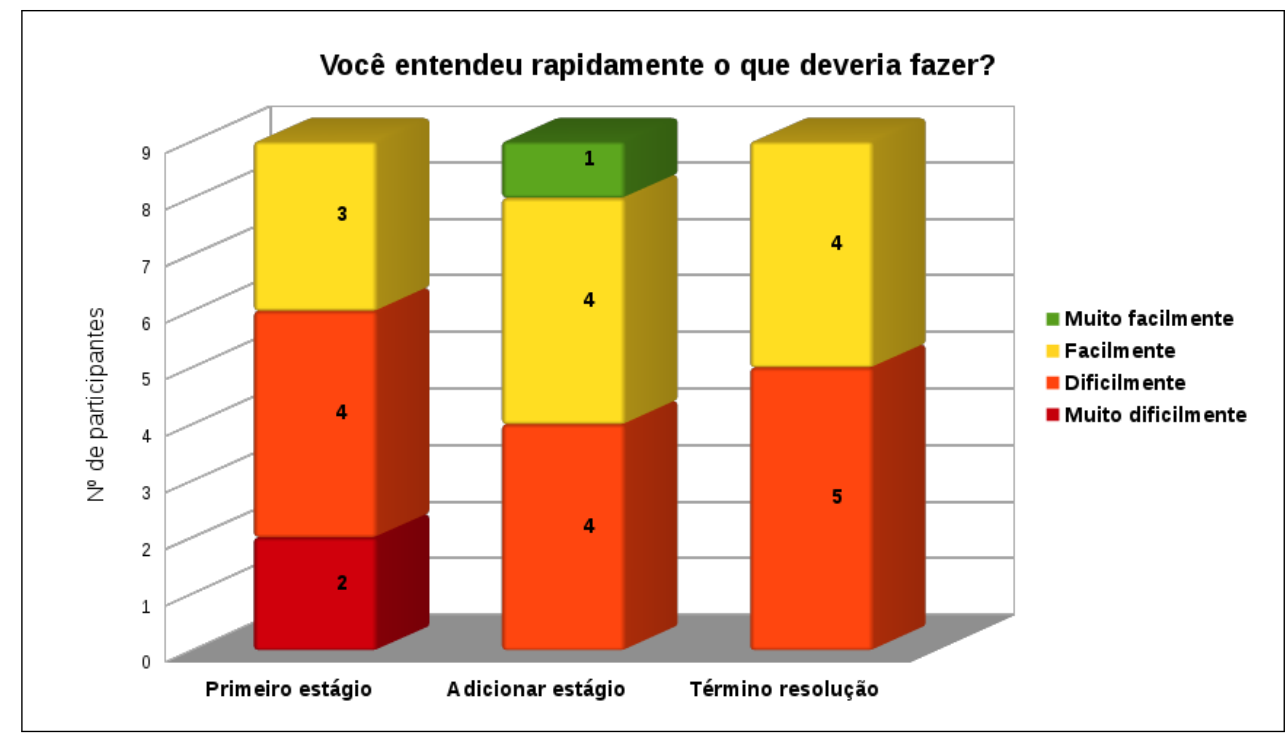

Figura 4.6: Gráfico sobre o entendimento dos participantes em cada fase do processo de resolução.

Alguns usuários associaram os problemas de usabilidade durante o processo de resolução ao modo de encadeamento de ações do sistema e à estruturação dos elementos gráficos da interface (botões) que não lhes pareceram simples, principalmente na fase final. Na Tabela 4.3 encontra-se a síntese dos comentários dos usuários quanto aos pontos fracos do sistema.

Sobre o visual da interface do sistema, uma crítica foi quanto à adequação do posicionamento e ao tamanho das fontes nos rótulos dos botões. Os resultados estão sintetizados na Tabela 4.4.

Já a avaliação do recurso "ajuda" do iComb foi de regular a ruim, conforme mostra a Figura 4.7. Os usuários declararam que faltou feedback do sistema quando executada alguma ação errônea durante a resolução do exercício e que faltou uma documentação (tutorial) para iniciantes. Nos 
Tabela 4.3: Resumo dos comentários sobre os pontos fracos do iComb.

\begin{tabular}{|l|c|}
\hline Pontos fracos do $\boldsymbol{i}$ Comb & Número de ocorrências \\
\hline \hline Resolver uma única classe de exercícios de combinatória & 3 \\
\hline Interface não intuitiva & 2 \\
\hline Lentidão do sistema & 2 \\
\hline Tutorial sobre o sistema & 1 \\
\hline Termos usados são incompreensíveis & 1 \\
\hline Posicionamento dos botões dos recursos & 1 \\
\hline
\end{tabular}

Tabela 4.4: Tabela sobre a adequação dos elementos gráficos da interface do iComb.

\begin{tabular}{|l|c|}
\hline Posicionamento dos botões na interface & Número de ocorrências \\
\hline \hline Adequado & 3 \\
\hline Inadequado & 4 \\
\hline Nenhum comentário & 2 \\
\hline \hline Títulos dos botões & Número de ocorrências \\
\hline \hline Adequados & 4 \\
\hline Inadequados: Fontes pequenas & 2 \\
Inadequados: Termos incompreensíveis & 1 \\
\hline
\end{tabular}

registros do observador tem-se que cinco (5) usuários utilizaram a ajuda tradicional do $i C o m b$. Críticas quanto aos recursos de ajuda do sistema iComb já haviam sido feitas pelos usuários no experimento em 2009, conforme Eisenmann (2009).

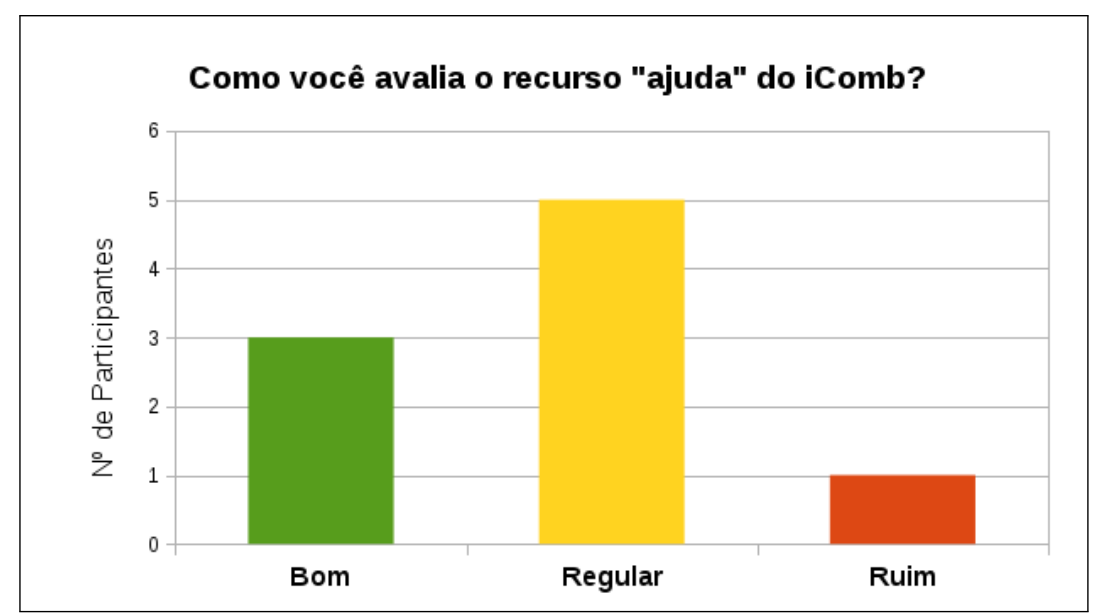

Figura 4.7: Gráfico sobre o recurso ajuda do iComb.

A seguir são analisadas as sugestões livres anotadas num campo ao final do questionário. Devese destacar a necessidade de criação de um mecanismo para manipulação interativa para construir supostos subconjuntos, sendo isso confirmado pelos vários registros de observação em que os usuários tentaram manipular as imagens do conjunto universo que é apresentado pelo iComb.

Quando é pedido uma propriedade que está ou não está em certo conjunto poderia aparecer o conjunto que foi selecionado pelo aluno. Ao apertar "mostrar universo" é muito legal saber tudo que está lá dentro. Poderia ter uma opção de contar todos os elementos, ou contar os elementos de um subconjunto, por exemplo seleciona um grupo e ele te 
mostra quantos elementos tem nesse grupo que você selecionou. Ajudaria bastante.

Acho que na exposição do conjunto universo, o aluno deveria poder contar os objetos com mais dinâmica. Não contá-los na tela. O programa é muito bom e tem muitos pontos favoráveis para o aprendizado de análise combinatória.

Uma evidência marcante na análise dos vídeos foi a dificuldade que os usuários tiveram para executar o sistema no navegador Web. O fato também foi registrado nas anotações do observador. As mensagens de advertência quanto a segurança lançadas pela máquina virtual $\mathrm{Java}^{5}$ e a demora em carregar o applet, cujo tempo médio de carga foi de 37 segundos, produziram um "tempo morto"6 para o usuário. Logo, isso vem a indicar que a opção pela tecnologia Java para Web deve ser revista.

Considerando todas essas dificuldades apontadas pelos usuários, levanta-se este conjunto de especificações do $i C o m b$ que apresentaram problemas:

- Tutorial ou ajuda - O recurso de ajuda tradicional do sistema não está muito claro e não ajudou o usuário nos momentos que foi requisitado.

- Deteç̧ão de erros - O feedback do sistema diante de ações errôneas do usuário, em muitos momentos não o ajudaram a corrigir seu erro.

- Interface para o usuário - O encadeamento entre os elementos gráficos (como botões, quadros e menus) da interface do $i C o m b$ necessita de uma reestruturação a fim de obter uma interface intuitiva e esteticamente agradável.

- Tecnologia Java $\boldsymbol{W e b}$ - As mensagens de advertência pelo fato de o projeto $i C o m b$ não ter pago à empresa que licencia a tecnologia Java por um certificado de seguranca e mais ainda, a atual política de carregamento no navegador que a cada carga de página recarrega novamente o pacote do iComb (anteriormente isso era feito uma única vez durante uma sessão de uso de applet), gerou um "tempo morto" desagradável para atividades didáticas.

Adicionalmente, foi identificada a necessidade de revisar a implementação do recurso "mostrar universo". Pois além de apresentar as imagens dos elementos do conjunto universo em questão, os usuários queriam poder manipulá-las, de modo, a facilitar o raciocínio durante a resolução do exercício, assim justificado por alguns.

\subsection{Reprojeto e Prototipagem Participativa do $i C o m b$}

A participação dos usuários no processo de design de interação vai além da simples avaliação das ferramentas, eles ajudam em todas as fases do ciclo de projeto, possibilitando aos projetistas detectar suas perspectivas e necessidades.

$\mathrm{Na}$ etapa para o reprojeto do $i C o m b$, foram convidados todos os participantes das sessões de teste de usabilidade. Nem todos os usuários aceitaram o convite, mas conseguiu-se formar uma equipe de sete (7) pessoas, seis (6) usuários mais a autora, responsável pelo projeto.

\footnotetext{
${ }^{5}$ Java Virtual Machine (JVM).

${ }^{6}$ Tempo morto é quando o usuário não está interagindo com o sistema (ou esperando resposta ou pensando).
} 
Como preconizado pelo modelo de reprojeto, deve-se envolver ativamente todos os usuários inclusive nas tomadas de decisões do processo, de modo que eles sintam-se como parte integrante do projeto.

As atividades do processo de reprojeto do $i C o m b$ foram desenvolvidas durante quatro (4) encontros da equipe, todos eles realizados em uma sala de estudos do IFSP Cubatão. Todos os encontros tiveram seu protocolo verbal gravados a fim de documentar cada atividade do processo e possibilitar sua posterior análise.

A Subseção 4.2.1 apresenta detalhes sobre o desenvolvimento de design da interface. Na Subseção 4.2.2 são apresentadas a construção e avaliação dos protótipos de baixa fidelidade. E finalizando a Subseção 4.2.3 descreve e apresenta as imagens dos novos conjuntos universo para o iCombH5.

\subsubsection{Designs da interface do $i C o m b$}

Visando uma maior participação dos usuários no desenvolvimento do design da interface de um novo iComb, optou-se por usar a técnica de roteiro visual (storyboarding). Mais especificamente, usou-se a técnica Cooperative Interative Storyboard Prototyping (CISP) que consiste em gerar e modificar cooperativamente desenhos de interfaces, além de avaliar as interfaces existentes e as comparar com algumas alternativas (Rocha e Baranauskas, 2003).

A revisão do projeto de interface do $i$ Comb foi realizada em duas (2) etapas. Na primeira avaliou-se a sequência de interfaces para resolver um exercício, depois buscou-se propor uma nova organização para as interfaces.

Assim, inicialmente criou-se um roteiro visual ou storyboard do processo de resolução de exercício para uma versão em papel a partir de imagens do $i C o m b$. Esse roteiro foi produzido a partir de recortes sobre imagens de telas do $i C o m b$, durante uma sessão de resolução de exercício.

Inicialmente foi feita uma análise cada tela da interface do $i C o m b$, anotando-se os problemas apontados no teste de usabilidade.

Ao final da discussão, foram produzidas as seguintes sugestões:

1. Reestruturação da interface do usuário - Reposicionamento dos elementos gráficos da interface (botões, quadros e menus), visando produzir uma interface mais agradável e simples.

2. Ajuda ou tutorial - O recurso de ajuda tradicional deveria ser reescrito numa tentativa de deixá-lo mais didático possível.

3. Tecnologia de implementação do sistema $i C o m b$ - O sistema deveria ser implementado utilizandose tecnologias associadas ao HTML5. Isso permitiria que o $i C o m b H 5$ funcionar em um número maior de ambientes $W e b$, além de eliminar as atuais restrições de segurança de applet Java.

4. Alteração da disposição das imagens dos elementos do conjunto universo no sistema e a implementação de um recurso que permita manipular essas imagens - A disposição das imagens deve estar diretamente na interface do usuário. O objetivo dessa alteração e do recurso seria melhorar as possibilidades de interação do usuário com o sistema e assim, auxiliá-lo no processo de aprendizagem.

5. Inserção de novos conjuntos universo - Proporcionando assim, uma gama maior de conjuntos universo para facilitar a criação de exercícios. As sugestões de novos conjuntos universo são: bolas coloridas, dados, automóveis, algarismos e meios de transporte. 
$\mathrm{Na}$ segunda etapa buscou-se propor novos desenhos para as interfaces para o iComb. A questão proposta os participantes foi:

"O que poderia ser mantido ou retirado da interface do iComb para deixá-la intuitiva?"

Foi discutido com a equipe os princípios de usabilidade, por exemplo, que ter poucas opções na interface, apenas aquelas necessárias à tarefa, geralmente significa uma melhor usabilidade do sistema, pois o usuário pode se concentrar em entender essas poucas opções.

A partir do roteiro visual apresentado na primeira etapa, a equipe analisou cada elemento gráfico da interface do sistema, estando ciente que cada elemento acarreta uma sobrecarga ao usuário, devendo assim considerar se o usa ou não.

Como resultado dessa atividade obteve-se o desenho de uma interface melhorada e o registro da interação dos usuários.

Os registros das discussões e decisões destas etapas de reprojeto do iComb encontram-se no Apêndice C.

\subsubsection{Prototipagem para o $i \mathrm{CombH} 5$}

A construção de protótipos de baixa fidelidade (em papel) é uma técnica bastante utilizada em projetos de interfaces para os usuários devido à sua simplicidade, ao seu baixo custo e por ser bastante efetiva. Segundo Wixon e Ramey (1996) prototipagem participativa é a atividade de construção de protótipos de baixa fidelidade envolvendo os usuários do sistema.

Assim, utilizando esta técnica, munidos do roteiro visual com a sugestão de interface para o iCombH5, a equipe construiu cooperativamente um protótipo alternativo em papel.

A partir desse protótipo em papel realizou-se mais um encontro da equipe, com duração total de 2 horas.

Nesta nova fase utilizou um sistema para prototipagem, o sistema livre Evolus Pencil ${ }^{7}$, que permite a geração de interfaces interativas.

A interface gerada reproduziu o protótipo em papel e deste modo, passou a existir uma boa representação para iCombH5. Na Figura 4.8 estão as imagens dos protótipos, em papel e digital.

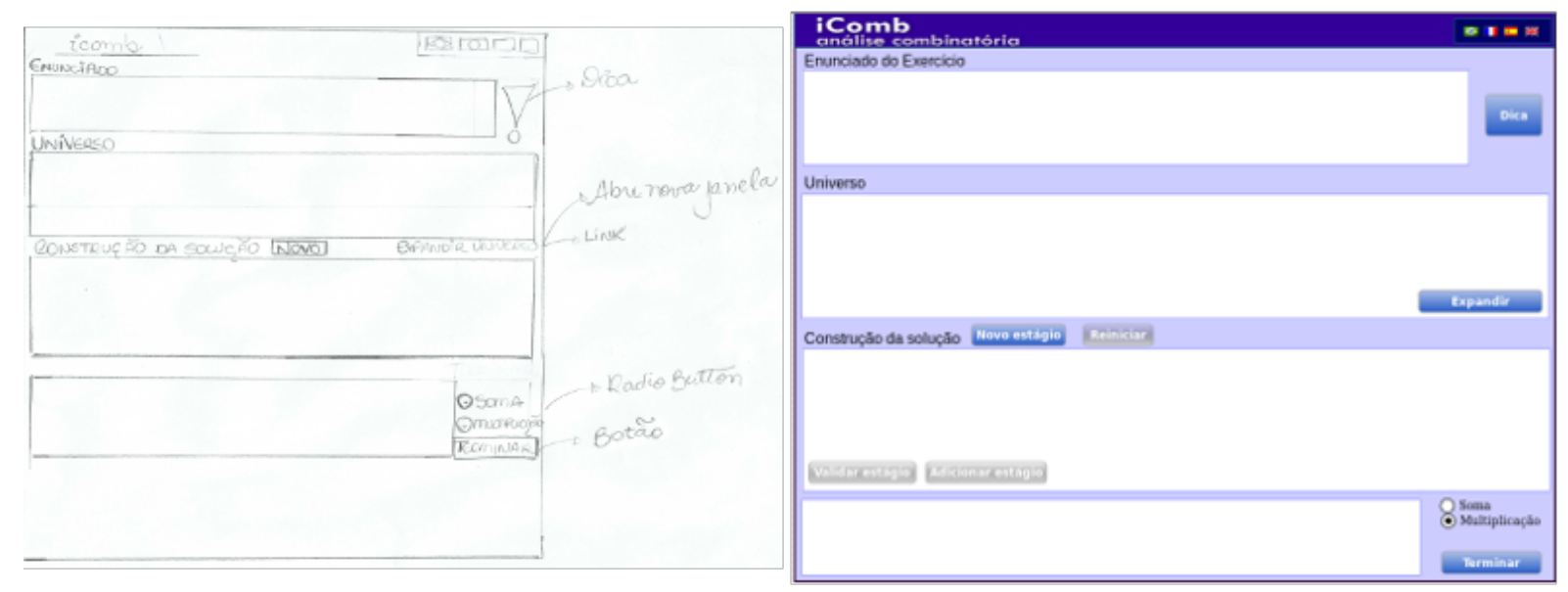

Figura 4.8: Imagens do primeiro protótipo do iCombH5.

7 O Evolus Pencil é uma ferramenta de prototipagem de interfaces de código aberto. Disponível em http://pencil.evolus.vn. Foi utilizada sua versão 2.0.5. 
Com o protótipo digital foram realizadas avaliações, sendo efetuadas alterações para se obter uma interface esteticamente agradável. As telas do protótipo final do $i$ CombH5, bem como todo o processo de resolução de exercício no novo sistema estão apresentados na Figura 4.9.

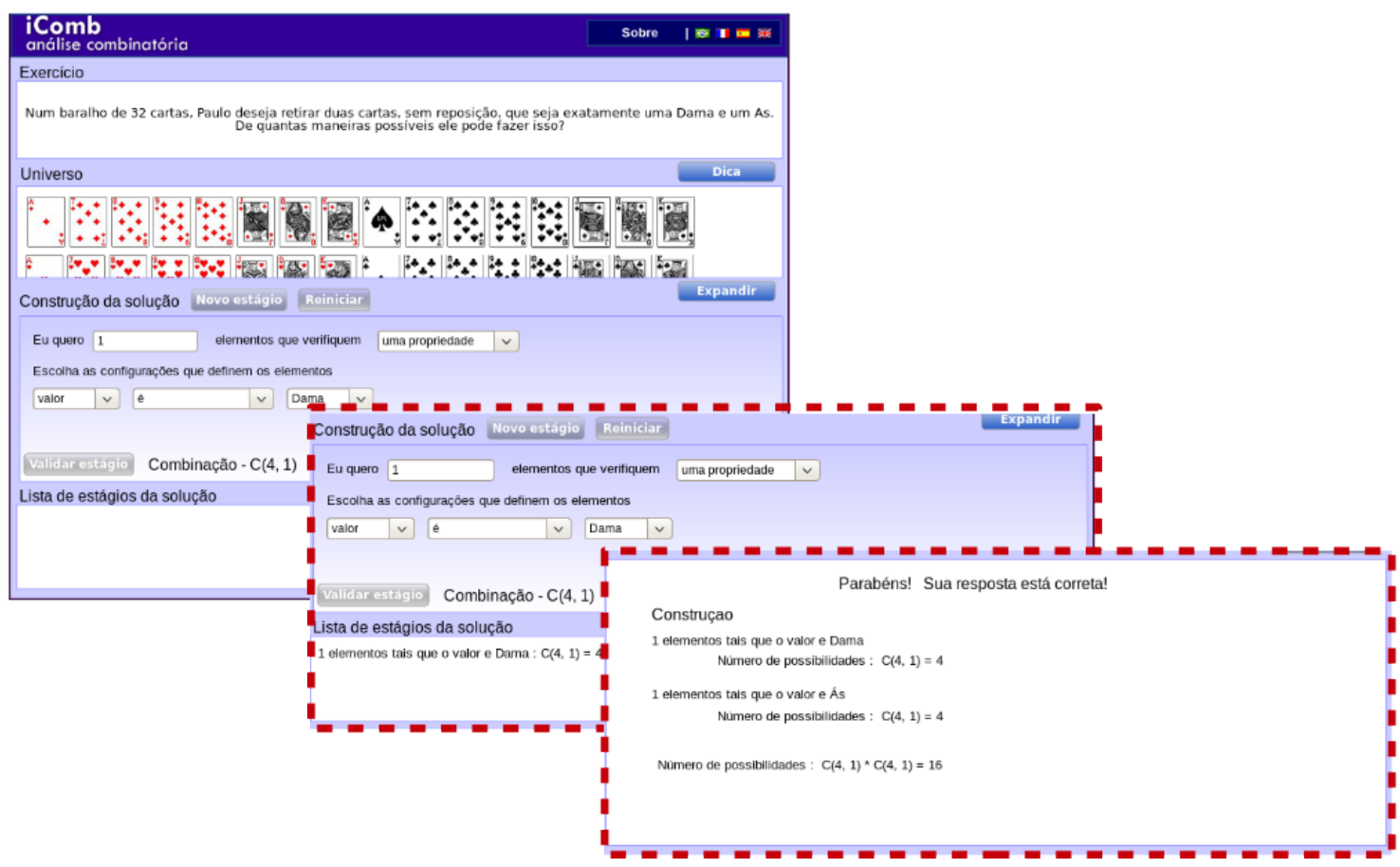

Figura 4.9: Interface do protótipo do iCombH5 durante o processo de resolução de exercício.

\subsubsection{Novos Conjuntos Universo}

Por simplicidade, nesta Subseção utilizaremos o termo universo para designar "conjunto universo".

A motivação principal do projeto $i C o m b$, em 2009, foi possibilitar integrar o modelo de resolução de exercícios introduzido pelo Combien? a sistemas gerenciadores de cursos Web. Para isso foram estabelecidos alguns requisitos apresentados na Seção 2.3, sendo o primeiro deles possibilitar que autoria de novos exercícios de maneira direta a partir da versão iComb na Web. Um segundo requisito, considerado importante, foi possibilitar a elaboração de novos "conjuntos universo". Deste modo, desde o iComb de 2009 era possível incorporar novos universos ao sistema, sem precisar alterar o código do iComb, a partir de uma arquitetura extensível (plugins) (Eisenmann, 2009).

A adição de novos universos era realizada pela incorporação de um novo diretório com as imagens do novo universo e um arquivo de descrição em XML. Desse modo, novos universos poderiam ser construídos para serem adicionados ao sistema. Na versão iComb de 2009 existiam dois universos, baralho de cartas e futebol.

Numa tentativa de contornar essa deficiência é que foi pensado e discutido, junto aos usuários da equipe, a construção e inserção de novos universos para o iCombH5.

Como no sistema cada exercício refere-se a determinado universo foram diversas as sugestões para novos universos e por isso, optou-se por implementar aqueles mais frequentes em textos didáticos de combinatória, como bolas coloridas, dados, automóveis, algarismos e meios de transporte.

Adicionalmente foi decidido gerar subconjuntos desses universos, do mesmo modo que o iComb já o fazia com o baralho de 52 cartas (usual, completo) e o baralho de 32 cartas. Pois sem isso 
não seria possível construir exercícios com estas restrições sobre o universo "completo". A lista dos universos selecionados está indicada na tabela 4.5.

Tabela 4.5: Tabela dos universos do iCombH5.

\begin{tabular}{|c|c|c|}
\hline Universos & $\mathrm{n}^{\circ}$ de elemetos & Descrição das imagens \\
\hline Algarismos & nove (9) & algarismos de 0 a 9 \\
\hline Automóveis & oito (8) & $\begin{array}{l}\text { com duas (2) portas: amarelo, azul, vermelho e verde } \\
\text { com quatro (4) portas: amarelo, azul, vermelho e verde }\end{array}$ \\
\hline Baralho com 52 cartas & cinquenta e dois (52) & 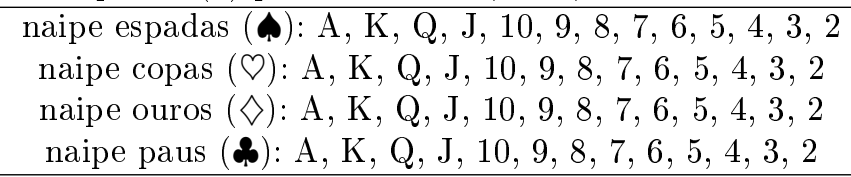 \\
\hline Baralho com 40 cartas & quarenta (40) & $\begin{array}{c}\text { naipe espadas }(\mathbf{(}): \mathrm{A}, \mathrm{K}, \mathrm{Q}, \mathrm{J}, 7,6,5,4,3,2 \\
\text { naipe copas }(\odot): \mathrm{A}, \mathrm{K}, \mathrm{Q}, \mathrm{J}, 7,6,5,4,3,2 \\
\text { naipe ouros }(\diamond): \mathrm{A}, \mathrm{K}, \mathrm{Q}, \mathrm{J}, 7,6,5,4,3,2 \\
\text { naipe paus (\$): A, K, Q, J, 7, 6, } 5,4,3,2\end{array}$ \\
\hline Baralho com 32 cartas & trinta e dois (32) & $\begin{array}{c}\text { naipe espadas }(\mathbf{Q}): \mathrm{A}, \mathrm{K}, \mathrm{Q}, \mathrm{J}, 10,9,8,7 \\
\text { naipe copas }(\mathrm{Q}): \mathrm{A}, \mathrm{K}, \mathrm{Q}, \mathrm{J}, 10,9,8,7 \\
\text { naipe ouros }(\diamond): \mathrm{A}, \mathrm{K}, \mathrm{Q}, \mathrm{J}, 10,9,8,7 \\
\text { naipe paus }(\mathbf{(}): \mathrm{A}, \mathrm{K}, \mathrm{Q}, \mathrm{J}, 10,9,8,7\end{array}$ \\
\hline Bolas coloridas & vinte $(20)$ & $\begin{array}{c}\text { bolas vermelhas numeradas de } 0 \text { a } 9 \\
\text { bolas azuis numeradas de } 0 \text { a } 9\end{array}$ \\
\hline Bolas vermelhas & $\operatorname{dez}(10)$ & numeradas de 0 a 9 \\
\hline Bolas azuis & $\operatorname{dez}(10)$ & numeradas de 0 a 9 \\
\hline Dados & doze $(12)$ & $\begin{array}{l}\text { faces de um dado amarelo numeradas de } 1 \text { a } 6 \\
\text { face de um dado cinza numeradas de } 1 \text { a } 6\end{array}$ \\
\hline Dado amarelo & seis $(6)$ & faces numeradas de 1 a 6 \\
\hline Dado cinza & seis $(6)$ & faces numeradas de 1 a 6 \\
\hline Futebol & quarenta e quatro (44) & $\begin{array}{l}\text { time amarelo com as camisas numeradas de } 1 \text { a } 11 \\
\text { time azul com as camisas numeradas de } 1 \text { a } 11 \\
\text { time verde com as camisas numeradas de } 1 \text { a } 11 \\
\text { time vermelho com as camisas numeradas de } 1 \text { a } 11\end{array}$ \\
\hline Meios de transporte & $\operatorname{dez}(10)$ & $\begin{array}{l}\text { avião, helicóptero, caminhão, carro, ônibus, } \\
\text { trem, navio, barco, bicicleta e moto }\end{array}$ \\
\hline Time amarelo & onze (11) & camisas numeradas de 1 a 11 \\
\hline Time azul & onze (11) & camisas numeradas de 1 a 11 \\
\hline Time verde & onze (11) & camisas numeradas de 1 a 11 \\
\hline Time vermelho & onze (11) & camisas numeradas de 1 a 11 \\
\hline Transportes aéreos & dois $(4)$ & avião e helicóptero \\
\hline Transportes terrestres & seis $(6)$ & caminhão, carro, ônibus, trem, bicicleta e moto \\
\hline Transportes aquáticos & dois $(4)$ & navio e barco \\
\hline
\end{tabular}

Na Figura 4.10 estão ilustradas as imagens de todos os elementos desses novos universos. 


\section{Algarismos \\ 0123456789}
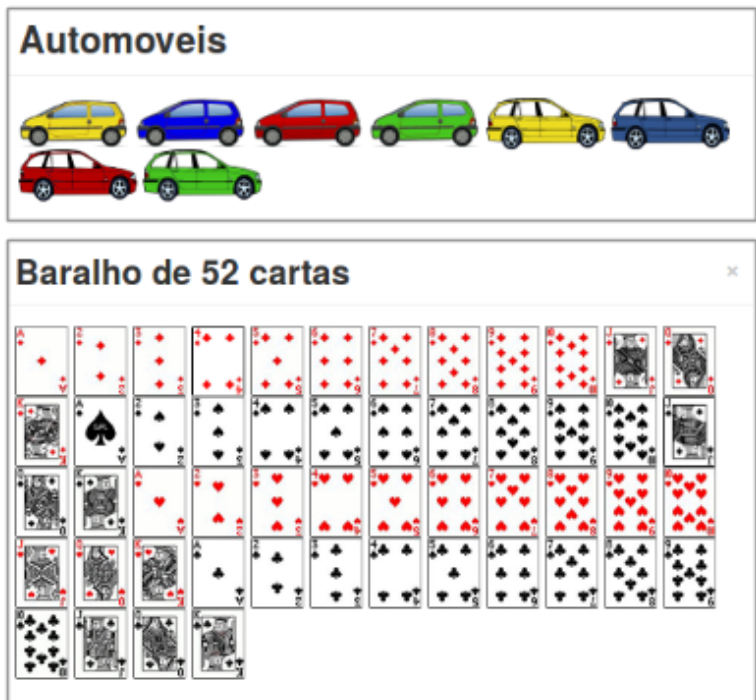

Meios de transporte

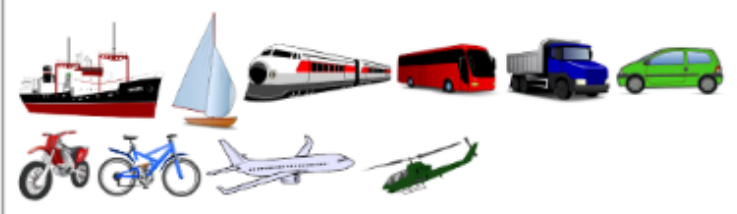

Bolas coloridas

$0{ }^{2}(3)(5) 68$

9023456

89

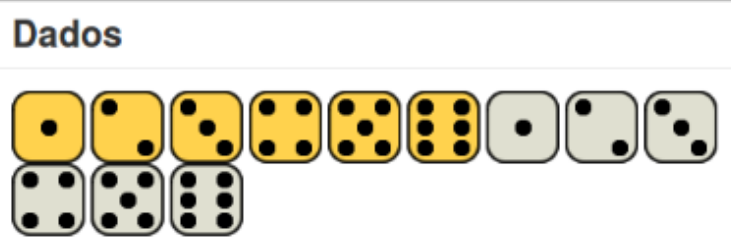

Futebol

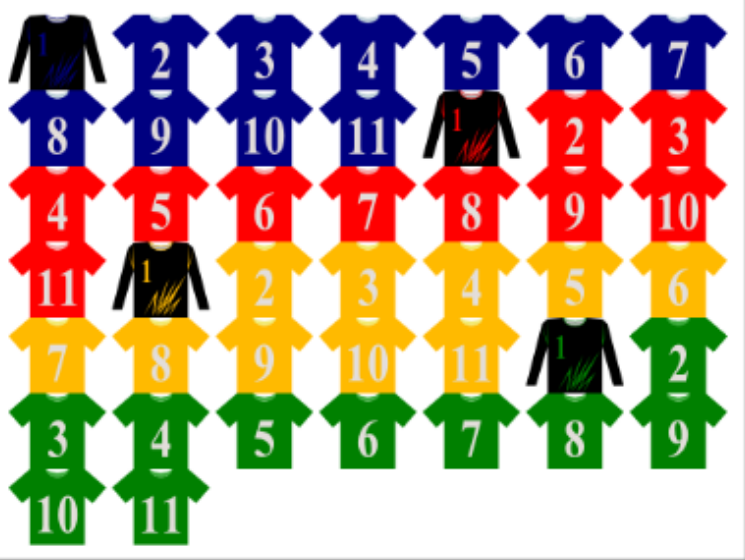

Figura 4.10: Imagens dos universos para o iCombH5.

\subsection{Avaliação do protótipo $i C o m b H 5$}

Avaliar durante o processo de desenvolvimento de um sistema computacional determina a usabilidade e aceitabilidade do mesmo. Os problemas que surgem durante a atividade de avaliação induzem a um novo ciclo de atividades do processo de projeto (Preece et al., 2005).

Gould e Lewis (1985) afirmam que sem a avaliação os designers não têm como certificar-se de que o sistema computacional é utilizável e que está de acordo com o que os usuários desejam. Pois a premissa básica é que as necessidades dos usuários sejam consideradas durante todo o processo de projeto e desenvolvimento, e corrigindo-o para que se adapte às necessidades dos usuários.

Neste contexto, o iCombH5 deveria ser avaliado antes do término do projeto de mestrado. Porém, não se tinha uma implementação total do $i \operatorname{CombH5}$, somente a implementação das funcionalidades para a resolução de exercícios, sem os recursos de ajuda tradicional e de manipulação das imagens do universo e também, sem o protocolo para integração ao SGC Moodle.

Então, buscou-se avaliar o protótipo iCombH5 no estado em que se encontrava. Para isso, organizou-se um teste preliminar ou piloto com o $i \mathrm{CombH5}$, com caráter experimental, limitando-se a testar e avaliar somente alguns aspectos do funcionamento e do visual da interface do protótipo.

Desta forma, realizou-se uma sessão de teste com a participação dos usuários da equipe de reprojeto, no laboratório de informática do IFSP Cubatão. Trata-se do mesmo laboratório que havia sido preparado anteriormente para a sessão de teste de usabilidade do $i C o m b$. 
Nesta sessão foram propostas duas (2) tarefas aos participantes:

(i) resolver um problema de combinatória utilizando o protótipo iCombH5. O problema proposto foi:

"Num baralho de 32 cartas, Paulo deseja retirar duas cartas, sem reposição, que seja exatamente uma Dama e um Ás. De quantas maneiras possíveis ele pode fazer isso?";

(ii) responder o questionário eletrônico.

A primeira tarefa teve como objetivo testar as funcionalidades disponíveis no iCombH5 durante o processo de resolução do exercício. Vale salientar, que este foi o primeiro contato dos usuários da equipe com o sistema que eles mesmos haviam redesenhado e discutido sobre suas especificações.

A segunda, teve o objetivo de coletar informações para avaliar o protótipo. Para isso, o questionário foi composto de questões, qualitativas e quantitativas, relativas as especificações discutidas nas atividades de reprojeto e que foram implementadas no iCombH5.

A seguir, na Subseção 4.3.1, são apresentados os resultados coletados no questionário nesta sessão de teste.

\subsubsection{Resultados do teste do protótipo $i \mathrm{CombH5}$}

O aspectos visuais da interface do iCombH5 foram avaliados como "Bom" ou "Muito bom", conforme apresenta-se na Tabela 4.6. Alguns destes aspectos visuais são relativos à reestruturação dos elementos gráficos da interface discutida no reprojeto, logo pode-se dizer que essa reestruturação foi muito bem avaliada.

Tabela 4.6: Valores relativos ao aspecto visual da interface do iCombH5.

\begin{tabular}{|l|c|c|c|c|}
\hline Aspectos visuais da interface do $\boldsymbol{i C o m b H 5}$ & \multicolumn{4}{|c|}{ Número de ocorrências } \\
& Muito ruim & Ruim & Bom & Muito bom \\
\hline \hline Cores & 0 & 0 & 1 & 5 \\
\hline Posicionamento dos botões & 0 & 0 & 2 & 4 \\
\hline Posicionamento dos menus & 0 & 0 & 3 & 3 \\
\hline Posicionamento dos quadros & 0 & 0 & 2 & 4 \\
\hline Tamanho das fontes & 0 & 1 & 2 & 3 \\
\hline Termos empregados & 0 & 1 & 0 & 5 \\
\hline Títulos dos botões & 0 & 0 & 2 & 4 \\
\hline Títulos dos quadros & 0 & 0 & 2 & 4 \\
\hline
\end{tabular}

Sobre o encadeamento de ações do sistema no processo de resolução pode observar que houve uma melhora significativa, pois os resultados apresentados na questão sobre o entendimento do usuário quanto ao que fazer em cada fase do processo de resolução do exercício, foram bem diferentes daquelas apresentadas anteriormente no teste de usabilidade do iComb, conforme mostra a Figura 4.11. Esta avaliação é relativa ao critério de usabilidade facilidade de aprendizagem (learnability) do iCombH5.

Apesar de não estar implementado o recurso de ajuda tradicional os participantes que cometeram eventuais erros durante a resolução do exercício obtiveram ajuda por meio do feedback do tutor 


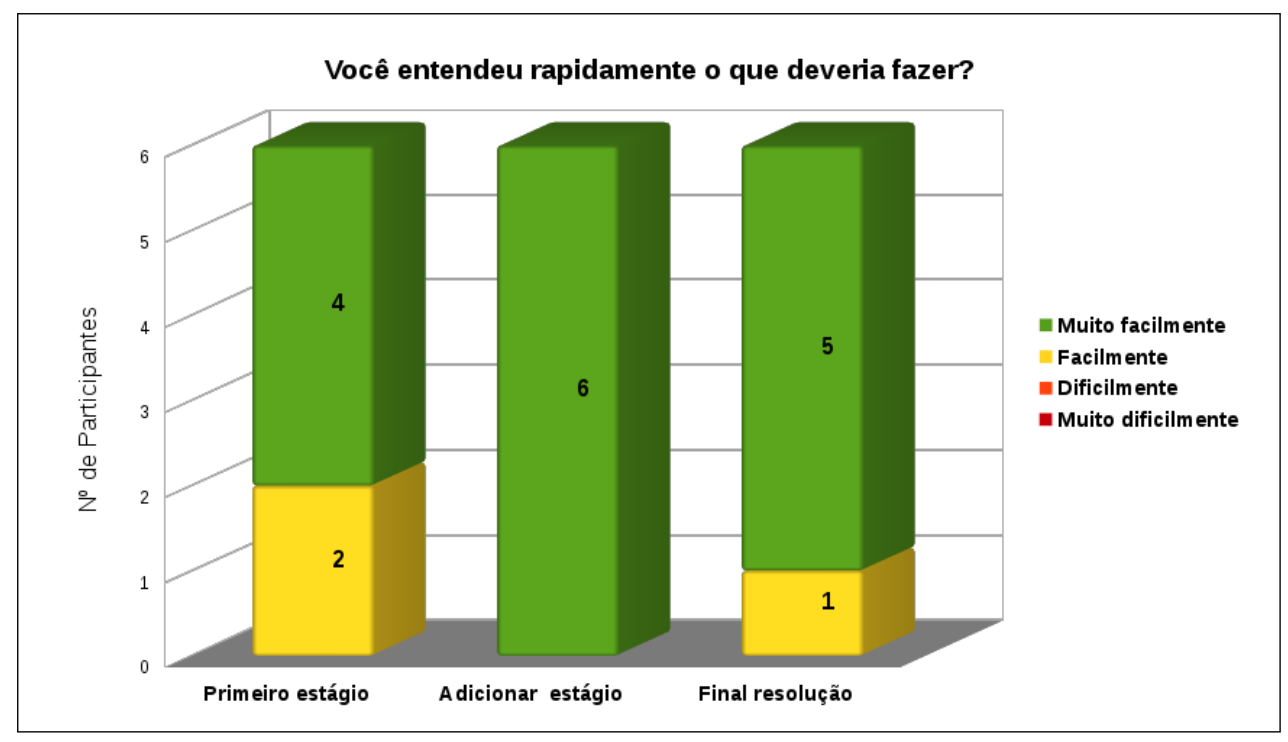

Figura 4.11: Gráfico sobre o entendimento dos participantes em cada fase do processo de resolução.

automático. Sendo assim, os quatro (4) participantes que cometeram erros durante a resolução afirmaram que o feedback do iCombH5 os ajudaram a corrigir seus erros, conforme apresenta-se a Figura 4.12.

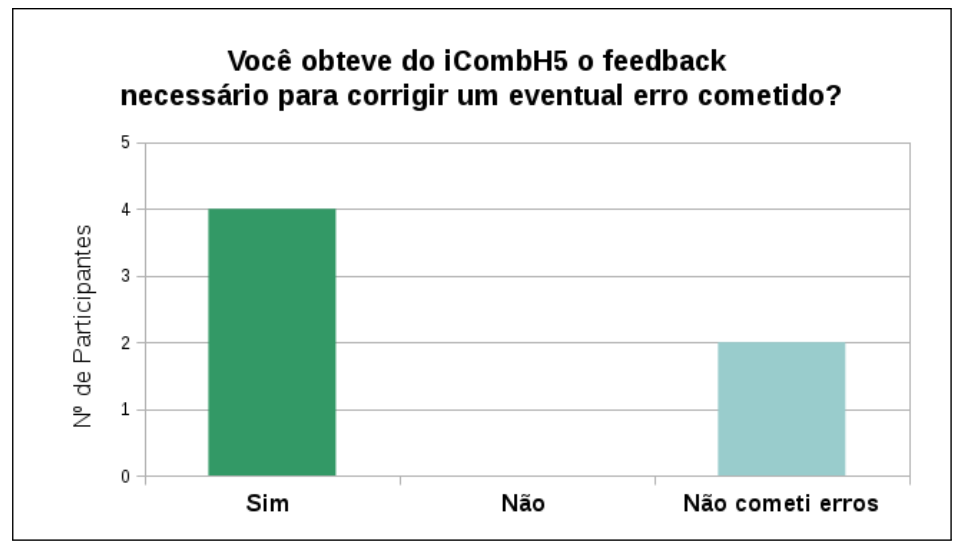

Figura 4.12: Gráfico sobre o feedback do iCombH5 para corrigir erros cometidos.

Todos os participantes afirmaram que só o fato de visualizar os elementos do universo diretamente na interface já auxilia bastante o raciocínio em cada estágio do exercício.

Os comentários destacados a seguir, não deixam dúvidas sobre a ótima avaliação que os participantes fizeram do $i \mathrm{CombH}$ :

"Em relação a interface antiga do sistema, houve melhoras significativas. A nova disposição dos botões e títulos já dão ao usuário com conhecimentos em analise combinatória uma noção do tem que ser feito."

"A nova interface ficou muito mais intuitiva e amigável, em relação a anterior. Dicas poderiam ser adicionadas no passo a passo da resolução ajudando, por exemplo, quem esqueceu como solucionar(uso das fórmulas), ou dicas mais elaboradas para "iniciantes". De um modo geral, o sistema é muito bem elaborado, de fácil uso, interface agradável e fácil entendimento." 
Apesar da limitação das funcionalidades, a avaliação dos participantes para o protótipo iCombH5 foi muito boa e outra constatação que deve ser considerada é que ele não apresentou falha em nenhum momento. No futuro, novos testes devem ser conduzidos para avaliar os recursos que ainda serão implementados, ajuda tradicional e manipulação das imagens do universo, e também, deverá ser averiguada a integração do $i$ CombH5 ao SGC Moodle, devido ao fato da implementação em nova tecnologia. 


\section{Capítulo 5}

\section{Conclusões}

As formas de agir e pensar da nova geração de alunos está fortemente influenciada pelas novas tecnologias. Segundo Barbosa et al. (2010); Weiss e Cruz (1999) os jovens alunos já nascem mergulhados nesse mundo repleto de tecnologias e seus interesses e padrões de pensamento já fazem parte desse universo.

Deste modo, considerar a familiaridade e atração dos alunos atuais pela tecnologia pode auxiliar no processo de ensino e aprendizagem. Além disso, motivar os alunos a aprenderem conceitos matemáticos é geralmente considerado uma tarefa desafiadora. Neste sentido, o uso de tecnologia pode estimular os alunos, tornando-os mais participativos no processo de aprendizagem (Raines e Clark, 2011; Tanbellini e Brandão, 2010).

De um lado, nota-se a necessidade de fornecer ao professor ferramentas que auxiliem este processo de motivação a aprender. De outro, busca-se oferecer um sistema para apoiar ensino e aprendizagem de combinatória, no qual forneça um modelo interessante para o professor e para o aluno e também, que seja de fácil utilização e interface agradável.

Dessa forma, o presente projeto de mestrado desenvolveu o reprojeto do $i$ Comb abordando as atividades e as técnicas do processo de design de interação, do qual se tem como premissa básica a consideração das necessidades dos usuários quanto a um sistema computacional.

Inicialmente, o reprojeto concentrou-se em avaliar a versão iComb Java. Para isso, foram realizadas sessões com usuários para testar a usabilidade do sistema. Em seguida, desenvolveu o design da interface do sistema utilizando-se da técnica de roteiro visual (storyboarding). A técnica de prototipagem participativa guiou a atividade para a construção dos protótipos do iCombH5. E por fim, avaliou-se o protótipo $i$ CombH5 utilizando-se da metodologia de teste piloto.

Nas sessões de teste da usabilidade do $i C o m b$ foram combinadas várias técnicas para coleta de dados, onde avaliou-se a interação de professores e alunos com o sistema. Os pontos fortes identificados no $i C o m b$ foram mantidos e confirmaram a eficácia do sistema mesmo sendo somente para uma classe específica de problemas combinatórios. Já os pontos fracos apontados pelos usuários, foram apresentados como especificações problemáticas no $i C o m b$, das quais guiaram o desenvolvimento do design da interface do sistema.

Aplicar a técnica de roteiro visual no desenvolvimento de design da interface do iComb pode identificar algumas necessidades dos usuários quanto ao sistema. O resultado dessa atividade foi o desenho de uma interface melhorada para o $i C o m b$. A interação do usuário durante essa atividade foram registradas no roteiro visual, o qual guiou a atividade de prototipagem.

Com a técnica de prototipagem participativa pode gerar, modificar e avaliar os protótipos da 
interface do sistema $i C o m b$. Obtendo como resultado final, nesta atividade, um protótipo com uma interface esteticamente agradável.

Apesar da limitação das funcionalidades, o teste piloto do protótipo do iCombH5 obteve uma avaliação muito boa relativa à usabilidade e aspectos visuais da interface e não apresentou falhas em momento algum.

Concluiu-se que o envolvimento de usuários finais em todas atividades para reprojetar o iComb foi extremamente importante para a evolução do sistema. Isso porque os usuários puderam discutir requisitos, necessidades, desejos e aspirações a respeito do que é realmente necessário e viável para o sistema $i C o m b$.

A seguir, na Seção 5.1 apresentam-se as principais contribuições científicas deste trabalho. E na Seção 5.2 estão algumas sugestões de trabalhos futuros a partir do que foi desenvolvido neste.

\subsection{Contribuições}

Uma contribuição da ciência de computação para a educação é proporcionar sistemas educacionais que possam informar rapidamente o desempenho do estudante.

A contribuição deste trabalho é a implementação de uma versão melhorada do $i C o m b$, focando o incremento da interatividade do aluno com o conteúdo de análise combinatória e considerando modelos para avaliação automática a partir de ferramentas Web.

E outra contribuição importante desse do trabalho foi a pesquisa com aspectos interdisciplinares, Educação Matemática, Design de Interação e Computação, identificando aspectos de qualidade de um objeto de aprendizagem.

\subsubsection{Produção Científica}

Desde o início do projeto de mestrado, a autora esteve envolvida em diversos trabalhos junto ao grupo de pesquisa. Esses trabalhos geraram publicações para o Congresso Brasileiro de Informática na Educação no Workshop de Informática na Escola (WIE) listados a seguir:

- "O uso de Geometria Interativa em cursos a distância para motivar e aprofundar conhecimentos de Matemática: um estudo com alunos do ensino fundamental II". (Artigo resumido) (Rodrigues et al., 2011)

- "Uma Investigação Sobre o Papel da Geometria Interativa no Processo de Aquisição do Conceito de Circunferência Com Alunos do 6o Ano do Ensino Fundamental". (Artigo completo) (Franco et al., 2013)

\subsection{Trabalhos Futuros}

Como trabalhos futuros, para que o iComb versão HTML5 possa ser avaliado significativamente, são necessários estudos mais acurados sobre a utilização do sistema em ambientes educacionais reais. Novos testes com esta versão devem ser realizados, desta vez com alunos do Ensino Médio de escolas públicas. E posteriormente, deverá ser realizada uma investigação dos aspectos educacionais, sobretudo com respeito à efetividade de aprendizagem propiciada pelo uso do sistema. 
Além disso, deverá ser disponibilizado o código do iComb versão em HTML5 na forma de código livre, utilizando licença GPL.

Outra perspectiva interessante seria estender o $i C o m b$, de tal forma a torná-lo adequado a trabalhar outras classes de problemas combinatórios diferentes baseando-se nas outras interfaces do Combien?. 


\section{Apêndice A}

\section{Exemplar da carta de consentimento}

Neste Apêndice encontra-se o exemplar da carta de consentimento para uso dos dados coletados nas atividades no processo de reprojeto do iComb. Esta carta foi assinada por todos os usuários que fizeram parte da equipe de reprojeto e encontram-se aos cuidados da autora.

\section{Carta de Consentimento}

Afirmo que sou maior de 18 anos e desejo participar do projeto de pesquisa que está sendo conduzido por Márcia Roberta S. Pires Silva, aluna de mestrado do Departamento de Ciência da Computação no Instituto de Matemática e Estatística da Universidade de São Paulo - IME USP.

O propósito da pesquisa é reprojetar o sistema iComb: Combinatória Interativa na Internet, para isso serão realizadas sessões para desenvolvimento das atividades de avaliação de usabilidade do sistema existente, desenvolvimento de designs da interface, construção de protótipos participativos e avaliação do protótipo para novo sistema. Nestas sessões responderei a questões abertas relacionadas ao sistema iComb. Também serão feitas gravações de vídeo da tela do computador e de áudio.

Todas as informações coletadas neste estudo são confidenciais, e meu nome não será identificado em momento algum.

Estou ciente que posso fazer perguntas ou desistir da colaboração em qualquer momento, sem qualquer tipo de penalidade.

Autorizo a divulgação dos resultados na apresentação desta pesquisa e em artigos científicos.

São Paulo, de de 2014 .

Assinatura do participante

Figura A.1: Carta de consentimento assinada pelos participantes da equipe. 


\section{Apêndice B}

\section{Documentação dos testes de usabilidade do $i C o m b$}

Neste Apêndice encontram-se os documentos referentes as tarefas aplicadas nas sessões de teste de usabilidade do $i C o m b$ descritas no capítulo 4, a saber:

- Pré-teste;

- Enunciados dos exercícios aplicados no $i C o m b$;

- Pós-teste;

- Quadro de observação para registro do comportamento dos participantes perante algum fato inesperado durante o uso do $i C o m b$;

- Questionário eletrônico aplicado após o uso do sistema. 
Nome do participante:

Data:

Resolva as questões propostas, apresentando as soluções e justificando os resultados:

Questão 1 - Com um baralho de 32 cartas, quantas mãos de 2 cartas é possível formar com exatamente uma Dama e um Ás?

Dado: o baralho de 32 cartas é composto das cartas ás, 7, 8, 9, 10, valete, dama e rei dos quatro naipes.

Questão 2 - Com um baralho de 32 cartas, quantas mãos de 5 cartas é possível formar com exatamente duas Copas e duas Espadas?

Dado: o baralho de 32 cartas é composto das cartas ás, 7, 8, 9, 10, valete, dama e rei dos quatro naipes.

Questão 3 - Com um baralho de 32 cartas, quantas mãos de 13 cartas é possível formar com no mínimo 1 carta de Copas, exatamente 5 cartas pretas e exatamente 4 ases?

Dado: o baralho de 32 cartas é composto das cartas ás, 7, 8, 9, 10, valete, dama e rei dos quatro naipes. 
Informatica na Educacich

\section{Enunciado dos exercícios aplicados no iComb}

Universo baralho de 32 cartas: O baralho de 32 cartas é composto das cartas ás, 7, 8, 9, 10, valete, dama e rei dos quatro naipes.

1. (iComb - 1) Num baralho de 32 cartas, Paulo deseja retirar duas cartas, sem reposição, que seja exatamente uma Dama e um ás. De quantas maneiras possíveis ele pode fazer isso?

2. (iComb - 3) De um baralho de 32 cartas, retira-se sucessivamente e sem reposição oito cartas que sejam exatamente um Ás, 2 Reis e 2 Valetes. Quantas maneiras possíveis pode-se fazer esta extração?

Universo Futebol: O futebol possui 44 elementos, sendo 4 times (Amarelo, Azul, Verde e Vermelho) e cada time com 11 jogadores que se diferem pela numeração das camisas e posição do jogador em campo (goleiro, zagueiros, meio-campos, atacantes).

3. (iComb - 2) Existem 44 jogadores de futebol que estão divididos em dois grupos no treino, o grupo dos goleiros e o dos jogadores de linha. $\mathrm{O}$ assessor de imprensa precisa escolher um jogador para ser entrevistado. Para isso, ele terá que escolher um jogador ou do grupo dos goleiros ou do outro grupo. De quantas maneiras ele pode fazer esta escolha?

4. (iComb - 4) Existem 11 jogadores de futebol de salão do time Vermelho, entre eles o Diego, que por sinal é o único que joga como goleiro. Nessas condições, quantos times de 5 pessoas podem ser escalados? 
Data:

Nome do participante:

Resolva a questão proposta, apresentando a solução e justificando os resultados:

Com um baralho com 32 cartas, Regina deseja retirar 5 cartas que sejam exatamente 3 damas e exatamente 2 copas. De quantas maneiras possíveis ela pode fazer isso?

Dado: o baralho de 32 cartas é composto das cartas ás, 7, 8, 9, 10, valete, dama e rei dos quatro naipes.

- O iComb, aplicativo que você acabou de utilizar, contribuiu de alguma maneira na resolução dessa questão? Se sim, quais foram as contribuições? 


\section{Quadro de Observação Participante}

Nome do(a) participante(a):

data:

Horário de inicio dos exercícios no iComb: horário de término:

\begin{tabular}{|c|c|c|c|c|c|c|}
\hline $\begin{array}{l}\text { Na construção da } \\
\text { resposta da questão: }\end{array}$ & $\begin{array}{l}\text { Usou a ajuda } \\
\text { interna do iComb? }\end{array}$ & $\begin{array}{l}\text { Apresentou dificuldades na } \\
\text { cronologia dos estágios }\end{array}$ & $\begin{array}{l}\text { Fez uso de } \\
\text { rascunho }\end{array}$ & Pediu auxilio & $\begin{array}{r}\text { Desistiu } \\
\text { a q }\end{array}$ & $\begin{array}{l}\text { resolver } \\
\text { stão }\end{array}$ \\
\hline 1 & ( ) não & ( ) não & ( ) não & ( ) não & ( ) $\operatorname{sim}$ & ( ) não \\
\hline 2 & ( ) não & ( ) não & ( ) não & ( ) não & ( ) $\operatorname{sim}$ & ( ) não \\
\hline 3 & ( ) não & ( ) não & ( ) não & ( ) sim & ( ) $\operatorname{sim}$ & ( ) não \\
\hline 4 & ( ) não & ( ) não & ( ) não & ( ) não & ( ) $\operatorname{sim}$ & ( ) não \\
\hline
\end{tabular}

Observações gerais sobre o comportamento do participante ao realizar a atividade, tais como: motivação, empenho, irritabilidade, persistência, entre outros. 


\section{Questionário iComb}

Sobre Análise Combinatória

$1^{*} \quad$ Você já estudou análise combinatớria?

$\bigcirc$ sim $\bigcirc$ Não

2 Se sim, em que nivel de ensino?

Ensino Médio $\bigcirc$ Graduação $\bigcirc$ Pós graduação $\bigcirc$ Sem resposta

3 Descreva sucintamente qual é a aplicaçăo/ finalidade da Análise Combinatória?

\section{Descer such}

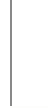

\section{Sobre informática}

4 * Com que frequência você utiliza software nas suas aulas?

$\bigcirc$ nunca às vezes $\bigcirc$ pouco $\bigcirc$ sempre

5 Se sim, cite qual(is) software(s) e em qual(is) disciplinas?

\section{Experiência utilizando o iComb}

$6^{*} \quad$ Você resolveu os exercicicios:

sozinho $\bigcirc$ em dupla $\bigcirc$ em trio

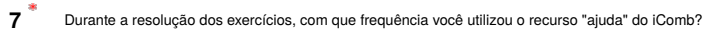
$\bigcirc$ nunca $\bigcirc$ às vezes $\bigcirc$ pouco $\bigcirc$ sempre

8 * Como você avalia o recurso "ajuda" do iComb?

$\bigcirc$ excelente $\bigcirc$ muito bom $\bigcirc$ bom $\bigcirc$ regular $\bigcirc$ ruim $\bigcirc$ muito ruim

9 Justifique sua avaliação a respeito do recurso "ajuda" do iComb, no quadro abaixo: sim $\bigcirc$ Năo

23 Se sim, diga em qual(is) situação(ōes):

24 No final do teste este sentimento perdurou?

25 O que você pode dizer do método exigido?

26

O que você achou dos exercícios propostos?

Visual do iComb

27 A posição dos botōes, os respectivos tiftulos dos botồes, as cores utilizadas e as mudanças de cores durante a construçăo, você acha que foram propícias para aprendizagem?

Posição dos botồes:

$10^{*}$ Para você, como foi a utilizar o iComb?

$\bigcirc$ muito fácil $\bigcirc$ fácil $\bigcirc$ dificil $\bigcirc$ muito difícil

11 Se você encontrou dificuldades na ultilizaçăo do iComb, descreva-as no quadro abaixo:

Aprendizagem da resolução de exercícios utilizando o iComb

$12{ }^{*}$

$\bigcirc \operatorname{sim} \bigcirc$ Não

13

Se năo, especifique-os:

14 * Você entendeu rapidamente o que deveria fazer?

- No primeiro estágio

$\bigcirc$ muito facilmente $\bigcirc$ facilmente $\bigcirc$ dificilmente $\bigcirc$ muito dificilmente

$15^{*}$ - No adicionar estágio

$\bigcirc$ muito facilmente $\bigcirc$ facilmente $\bigcirc$ dificilmente $\bigcirc$ muito dificilmente

$16{ }^{*}$ - No processo final de construçăo

$\bigcirc$ muito facilmente $\bigcirc$ facilmente $\bigcirc$ dificilimente $\bigcirc$ muito dificilmente

$17^{*}$ Se sentiu perdido?

$\bigcirc$ no inicio $\bigcirc$ muitas vezes $\bigcirc$ às vezes $\bigcirc$ nunca

18 Se sim, em qual situaçă

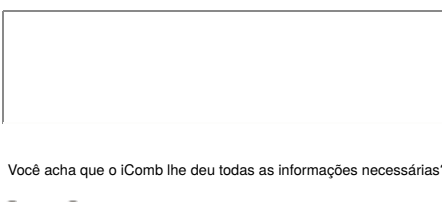

$\bigcirc$ sim $\bigcirc$ Não

28

Titulos dos botōes:

29

Cores utilizadas:

30

Mudanças de cores durante a construçâà:

Opinião Geral

31 De acordo com sua opinião, quais săo os pontos fortes do iComb?

De acordo com sua opiniâo, quais são os pontos fracos do iComb?

Deixe seus comentários e sugestōes sobre o iComb:

Fechar esta janela 


\section{Apêndice C}

\section{Roteiro visual para o design da interface do $i C o m b$.}

Neste Apêndice encontra-se a digitalização do roteiro visual utilizado nas duas etapas da atividade para o design da interface do $i C o m b$.

Na primeira etapa foi realizada a análise e a discussão de cada especificação problemática apontada no teste de usabilidade do $i C o m b$, sendo feito o registro das discussões, bem como, as sugestões dos usuários para tentar sanar tais problemas.

$\mathrm{Na}$ segunda etapa foi proposto novos desenhos para a interface do $i C o m b$. Utilizando-se do roteiro visual da primeira etapa examinou-se cada elemento gráfico existente discutindo sobre sua ação e posicionamento. E assim, modificou-se cooperativamente a interface obtendo o desenho de uma interface melhorada. 

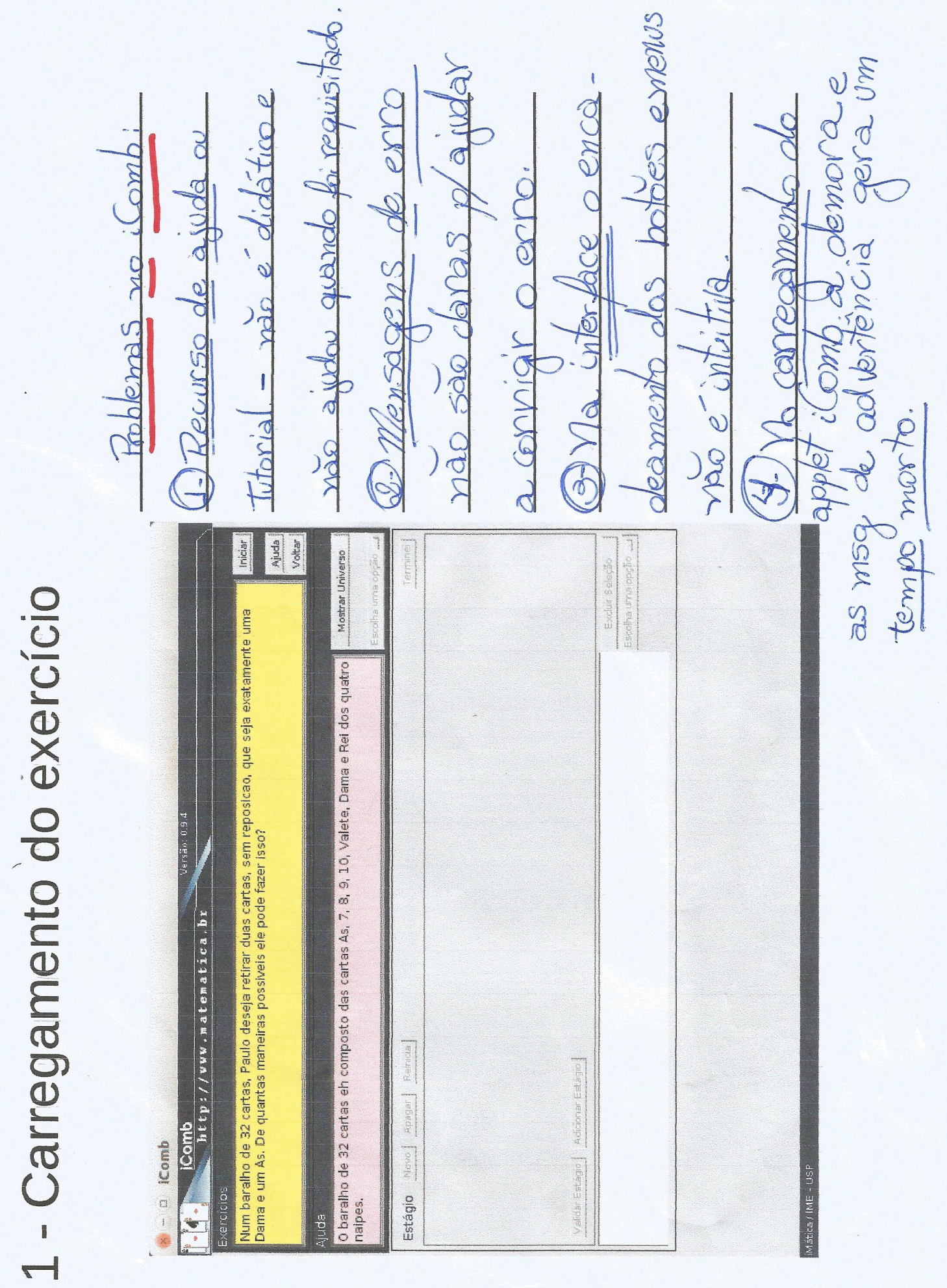


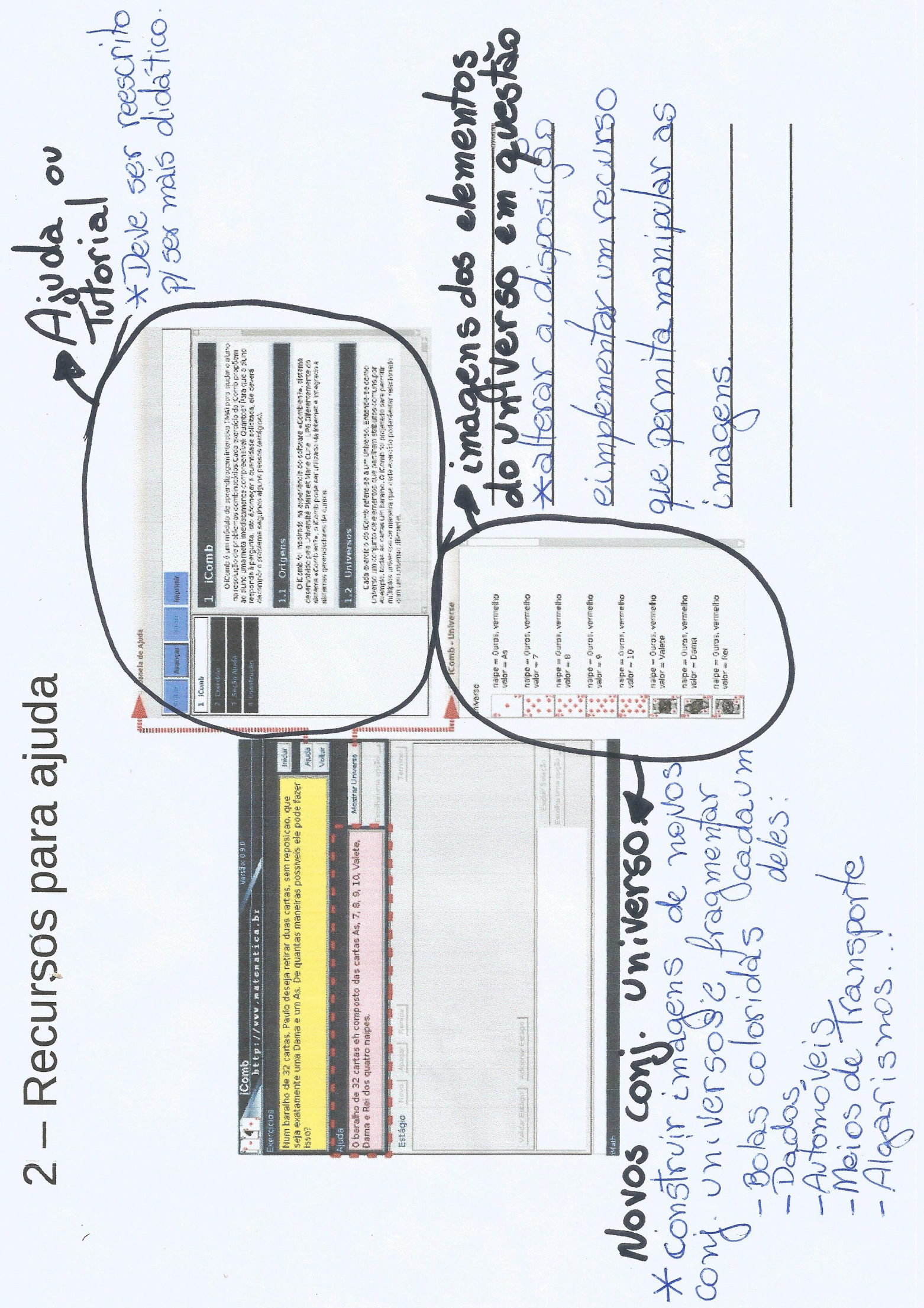




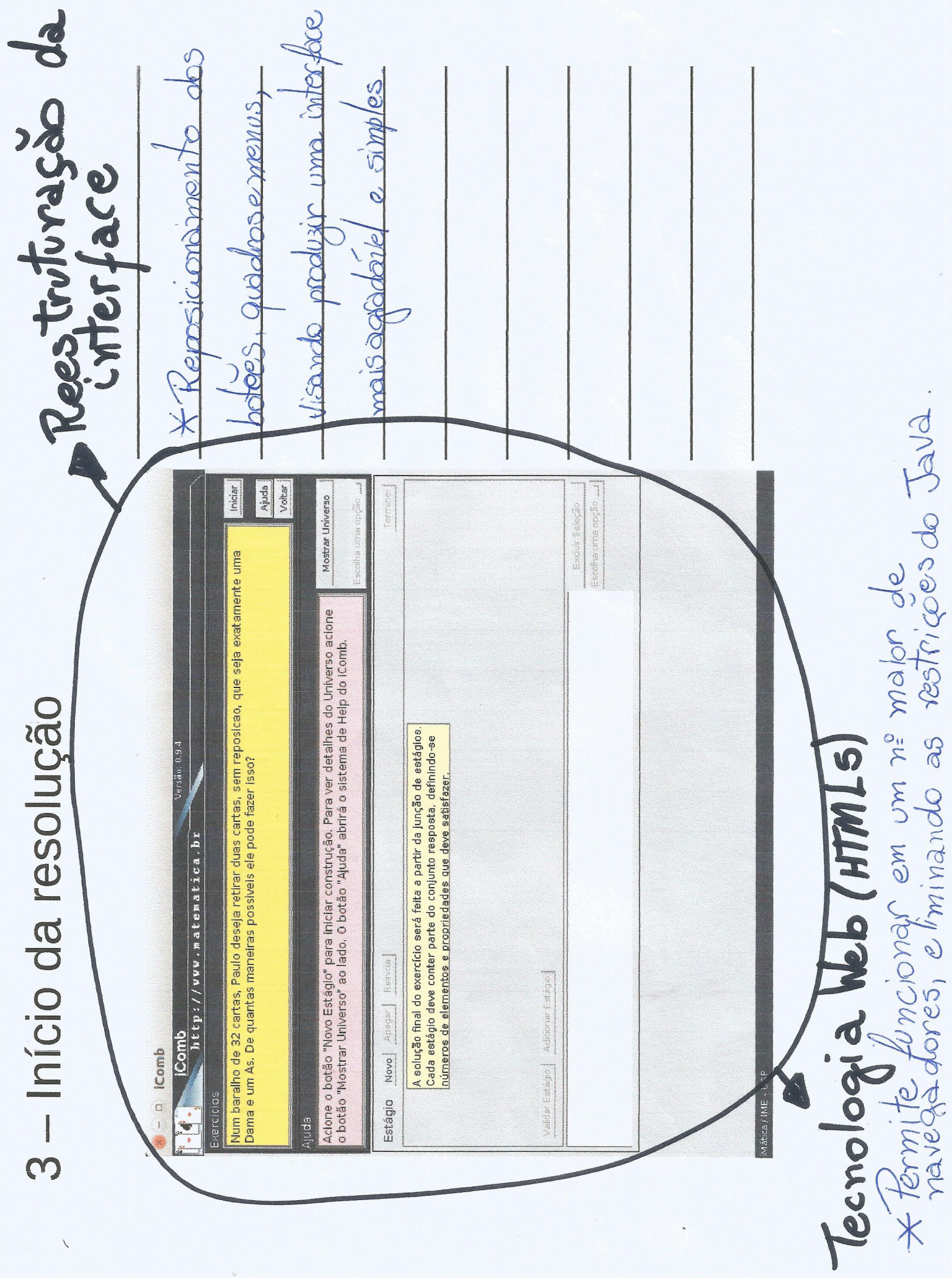




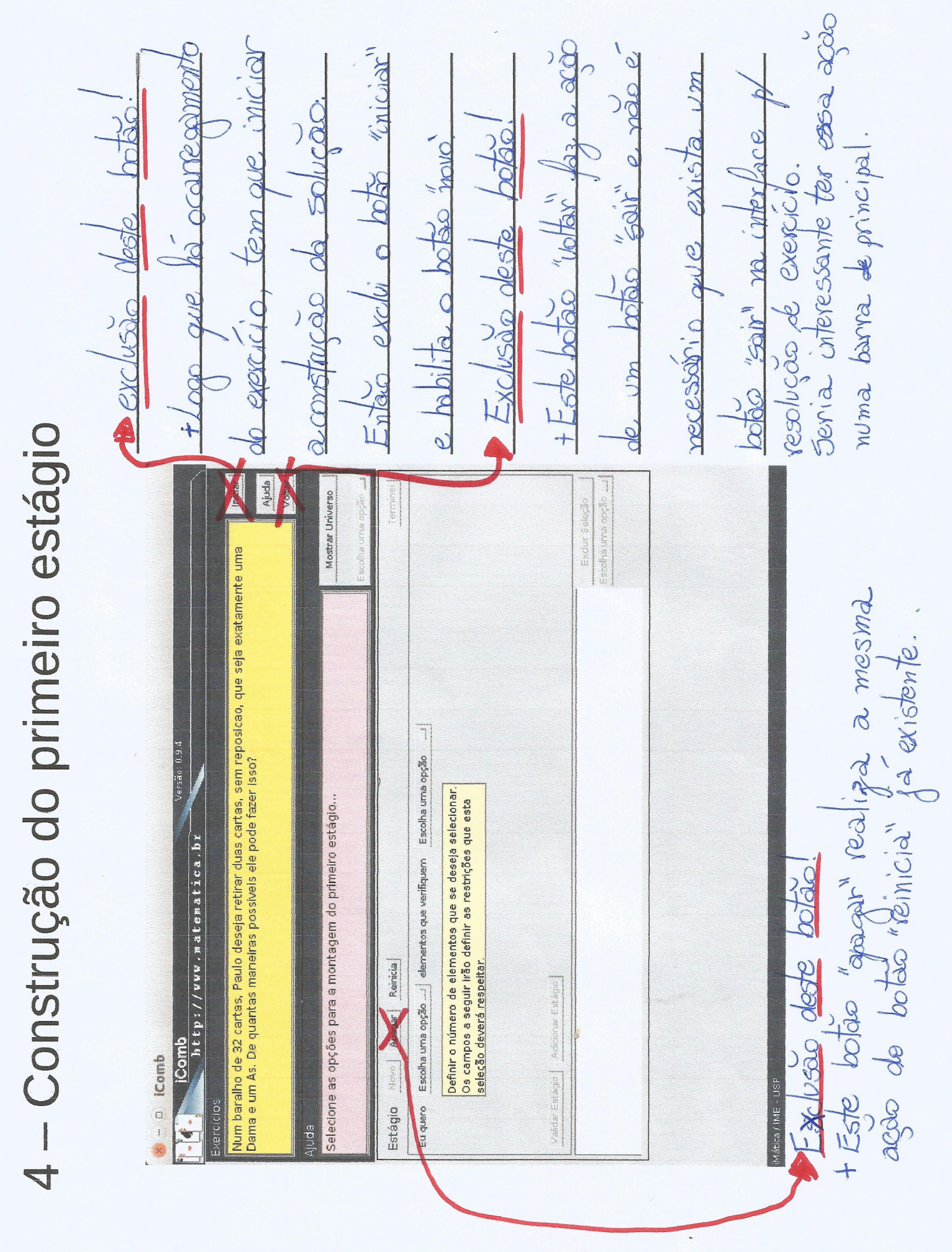




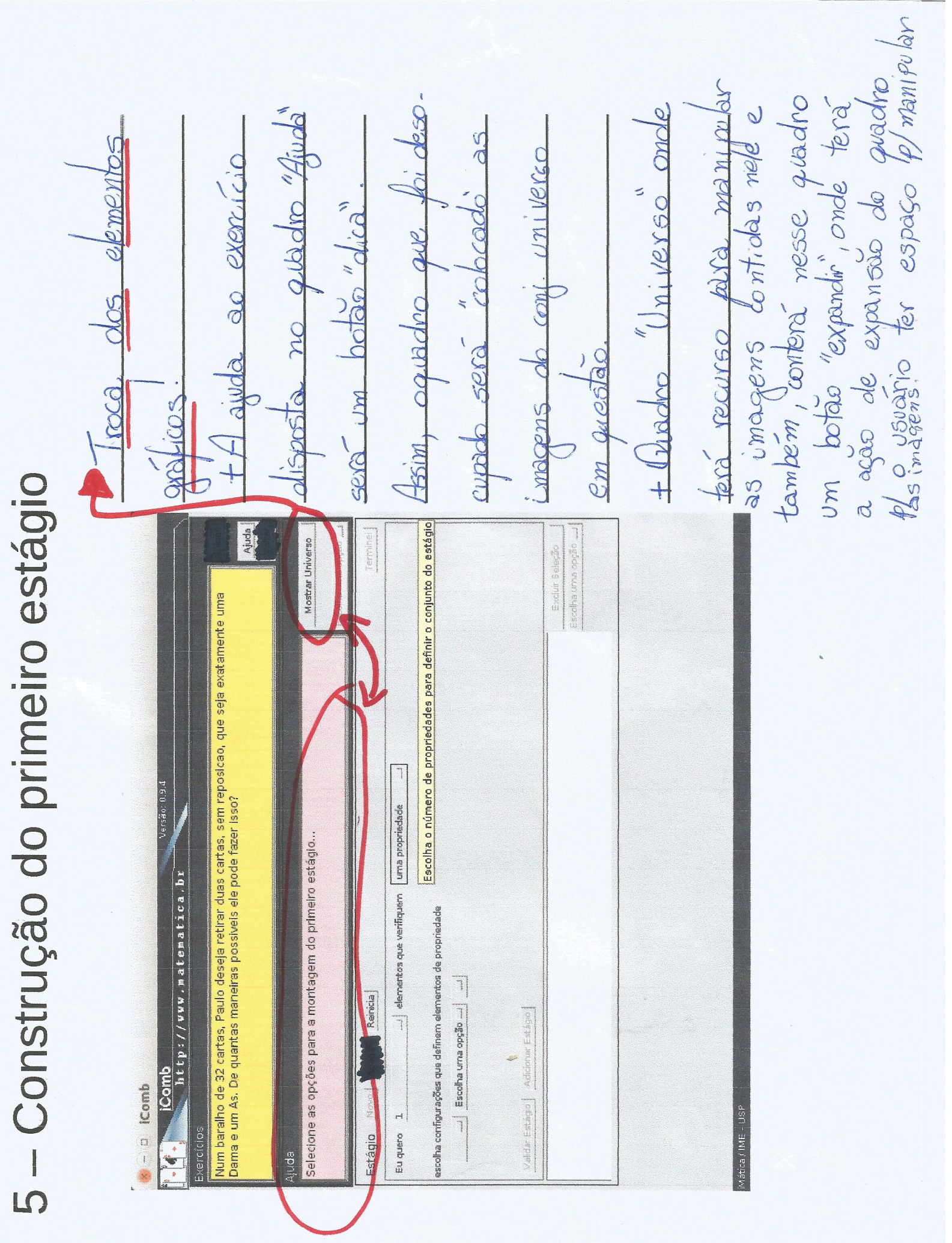




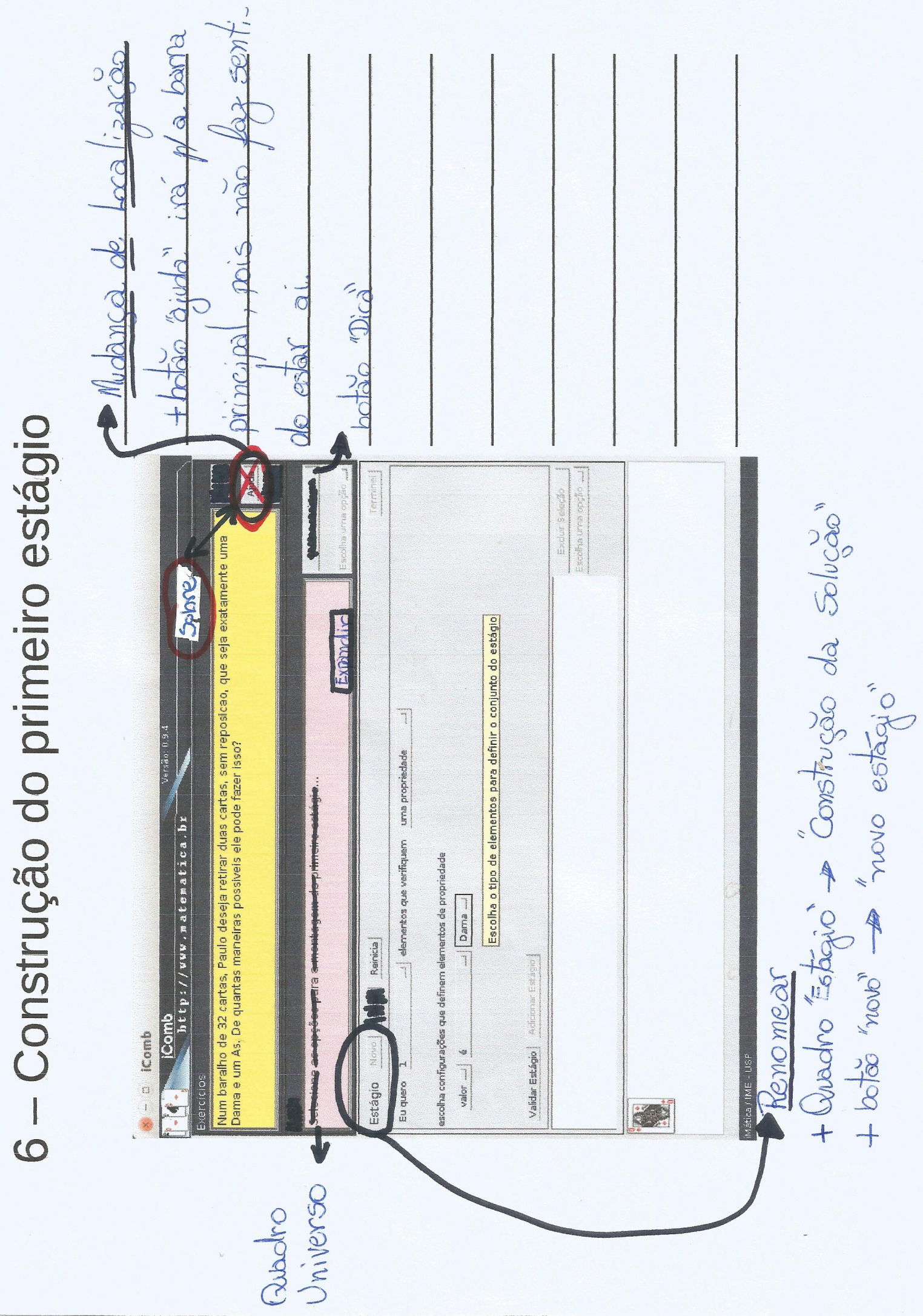




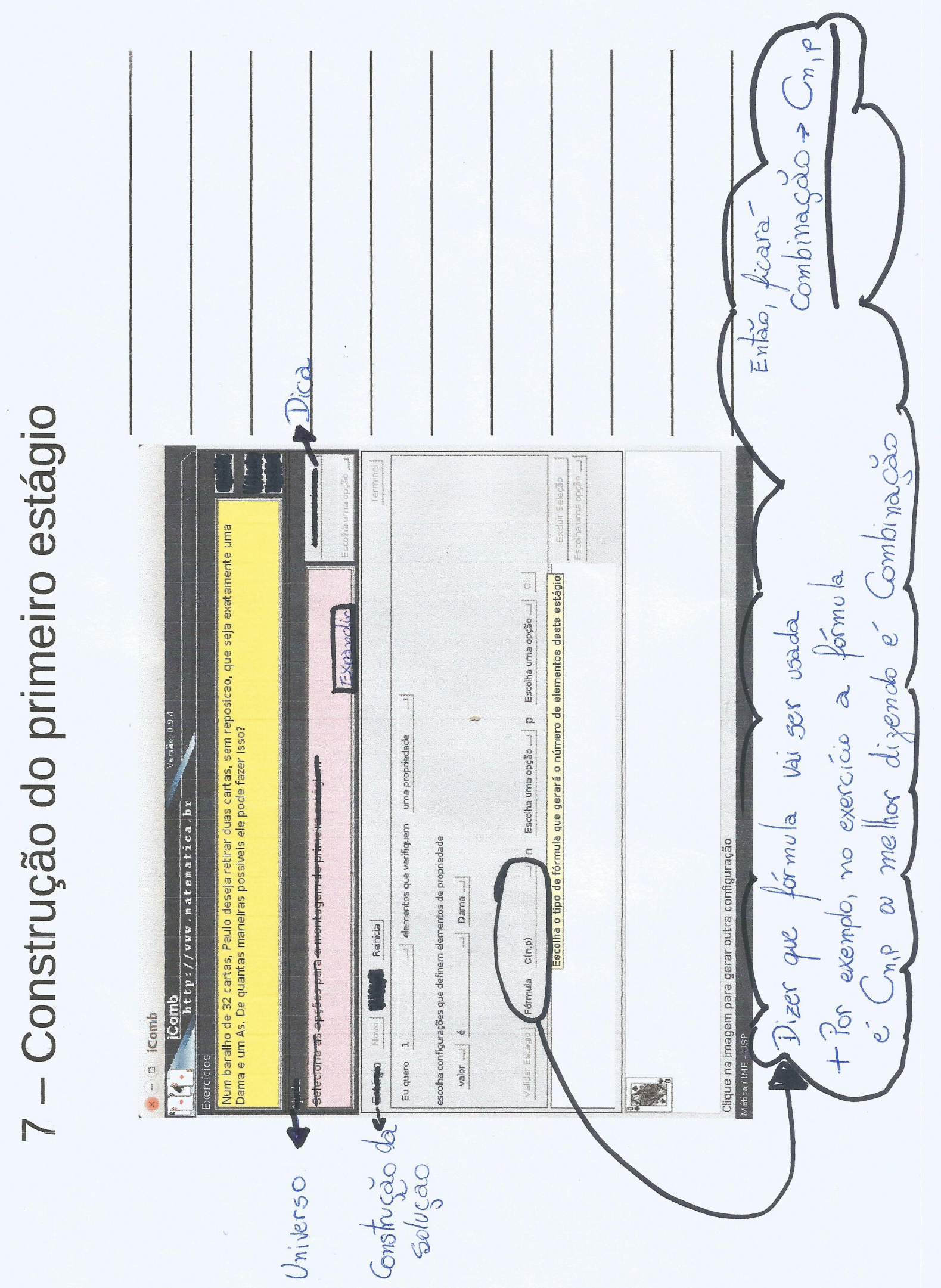




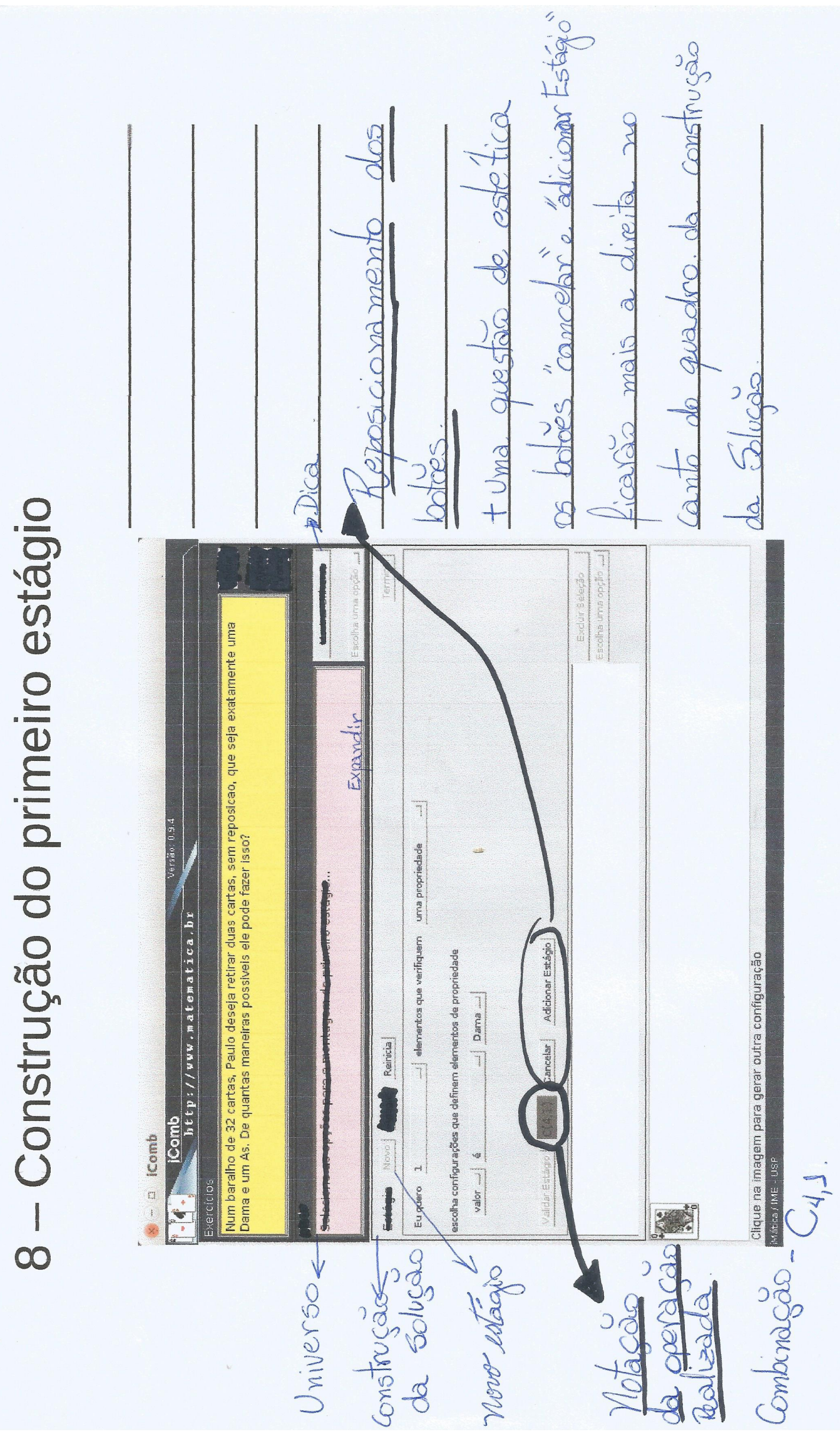




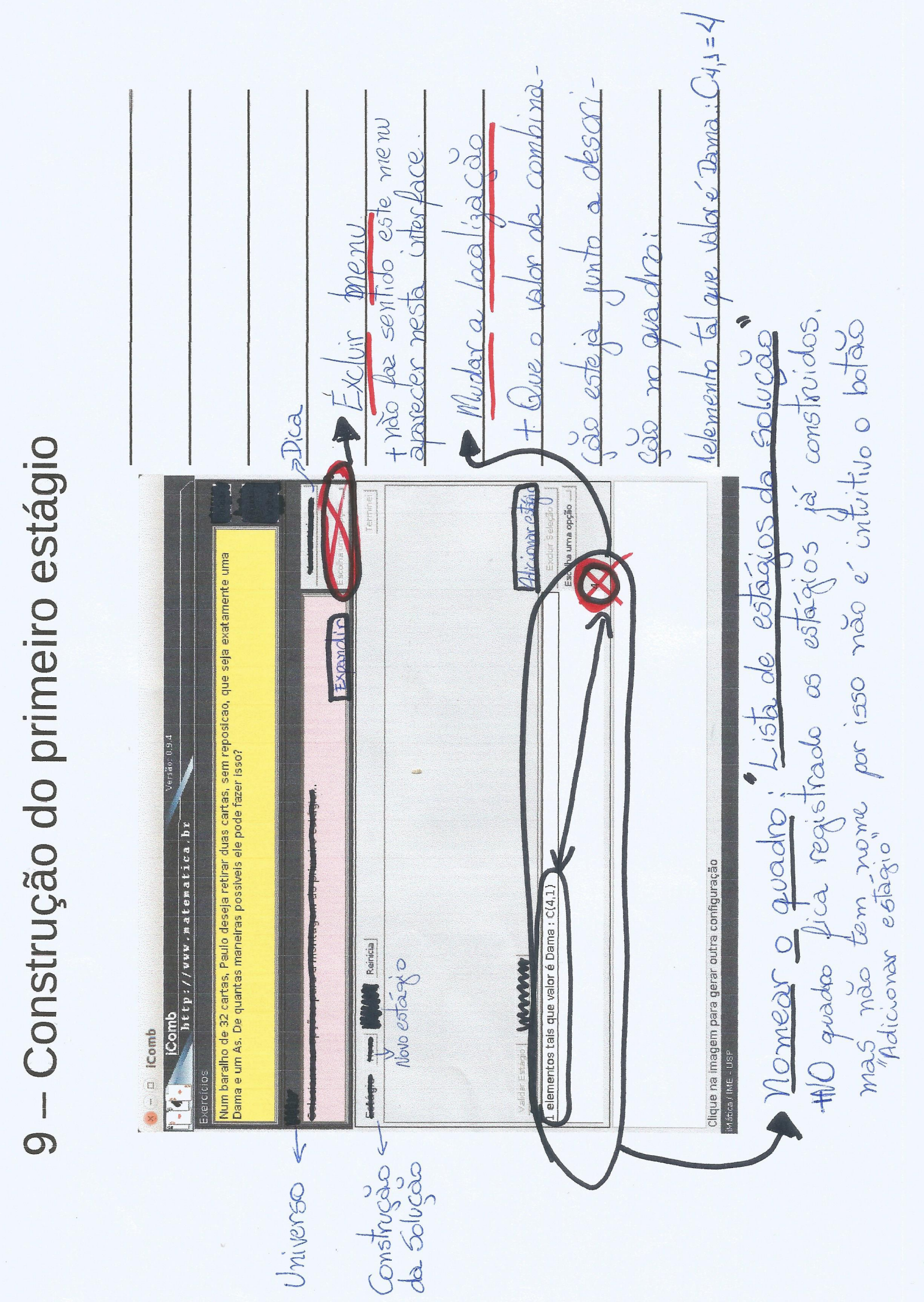




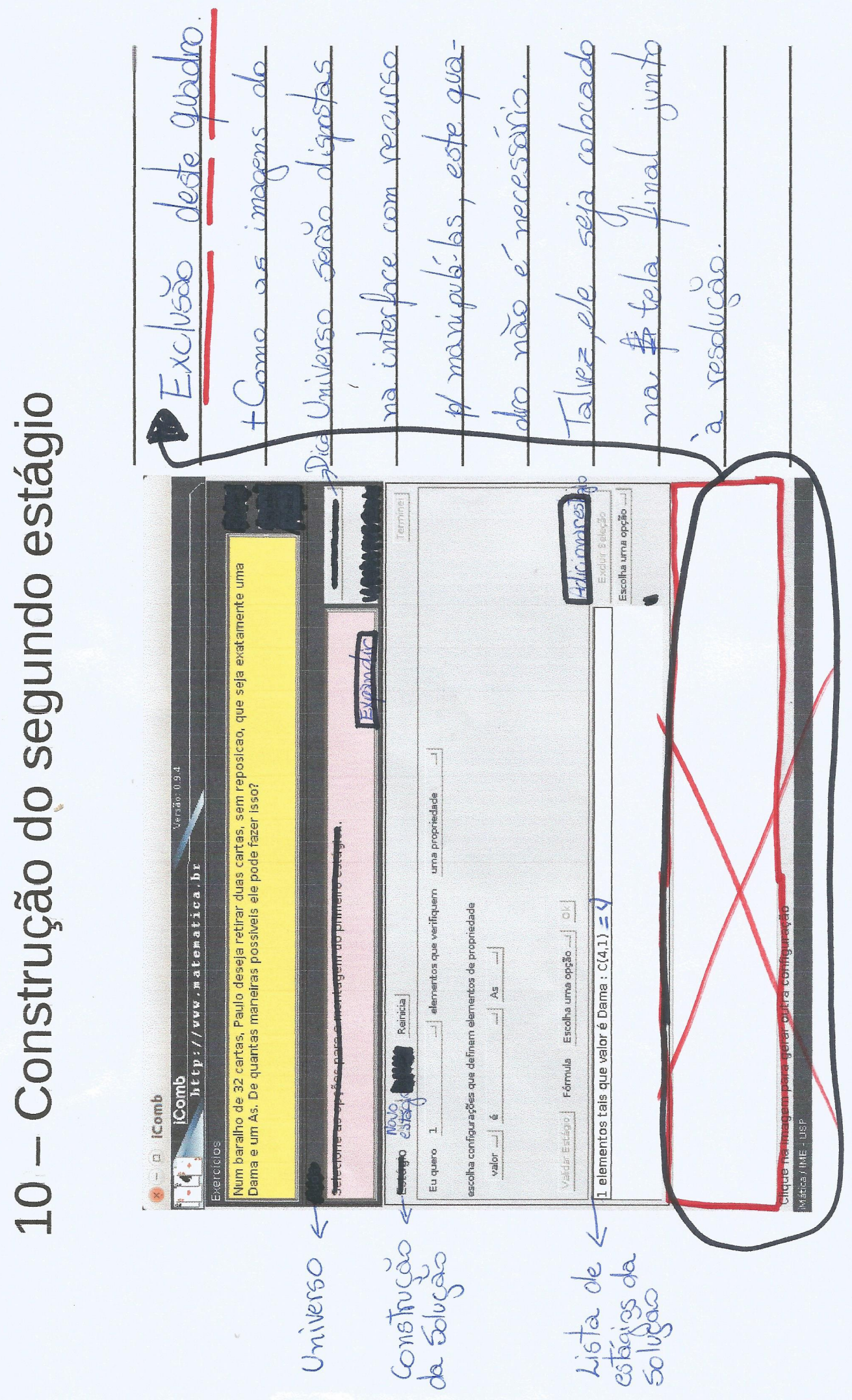




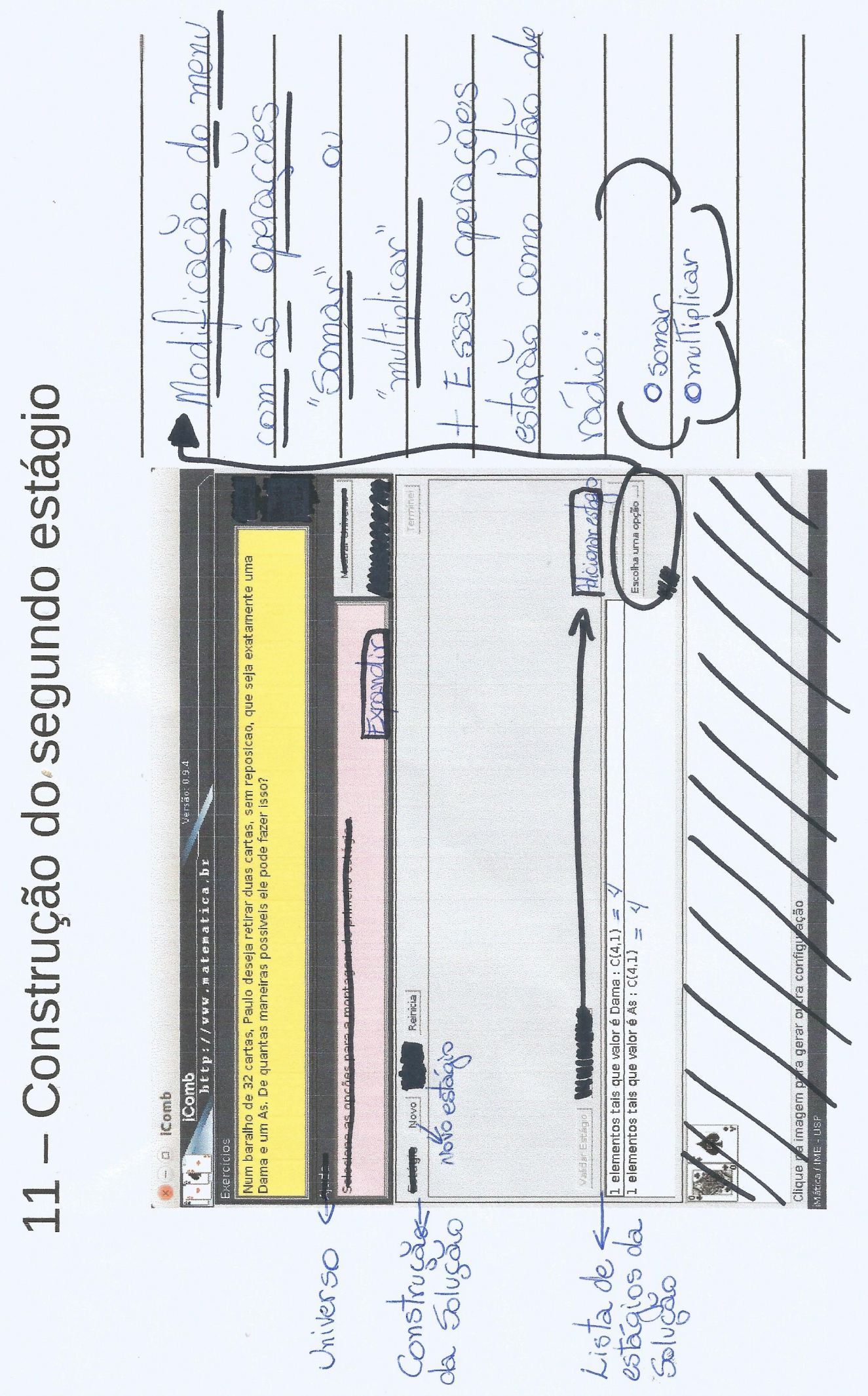




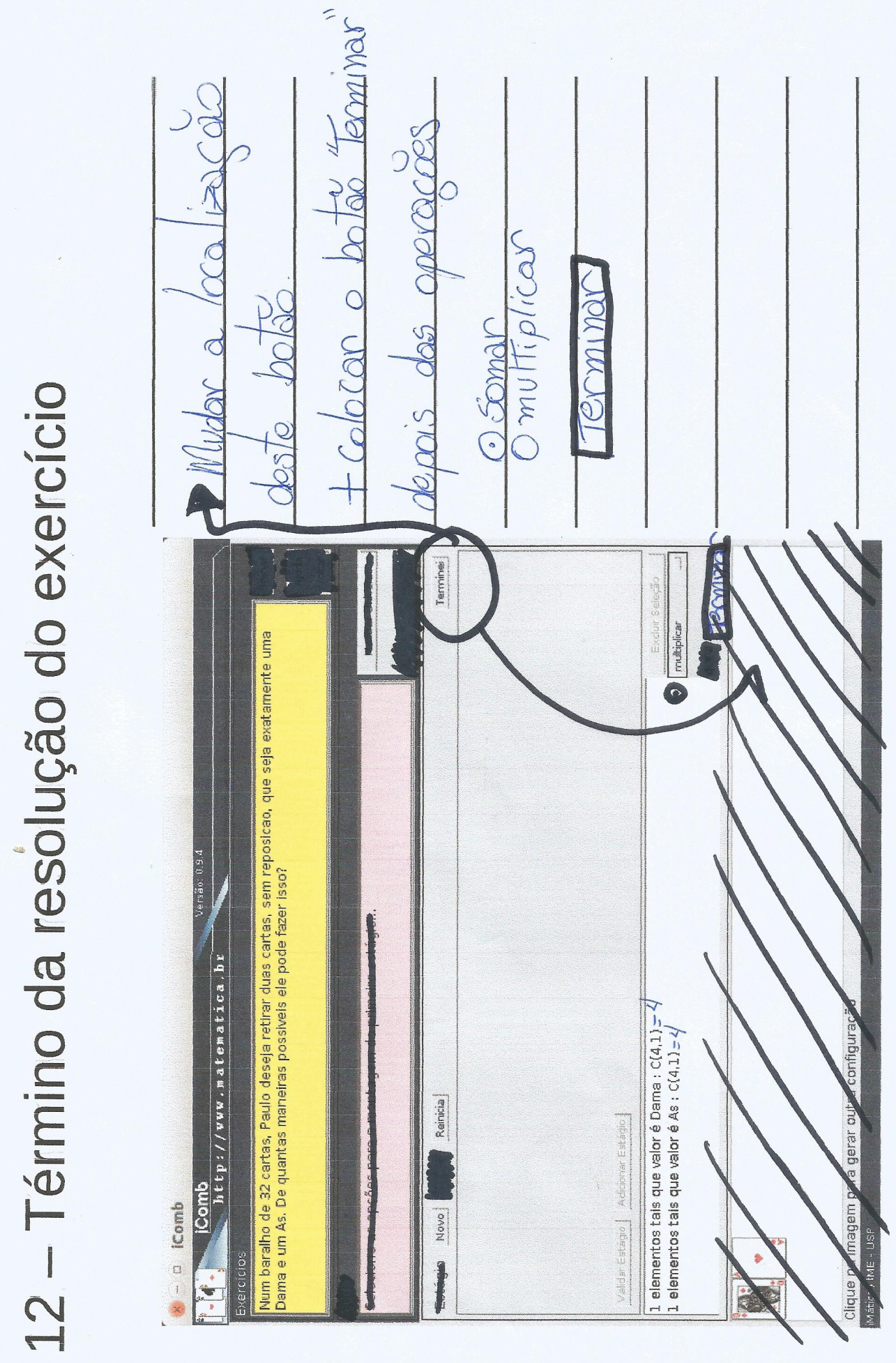




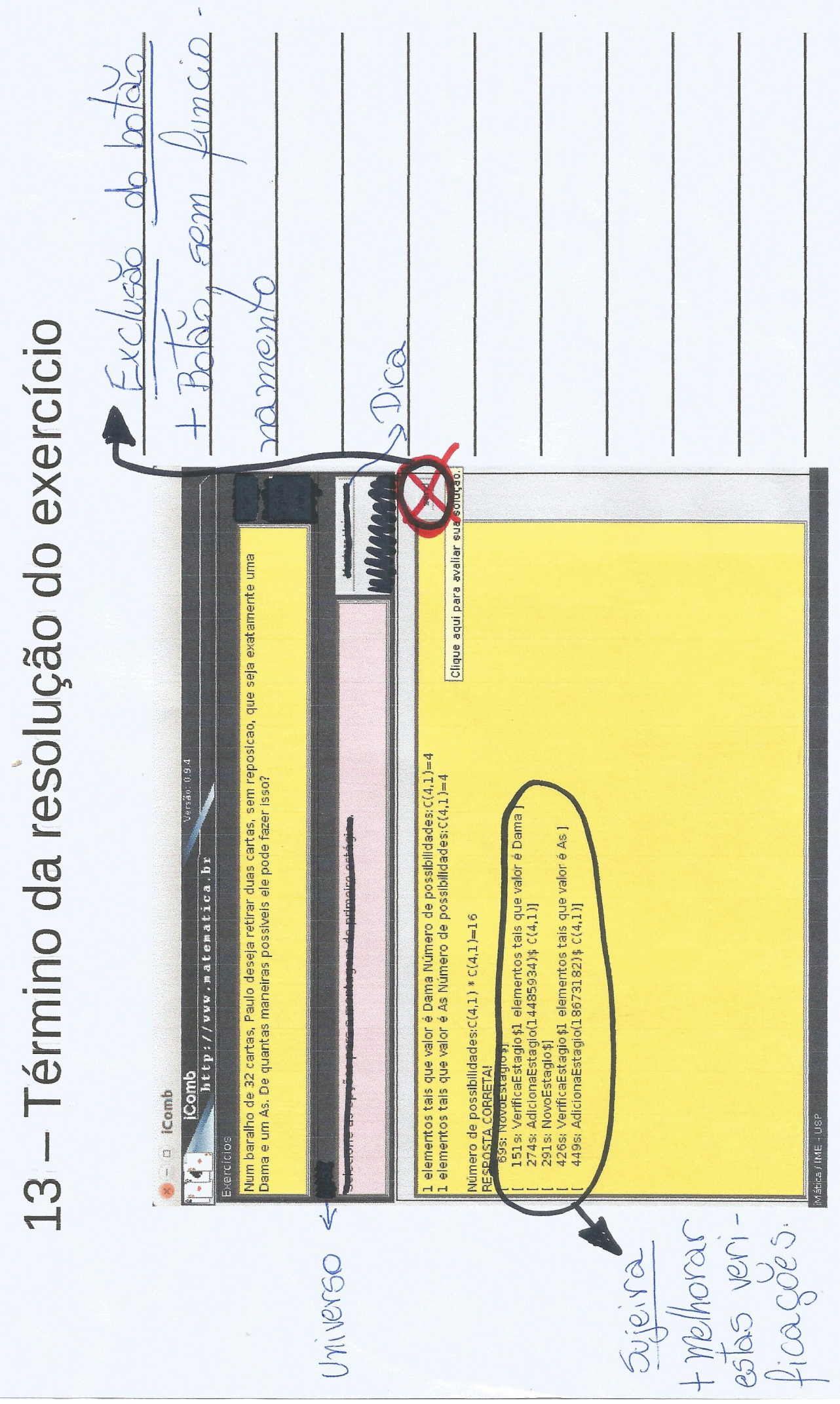



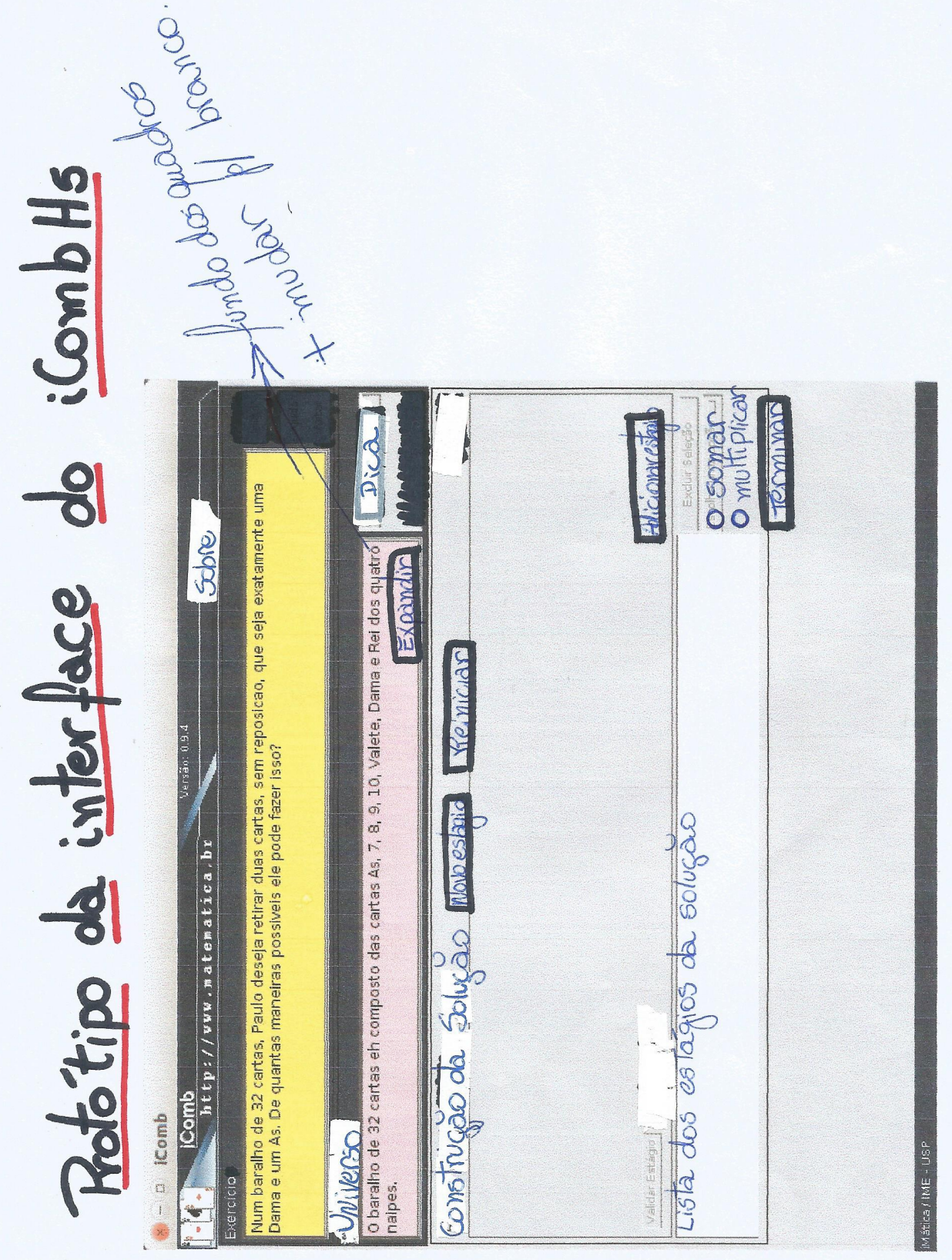


\section{Referências Bibliográficas}

Aleven et al.(2008) Vincent Aleven, Bruce M. Mclaren, Jonathan Sewall e Kenneth R.Koedinger. A new paradigm for intelligent tutoring systems: Example-tracing tutors. International Journal of Artificial Intelligence in Education, 19:105-154. Citado na pág. 5

Ardito et al.(2006) C. Ardito, M. F. Costabile, M. De Marisco, R. Lanzilotti, S.Levialdi, T. Roselli e V. Rossano. An approach to usability evaluation of e-learning applications. Univ Access Inf Soc, 4:270-293. Citado na pág. 19

Barbosa et al.(2010) Jaiane Ramos Barbosa, Alisandra Cavalcante Fernandes, Lavina Lúcia Vieira Lima, Raquel Santiago Freire, Shirliane Matos de Souza, José Aires de Castro Filho e Mauro Cavalcante Pequeno. Objetos de aprendizagem: análise de seu uso em uma sala de aula do ensino fundamental. Anais do XX Simpósio Brasileiro de Informática na Educação. Citado na pág. 39

Bardin(1986) Laurence Bardin. L'Analyse de Contenu. Paris, Presses universitaires de France, 4 edição. Citado na pág. 16, 25

Batanero et al.(1997) Carmen Batanero, Virginia Navarro-Pelayo e Juan D. Godino. Effect of the implicit combinatorial model on combinatorial reasoning in secondary school pupils. Educational Studies in Mathematics, volume 32:181-199. Citado na pág. 5

Brandão et al.(2004) Leônidas O. Brandão, Seiji Isotani e Janine G. Moura. Geometria dinâmica com o igeom: Algoritmos geométricos, autoria e avaliação automática de exercícios. Anais do XV Simpósio Brasileiro de Informática na Educação. Citado na pág. 13

Buckingham(2007) David Buckingham. Beyond Technology: Children's Learning in the Age of Digital Culture. Cambridge, MA: Polity Press. Citado na pág. 1

Buxton(1985) Laurie Graham Buxton. Cognitive-affective interaction in the teaching and learning of mathematics. Phd thesis, University of Warwick. Citado na pág. 5

Cadaval e Hartmann(2014) Carolina Robertson P. Cadaval e Rochus Hartmann. Evaluation of schools activities with digital interactive simulations. Proceedings of the 2014 Workshop on Interaction Design in Educational Environments, página 52. Citado na pág. 18

Calvez et al.(2003) Françoise Le Calvez, Hélène Giroire, Jacques Duma, Gérard Tisseau e Marie Urtasun. Combien? a Software to Teach Students How to Solve Combinatorics Exercises. Proceedings of Artificial Intelligence in Education, páginas 447-453. Citado na pág. 6, 11

Cooper et al.(2007) Alan Cooper, Robert Reimann e Dave Cronin. About Face 3: The Essentials of Interaction Design. Wiley, Indianapolis, Indiana. ISBN 9780470084113. Citado na pág. 17

Dalmon et al.(2010) Danilo L. Dalmon, Seiji Isotani e Leôonidas O. Brandão. Sistemas de geometria interativa e tutores inteligentes: desafios e perspectivas de uma abordagem conjunta. Anais do XXI Simpósio Brasileiro de Informática na Educação. Citado na pág. 5

Dalmon et al.(2011a) Danilo Leite Dalmon, Maria José Guimarães de Souza Tanbellini, Alexandre Luis K. Eisenmann, Maurício Nascimento, Patrícia Alves Rodrigues, Reginaldo do Prado, 
Reginaldo Kamiya, Seiji Isotani, Anarosa Brandão e Leônidas de Oliveira Brandão. Interactive learning modules in engineering education and as a motivational tool for middle and high school students. Proceedings of International Symposium on Engineering Education - IGIP. Citado na pág. 13,15

Dalmon et al.(2011b) Danilo Leite Dalmon, Seiji Isotani, Leônidas Oliveira Brandão e Anarosa A. Franco Brandão. Work in progress - a framework for building interactive learning modules. Proceedings of 41st Frontiers in Education Conference, páginas S3E-1 - S3E-2. Citado na pág. 1

Dalmon et al.(2012) Danilo Leite Dalmon, Leônidas Oliveira Brandão, Anarosa A. Franco Brandão e Seiji Isotani. A domain engineering for interactive learning modules. Research and Practice in Information Technology, 44:309. Citado na pág. 1

Eisenmann(2009) Alexandre L. K. Eisenmann. iComb: Um sistema para o ensino e aprendizagem de combinatória em ambiente Web. Master's thesis, Instituto de Matemática e Estatística da Universidade de São Paulo, IMEUSP. Citado na pág. 1, 2, 3, 22, 23, 29, 33

Eisenmann e Brandão(2009) Alexandre Luís Kundrát Eisenmann e Leônidas O. Brandão. iComb: Um sistema para o ensino e aprendizagem de combinatória em ambiente web. Anais do XX Simpósio Brasileiro de Informática na Educação. Citado na pág. 1, 3, 8

Fontanette et al.(2002) Valdirene Fontanette, Vinícius C. Garcia, Adriano A. Bossonaro, Angela B. Perez e Antonio F. do Prado. Reprojeto de sistemas legados baseado em componentes de software. XXVIII Conferência Latinoamericana de Informática. Citado na pág. 22

Franco et al.(2013) Leiliana S. Franco, Leônidas O. Brandão, Márcia Roberta S. Pires da Silva e Patrícia A. Rodrigues. Uma investigação sobre o papel da geometria interativa no processo de aquisição do conceito de circunferência com alunos do $6^{\circ}$ ano do ensino fundamental. Anais do Workshop de Informática na Escola, 1(1). Citado na pág. 40

Franco(2012) Maria Laura Puglisi Barbosa Franco. Análise de Conteúdo. Brasilia: Liber Livro, 4 edição. Citado na pág. 16

Giroire et al.(2006) Helene Giroire, Francoise Le Calvez e Gerard Tisseau. Benefits of knowledgebased interactive learning environments: A case in combinatorics. páginas 285-289. Citado na pág. 5,11

Gould e Lewis(1985) John D. Gould e Clayton Lewis. Designing for usability: key principles and what designers think. Communications of the ACM, v. 28:300-311. Citado na pág. 18, 35

Hara e Kling(1999) Noriko Hara e Rob Kling. Students' frustrations with a web-based distance education course. First Monday: Journal on the Internet, v. 4(12). Citado na pág. 5

Hentea et al.(2003) Mariana Hentea, Mary Jo Shea e Lisa Pennington. A perspective on fulfilling the expectations of distance education. Em Proceedings of the 4 th conference on Information technology curriculum, páginas 160-167. ACM Press New York, NY, USA. Citado na pág. 5

ISO9241(1998) ISO9241. Software Ergonomics Requirements for office work with visual display terminal (VDT). International Organisation for Standardisation. Citado na pág. 19

Isotani e Brandão(2008) Seiji Isotani e Leônidas Oliveira Brandão. An algorithm for automatic checking of exercises in a dynamic geometry system: igeom. Comput. Educ., 51:1283-1303. Citado na pág. 13

Isotani e Brandão(2003) Seiji Isotani e Leônidas Oliveira Brandão. Uma ferramenta para o ensino de geometria dinâmica na internet: igeom. Anais do IX Workshop de Informática na Educação, 1:146-148. Citado na pág. 13 
Jones(2008) Ian Jones. Storyboarding: A method for bootstrapping the design of computer-based educational tasks. Computers \& Education, 51 Issue 3:1353-1364. Citado na pág. 21

Kamiya e Brandão(2009) Reginaldo Rideaki Kamiya e Leônidas Oliveira Brandão. ivprog - um sistema para introdução à programação através de um modelo visual na internet. Anais do $X X$ Simpósio Brasileiro de Informática na Educaçâo. Citado na pág. 13

Le Calvez et al.(2008) Françoise Le Calvez, Hélène Giroire e Gérard Tisseau. Design of a learning environment in combinatorics based on problem solving: Modeling activities, problems and errors. International Journal of Artificial Intelligence in Education, 18:59-94. Citado na pág. 6, 8

Leite et al.(2009) Maici Duarte Leite, Cristiane Azevêdo dos Santos Pessoa, Martha Cornélio Ferraz e Rute Elizabete de Souza Rosa Borba. Softwares Educativos e Objetos de Aprendizagem: um olhar sobre a Análise Combinatória. X Encontro Gaúcho de Educação Matemática. Citado na pág. 1

Lima(2012) Roberto Sarmento Lima. O uso do hífen segundo o acordo ortográfico, 2012. URL www.fale.ufal.br/files/Artigos/uso-hifen-segundo-acordo.doc. Citado na pág. 1

Lindgaard e Chattratichart(2007) Gitte Lindgaard e Jarinee Chattratichart. Usability testing: What have we overlooked? Proceedings of the SIGCHI Conference on Human factors in Computing Systems, páginas 1415-1424. Citado na pág. 23

Llamas et al.(2011) Martín Llamas, Manuel Caeiro Rodriguez, Manuel Castro, I. Plaza e Edmundo Tovar. Use of lms functionalities in engineering education. Frontiers in Education Conference (FIE), páginas $\mathrm{S} 1 \mathrm{G}-1-\mathrm{S} 1 \mathrm{G}-6$. Citado na pág. 1

Mayhew(1999) Deborah L. Mayhew. LinkThe usability engineering lifecycle : a practitioner's handbook for user interface design. San Francisco: Morgan Kaufmann Publishers. Citado na pág. 19,24

Medeiros et al.(2013) Francisco Medeiros, Alex Gomes, Ricardo Amorim e Gabriela Medeiros. Redesigning collaboration tools to enhance social presence in online learning environments. Collaboration and Technology, Springer Berlin Heidelberg, 24:175?191. Citado na pág. 18

Medeiros et al.(2007) Leonardo Medeiros, Alex Sandro Gomes, Carina Alves, Fábio Caparica, Rogério Nibon e Alexandre Vasconcelos. Uso de storyboards para a documentação dos requisitos no desenvolvimento distribuído de software. I Workshop de Desenvolvimento Distribuído de Software, WDDS. Citado na pág. 21

Morgado et al.(1991) Augusto C. O. Morgado, João Bosco P. Carvalho, Paulo Cézar P. Carvalho e Pedro Fernandez. Análise Combinatória e Probabilidade. Coleção do Professor de Matemática. Sociedade Brasileira de Matemática, 9a edição edição. Citado na pág. 5

Moura e Brandão(2005) Janine G. Moura e Leônidas O. Brandão. Aplicações no saw - sistema de aprendizagem pela web. Anais do XVI Simpósio Brasileiro de Informática na Educação. Citado na pág. 14

Moura et al.(2007) Janine G. Moura, Leônidas O. Brandão e Anarosa A. F. Brandão. A web-based learning management system with automatic assessment resources. Anais do XVIII Simpósio Brasileiro de Informática na Educação. Citado na pág. 14

Muñoz et al.(2012) Roberto Muñoz, Francisco Mancilla, Thiago Barcelos, Virgínia Chalegre e Sandra Kreisel. Development of software that supports the improvement of the empathy in children with autism spectrum disorder. Proceedings of the I Chilean Workshop on User Experience with Information Technology, Valparaíso, Chile. Citado na pág. 18 
Nascimento(2014) Mauricio Garcia Franco Nascimento. irepositório - repositório interativo de conteúdos digitais para cursos baseados na internet. Dissertação de Mestrado, Instituto de Matemática e Estatística - USP. Citado na pág. 13

Nielsen(2003) Jakob Nielsen. Usability 101: Introduction to Usability, 2003. URL http://www. useit.com/alertbox/20030825.html. Citado na pág. 23

Olson e Moran(1996) Judith Olson e Thomas Moran. Mapping the method muddle: Guidance in using methods for user interface. Human-computer interface design: Success Cases, emerging methods, and real world contexts, páginas 269-302. Citado na pág. 24

Perrenoud(1999) Philippe Perrenoud. L'évaluation des élèves: de la fabrication de l'excellence à lá régulation des apprentissages. Entre deux logiques. Bruxelles: De Boeck. ISBN 9788573075441. Citado na pág. 4

Perrotta et al.(2013) Carlo Perrotta, Gill Featherstone, Helen Aston e Emily Houghton. Gamebased learning: Latest evidence and future directions. The NFER Research Programme. URL https://www.nfer.ac.uk/nfer/publications/GAME01/GAME01.pdf. Citado na pág. 5

Prado(2008) Reginaldo Prado. igraf: Uma proposta de sistema para ensino de função via web. Dissertação de Mestrado, Instituto de Matemática e Estatística - USP. Citado na pág. 13

Preece et al.(2005) Jennifer Preece, Yvone Rogers e Helen Sharp. Interaction design: beyond homan-computer interaction. Willey, 3rd edição. Citado na pág. x, 17, 18, 22, 27, 35

Raines e Clark(2011) Joan M. Raines e Linda M. Clark. A Brief Overview on Using Technology to Engage Students in Mathematics. Current Issues in Education, 14(2). Citado na pág. 39

Ribeiro(2013) Igor S. Ribeiro. Software educacional para o ensino-aprendizagem de equação do $2^{\circ}$ grau: Desenvolvimento e avaliação. Master's thesis, Departamento de Ciências Exatas e Tecnológicas da Universidade Estadual de Santa Cruz, UESC. Citado na pág. 1

Ribeiro et al.(2014) Romenig Silva Ribeiro, Leônidas O. Brandão, Tulio Vitor Machado Faria e Anarosa Alves Franco Brandão. Programming web-course analysis: how to introduce computer programming. Proceedings of 41st Frontiers in Education Conference. Citado na pág. 22

Rocha e Baranauskas(2003) Heloísa Vieira Rocha e Maria Cecília Calani Baranauskas. Design e Avaliação de Interfaces Humano-Computador. Campinas: UNICAMP. ISBN 8588833042. Citado na pág. $19,20,31$

Rodrigues e Brandão(2009) Patricia A. Rodrigues e Leônidas O. Brandão. Tarefa Interativa: uma proposta flexível de interatividade para o Moodle. Anais do XX Simpósio Brasileiro de Informática na Educação. Florianópolis, SC. Citado na pág. 14

Rodrigues et al.(2010) Patricia A. Rodrigues, Leônidas O. Brandão e Anarosa A. F. Brandão. Interactive Assignment: a Moodle Component to Enrich the Learning Process. 40th Annual Frontiers in Education Conference, páginas T4F-1 - T4F-6. Citado na pág. 1

Rodrigues et al.(2011) Patrícia A. Rodrigues, Márcia Roberta S. Pires da Silva, Danilo L. Dalmon e Leônidas O. Brandão. O uso de geometria interativa em cursos a distância para motivar e aprofundar conhecimentos de matemática: um estudo com alunos do ensino fundamental ii. Anais do Workshop de Informática na Escola, páginas 1402-1406. Citado na pág. 40

Rosen(2007) Kenneth H. Rosen. Discrete mathematics and its applications. Boston: McGraw-Hill Higher Education, 6th edição. ISBN 9780072880083. Citado na pág. vii

Santos(2005) João Francisco Severo Santos. Avaliação no ensino a distância. Revista Iberoamericana de Educación, páginas 1681-5653. Citado na pág. 4 
Souza et al.(1999) CLarisse S. Souza, Jair C. Leite, Raquel O. Prates e Simone D.J. Barbosa. Projeto de Interfaces de Usuário Perspectivas Cognitivas e Semióticas. XIX Congresso da Sociedade Brasileira de Computação, Rio de Janeiro, RJ. Citado na pág. 24

Souza et al.(2008) Eliane Reame Souza, Maria Ignez de Souza Vieira Diniz, Rosa Monteiro Paulo e Fusako Hori Ochi. A matemática das sete peças do tangram - Matemática Ensino Fundamental, volume 7. CAEM - IMEUSP. Citado na pág. 14

Squires e Preece(1999) David Squires e Jenny Preece. Predicting quality in educational software: evaluating for learning, usability and the synergy between them. Interacting with Computers, 11: 467-483. Citado na pág. 19

Tanbellini e Brandão(2010) Maria José G. S. Tanbellini e Leônidas O. Brandão. O uso da Geometria Interativa como Facilitador no Ensino e Aprendizagem de Matemática: estudo com duas turmas de sexta série do ensino fundamental. Anais do XXX Congresso da Sociedade Brasileira de Computação. Belo Horizonte, $M G$. Citado na pág. 39

Tisseau et al.(2000) Gerard Tisseau, Hélène Giroire, Françoise Le Calvez, Marie Urtasun e Jacques Duma. Design principles for a system to teach problem solving by modelling. Lecture Notes in Computer Science, páginas 393-402. Citado na pág. 11

Villarreal e Borba(2010) Mônica E. Villarreal e Marcelo C. Borba. Collectives of humans-withmedia in mathematics education: notebooks, blackboards, calculators, computers and ...notebooks throughout 100 years of icmi. ZDM Math Education, 42:49-62. Citado na pág. 1

Weiss e Cruz(1999) A. M. L. Weiss e M. L. R. Cruz. A informática e os problemas escolares de aprendizagem. Rio de Janeiro Ed. DPA, 2 edição. Citado na pág. 39

Wixon e Ramey(1996) Dennis Wixon e Judith Ramey. Field methods casebook for software design. New York, NY, USA: John Wiley \& Sons. Citado na pág. 18, 32

Young(2011) Rowin Young. Technical standards in education, part 6: Standards for assessment and item banks. Learning Technology Advisor, CETIS, University of Strathclyde. Citado na pág. 4

Zaharias e Poylymenakou(2009) Panagiotis Zaharias e Angeliki Poylymenakou. Developing a usability evaluation method for e-learning applications: beyond functional usability. Intl $J$. Hum.-Comput. Interact., 25:75-98. Citado na pág. 19 
